\author{
Universidade de São Paulo \\ Instituto de Astronomia, Geofísica e Ciências Atmosféricas \\ Departamento de Geofísica
}

Rafael Monteiro da Silva

\title{
Influence of surface processes on post-rift faulting during divergent margins evolution
}

São Paulo 



\author{
Rafael Monteiro da Silva
}

\title{
Influence of surface processes on post-rift faulting during divergent margins evolution
}

Versão Corrigida. O original encontra-se disponível na Unidade.

Tese apresentada ao Departamento de Astronomia do Instituto de Astronomia, Geofísica e Ciências Atmosféricas da Universidade de São Paulo como requisito parcial para a obtenção do título de Doutor em Ciências.

Área de Concentração: Geofísca

Orientador: Prof. Dr. Victor Sacek

São Paulo 



\section{Acknowledgements}

Primeiramente, agradeço ao meu orientador Prof. Victor Sacek por todo o apoio durante a orientação deste trabalho. Muito obrigado pela amizade, conversas e momentos que compartilhamos durante essa longa jornada.

À minha esposa, Kathia, obrigado por me apoiar e ajudar sempre.

Aos meus pais, fundamentais em incentivar-me aos estudos.

À FAPESP, pelo apoio financeiro, sob o projeto $n^{o}$ : 2017/10554-4. À Petrobras, pelo financiamento do recurso computacional utilizado neste projeto.

À todos os amigos da faculdade com quem compartilhei muitos momentos felizes, especialmente aos amigos da "turma do café" pelos bons momentos em que estivemos juntos.

Aos Professores do IAG, por todo o conhecimento compartilhado durante os cursos e, especialmente, Prof. Fernando Brenha pelo acompanhamento deste trabalho. Ao IAG por proporcionar essa oportunidade.

Esta tese/dissertação foi escrita em ATEX com a classe IAGTESE, para teses e dissertações do IAG. 



\section{Resumo}

Silva, R. M. (2021). Influência de processos superficiais no falhamento pós-rifte durante a evolução de margens divergentes. Tese de Doutorado, Instituto de Astronomia, Geofísica e Ciências Atmosféricas, Universidade de São Paulo, São Paulo.

A evolução de margens continentais divergentes depende da interação entre a dinâmica do interior da Terra e os processos superficiais de erosão e sedimentação. Devido à complexidade dos diferentes processos envolvidos em regimes extensionais, o uso de modelos numéricos é uma ferramenta natural para o estudo do desenvolvimento dessas margens. $\mathrm{Na}$ última década, diferentes modelos numéricos foram desenvolvidos para simular a interação entre processos superficiais e tectônicos, principalmente com foco na evolução sin-rifte de margens divergentes, avaliando como a erosão e sedimentação podem afetar os estados térmico e de tensões da crosta e do manto durante o estiramento litosférico. Entretanto, do ponto de vista da comunidade de modelagem numérica, menor atenção foi dirigida a evolução pós-rifte de margens divergentes, dezenas de milhões de anos após a ruptura continental. Assim, o objetivo deste trabalho é o desenvolvimento e aplicação de modelos numéricos termo-mecânicos que simulam a formação e evolução de margens continentais divergentes deste o rifteamento continental, levando em consideração os processos superficiais de erosão e/ou sedimentação, através de experimentos numéricos por um período de tempo geológico de 50-100 milhões de anos. Baseado em dois modelos numéricos independentes apresentados nesta tese, eu concluo que o grau de acomplamento entre a crosta superior e o manto litosférico, a magnitde e extensão da erosão da paisagem costeira e a preexistência de zonas de fraquezas na crosta continental são elementos importantes que controlam a reativação de falhas ao longo de margens divergentes durante a fase pós-rifte. 
Os experimentos numéricos indicam que a presença de uma crosta inferior de viscosidade baixa, facilitando o desacoplamento da crosta superior e o desenvolvimento de margens hiper-extendidades, também podem contribuir para o desenvolvimento e/ou a reativação de falhas normais no interior do continente quando a margem é continuamente sujeita à denudação diferencial. Este efeito pode ser suprimido em cenários onde a crosta inferior apresenta viscosidade alta, consequentemente induzindo o acoplamento da crosta superior com o manto litosférico. Neste caso, o comprimento de onda longo da resposta flexural da litosfera em conjunto com a descarga erosiva tem um impacto menor na reativação de falhas na crosta superior. Adicionalmente, a preexistência de zonas de fraqueza na crosta superior, e.g. devido à baixa coesão interna das rochas, pode contribuir para nuclear falhas normais, amplificando a taxa de deformação nestas regiões durante os períodos de altas taxas de denudação. Essas conclusões foram aplicadas ao estudo da evolução pós-rifte da margem sudeste brasileira, onde um tectonismo Cenozóico originou o Rifte Continental do Sudeste do Brasil (RCSB). Eu proponho que a combinação de uma litosfera continental desacoplada e a preexistência de zonas de cisalhamento paralelas à costa contribuíram para o desenvolvimento do RCSB. Além disso, a magnitude da denudação pós-rifte ao longo da margem sudeste brasileira, entre 3 e $4 \mathrm{~km}$ como indicado por dados termocronológicos, amplificaram a resposta flexural e favoreceram o regime extensional da crosta superior, principalmente no interior continental.

Palavras-chave: processos superficiais, modelagem numérica, margens divergentes, reativação de zonas cisalhamento 


\section{Abstract}

Silva, R. M. (2021). Influence of surface processes on post-rift faulting during divergent margins evolution. Tese de Doutorado, Instituto de Astronomia, Geofísica e Ciências Atmosféricas, Universidade de São Paulo, São Paulo.

The evolution of divergent continental margins depends on the interaction between the Earth's interior dynamics and the surface processes of erosion and sedimentation. Due to the complexity of the different processes involved in extensional settings, the use of numerical models is a natural tool to study the development of these margins. In the last decade, different numerical models were developed to simulate the interplay between surface and tectonic processes, mainly focusing on the sin-rift evolution of divergent margins, evaluating how erosion and sedimentation can affect the thermal and stress states of the crust and mantle during lithospheric stretching. However, from the point of view of the numerical modelling community, little attention has been paid to the post-rift evolution of divergent margins, tens of millions of years after the continental breakup. Therefore, the aim of the present work is the development and application of thermo-mechanical numerical models that simulate the formation and evolution of divergent continental margins since continental rifting, taking into account surface processes of erosion and/or sedimentation, running the numerical experiments for a time-span of 50-100 million of years. Based on two independent numerical models presented in this thesis, I conclude that the degree of coupling between the upper crust and the lithospheric mantle, the magnitude and extent of erosion of the coastal landscape, and the preexistence of weakness zones in the continental crust are important elements that control the reactivation of faults along divergent margins during the post-rift phase. The numerical experiments indicate that the presence of a lower 
crust with a relatively low viscosity, facilitating the decoupling of the upper crust and the development of hyperextended margins, can also contribute to the development and/or reactivation of normal faults in the interior of the continent when the margin is continually subjected to differential denudation. This effect is suppressed in scenarios where the lower crust presents a relatively high viscosity, consequently inducing the coupling of the upper crust with the lithospheric mantle. In this case, the long wavelength of the flexural response of a coupled lithosphere to erosional unloading has a minor impact on the reactivation of faults in the upper crust. Additionally, the preexistence of weak zones in the upper crust, e.g. due to a low internal cohesion of the rocks, can contribute to nucleate normal faults, amplifying the strain rate in these regions during phases of high denudation rates. These conclusions are applied to study the post-rift evolution of the southeastern Brazilian margin, where a Cenozoic tectonism created the Continental Rift of Southeastern Brazil (CRSB). I propose that the combination of a decoupled continental lithosphere and the preexistence of shear zones parallel to the coast contributed to development of the CRSB. Furthermore, the magnitude of post-rift denudation along the Southeastern Brazilian margin, between 3 to $4 \mathrm{~km}$ as indicated by thermochronological data, amplified the flexural rebound and favoured the extensional regime in the upper crust, mainly in the hinterland.

Keywords: surface processes, numerical modeling, divergent margins, shear zone reactivation 


\section{List of Figures}

1.1 Processes acting on the formation and evolution of divergent margins. Extracted from Bishop (2007). Original figure from Beaumont et al. (2000). .

1.2 Post-rift interaction of surface and Earths interior's processes. Extracted from Burov and Cloetingh $(1997) \ldots \ldots \ldots \ldots$

2.1 (a) Map of southeastern Brazil. Black arrows indicate the Serra da Mantiqueira and the Serra do Mar escarpments. Triangles are locations of thermochronological data (Cogné et al., 2011). Lower inset shows the geological context of the CRSB. Orange areas are the CRSB basins and solid traces are main Precambrian shear zones (redrawn from Cogné et al. (2011)). (b) Elevation profile showed in (a) as XX'. Sedimentary stratigraphic profile $\mathrm{YY}^{\prime}$ in (a) was obtained from (Evain et al., 2015). Upper panel are the maximum post-rift denudation inferred from the thermochronological data considering a geothermal gradient of $30^{\circ} \mathrm{C} / \mathrm{km}$. (c) Representative denudation and sedimentation evolution patterns used in the model (black curve). The maximum magnitude varied across the model as shown in Figure 2.2 (upper panel). The coloured curves represent the thermal histories obtained from (Cogné et al., 2011) with the respective colours of total denudation

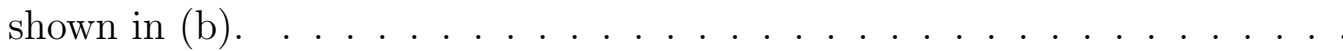


2.2 Model setup. Density contrasts were calculated based on reference densities for the crust and mantle of 2,800 and $3,250 \mathrm{~kg} / \mathrm{m}^{3}$ respectively. The dashed rectangle indicates the sections shown in Figure 2.3. The swell profile in the bottom part represents a thermal anomaly moving rightward with velocity of $v=2.3 \mathrm{~cm} / \mathrm{a}$ and initial position $x_{0}=-897.5 \mathrm{~km}$. These values were chosen to be in accordance with the magmatic history presented in the work of Ferrari and Riccomini (1999). Arrows in the upper panel represent the maximum load variation across the model. $\Delta \rho^{\prime}$ is a fictitious density contrast used to obtain the equivalent flexural load for a given necking depth. The denudation/sedimentation rate follows the linear pattern shown in Figure

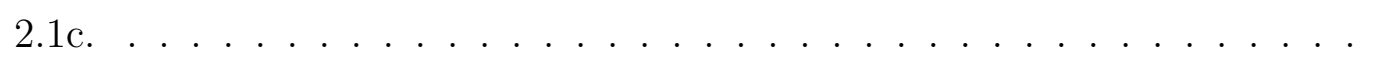

2.3 Deviatoric stress pattern along the continental margin for models with only surface processes (models $S$ and setup a). Only a section of the numerical domain is shown (see Figure 2.2 for location). Column $\mathrm{A}$ is for $z_{n}=8$ $\mathrm{km}$ and column $\mathrm{B}$ for $z_{n}=12 \mathrm{~km}$. The purple lines indicate the necking depth zn in each scenario. Blue and red line segments represent principal compression and tension respectively. Solid, dashed and dotted black lines are the failure limit assuming rock cohesion of 0,50 and $100 \mathrm{MPa}$ and with $\mu=\tan 30^{\circ}$. Top horizontal bar indicates the Serra da Mantiqueira (light green), the CRSB (light brown) and the Serra do Mar (dark green) areas. Dark grey area in the section corresponds to the mantle. See Figures S3-S16 in Data $\mathrm{S} 1 \mathrm{~A}$ for a detailed evolution of the models. . . . . . . . 32 
2.4 Timing when $d_{\max }$ is deeper than $1 \mathrm{~km}$ below the eroded surface for different necking depths and different cohesion values: (a) $\mathrm{c}=0 \mathrm{MPa}$, (b) $\mathrm{c}=$ $50 \mathrm{MPa},(\mathrm{c}) \mathrm{c}=100 \mathrm{MPa}$. The purple (Ar-Ar ages) and magenta (K-Ar ages) bars represent interbedded lava flows with sediments in CRSB basins (Riccomini et al., 2004, and references therein). The onset of the numerical experiments started at $130 \mathrm{Ma}$, close to the end of the rifting phase in the Santos Basin, SE Brazilian margin (Moreira et al., 2007). The horizontal orange bar represents the Paleocene epoch, indicating the oldest sedimentation preserved in the central portion of the CRSB (Riccomini et al., 2004). The model keys are: $S$ - denudation and sedimentation; $S U$ - denudation, sedimentation and regional uplift; $S C$ - denudation, sedimentation and horizontal compression. Models a are the scenarios with the total denudation and sedimentation indicated in Figure 2.2, while models b are with half of the magnitude of models a. The vertical dashed line indicates the moment when the top of the moving swell reaches the margin at the position $\mathrm{x}=$ $1,000 \mathrm{~km}$, only relevant for models $S U \ldots \ldots$. . . . . . . . . . . . .

3.1 Flowchart picturing the evaluation of equations that represent conservation of mass, momentum, and energy.

3.2 Finite element. Example of 2-D grid with 4-node bilinear element. Filled circles at corners indicate the nodes where velocity is defined and the centered open circle indicate where the pressure is defined. . . . . . . . .

3.3 "Case 2" model setup to evaluate the "sticky air" method. Extracted from Crameri et al. (2012) . . . . . . . . . . . . . . . . . .

3.4 Temporal evolution of the "Case 2" (Crameri et al., 2012) obtained with MANDYOC.

3.5 Temporal evolution of the surface for results shown on Figure 3.4 . . . . .

3.6 Comparison of the maximum topography with time for the "Case 2" (Figure 3.3) model setup (Crameri et al. 2012) . . . . . . . . . . . . .

4.1 Comparison of maximum topography for models with erosion. . . . . . . . 54

4.2 Comparison of topography for different $k_{d} \ldots \ldots \ldots \ldots \ldots$ 
4.3 Evolution of the model with erosion and sedimentation for $k_{d}=0 \mathrm{~m}^{2} / \mathrm{s}$. Colors represent differences in density and viscosity (refer to Figure 3.3) . . 56

4.4 Evolution of the model with erosion and sedimentation for $k_{d}=1.0 \times 10^{5}$ $\mathrm{m}^{2} / \mathrm{s}$. Colors represent differences in density and viscosity (refer to Figure

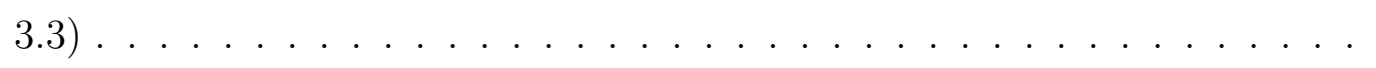

4.5 Evolution of the model with erosion and sedimentation for $k_{d}=2.0 \times 10^{4}$ $\mathrm{m}^{2} / \mathrm{s}$. Colors represent differences in density and viscosity (refer to Figure

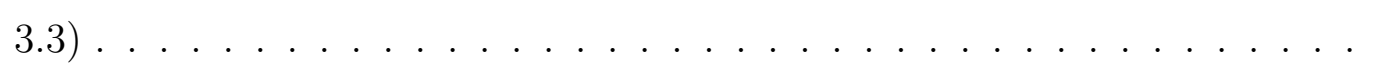

4.6 Package of sediments corresponding to the model of Figure 4.4 with $k_{d}=$

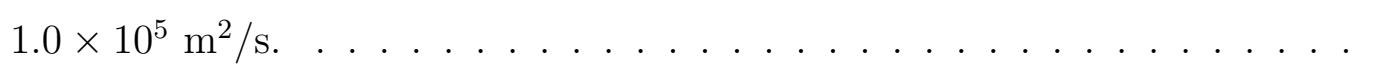

4.7 Package of sediments corresponding to the model of Figure 4.5 with $k_{d}=$ $2.0 \times 10^{4} \mathrm{~m}^{2} / \mathrm{s} \ldots \ldots \ldots \ldots \ldots \ldots \ldots \ldots$

5.1 Numerical model setup for the simulation of the lithospheric stretching. The thickness of the upper and lower crust is equal $h_{u c}=h_{l c}=20 \mathrm{~km}$ and the thickness of the lithosphere is $h_{\text {litho }}=130 \mathrm{~km}$. The series of horizontal black lines on the left and right boundaries of the model indicate the boundary condition adopted for the velocity field. The upper curve indicates the denudation function $e_{f}$ adopted, indicating that the maximum denudation occurs in the center of the domain, decreasing to the borders. Details about the function $e_{f}$ is indicated in the text. The small mark close to the center of the lithospheric mantle is the mantle seed, necessary to localize the lithospheric stretching in the center of the domain. Additionally two vertical weak seeds were introduced in the upper crust in some of the numerical

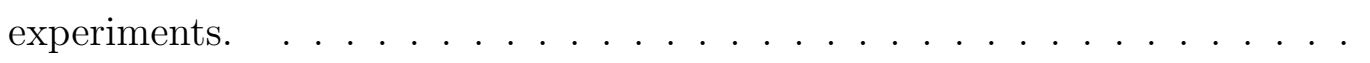

5.2 Yield strength envelope for the two reference numerical scenarios. The difference between the two scenarios is the scale factor $C$ for the lower crust: $C=1$ for decoupled lithosphere and $C=40$ for coupled lithosphere. The dashed lines represent the plastic yield criterion for the maximum and minimum internal angle of friction $\phi$ and internal cohesion $c_{0}$ adopted in this work. In these diagrams, the viscous stress was calculated assuming that $\dot{\varepsilon}_{I I}=10^{-15} \mathrm{~s}^{-1} \ldots \ldots \ldots \ldots \ldots \ldots \ldots$ 
5.3 Evolution of the reference numerical scenario with decoupled lithosphere, with $C=1$ for the lower crust and without surface processes. Dark and light orange represent the upper and lower crust, while dark and light green represent lithospheric and sublithospheric mantle. Shades of gray indicate the magnitude of cumulative strain. . . . . . . . . . . . . . . 70

5.4 Evolution of the reference numerical scenario with coupled lithosphere, with $C=40$ for the lower crust and without surface processes. Dark and light orange represent the upper and lower crust, while dark and light green represent lithospheric and sublithospheric mantle. Shades of gray indicate the magnitude of cumulative strain

5.5 Comparison between the two reference scenarios, both without surface processes. Both images were selected to be close to the moment of crustal breakup. Coupled lithosphere: scenario with the $C=40$ for the lower crust. Decoupled lithosphere: scenario with the $C=1$ for the lower crust. The blue and orange bars indicate the width of the extended continental crust in both conjugate margins. . . . . . . . . . . 72

5.6 Evolution of the strain rate for the reference scenario with decoupled lithosphere $\left(C=1\right.$ for the lower crust). The strain rate $\dot{\varepsilon}_{I I}$ is in $1 / \mathrm{s} . \ldots \ldots$. . . . .

5.7 Evolution of the strain rate for the reference scenario with coupled lithosphere ( $C=40$ for the lower crust). The strain rate $\dot{\varepsilon}_{I I}$ is in $1 / \mathrm{s}$.

5.8 Comparison of the strain rate field for the scenarios with and without erosion for the decoupled lithosphere $(C=1)$ for the lower crust. The strain rate $\dot{\varepsilon}_{I I}$ is in $1 / \mathrm{s}$. The letters $\mathrm{F}$ indicate zones in the upper crust with active faults and NS indicate the flexural neutral surface. . . . . . . . . .

5.9 Topographic profile and strain rate pattern in the lithosphere for the decoupled scenario ( $C=1$ for the lower crust) and with erosion. The upper panel presents the topographic profile in blue, indicating the position of the escarpment separating the coastal plain from the continental interior. The flexural neutral surface in shown as a red dashed line in the lower panel. 
5.10 Comparison of the strain rate field for the scenarios with and without erosion for the coupled lithosphere $(C=40)$ for the lower crust. The strain rate $\dot{\varepsilon}_{I I}$ is in $1 / \mathrm{s}$. The letters $\mathrm{F}$ indicate zones in the upper crust with active faults and NS indicate the flexural neutral surface. . . . . . . . . . . . . 77

5.11 Topographic profile and strain rate pattern in the lithosphere for the coupled scenario ( $C=40$ for the lower crust) and with erosion. The upper panel presents the topographic profile in blue, indicating the position of the escarpment separating the coastal plain from the continental interior. The flexural neutral surface in shown as a red dashed line in the lower panel.

5.12 Comparison of the strain rate field for the scenarios with and without weak seeds in the upper crust for the decoupled lithosphere $(C=1)$ for the lower crust. Both models have erosion acting on the surface. The strain rate $\dot{\varepsilon}_{I I}$ is in $1 / \mathrm{s}$. The letters $\mathrm{F}$ indicate zones in the upper crust with active faults and NS indicate the flexural neutral surface. Both axes are in km. . . . . .

5.13 Topographic evolution for the scenarios shown in Figure 5.12 , The blue line represents the sea level. . . . . . . . . . . . . . . .

5.14 Maximum strain rate in the upper crust along the interval between $x=500$ and $550 \mathrm{~km}$ for four scenarios. The erosion of the continent starts at $25 \mathrm{Myr}$ in the scenarios with erosion (green and orange curves). . . . . . . . . . . 81

5.15 Analytical solution for the flexure of a thin elastic plate under the load of a uniform load distributed in the interval between $-100 \mathrm{~km}$ and $100 \mathrm{~km}$. a) thickness $h_{\text {erod }}$ of the eroded crust, resulting in the unload of the lithosphere. b) Flexural response of the elastic plate for two different effective elastic thickness: $T_{e}=10$ and $40 \mathrm{~km}$. c) Curvature of the plate for the two cases shown in b. The symbols I and II indicate the locations of maximum curvature with downward concavity for $T_{e}=40$ and $10 \mathrm{~km}$, respectively. . . 
5.16 Topographic/bathymetric map of southeastern Brazil. The arrows indicate the two parallel escarpments in Southeastern Brazil: the Serra do Mar and Serra da Mantiqueira escarpments. These two escarpments are separated by an elongated depression associated with the Continental Rift of Southeastern Brazil. The thick red line indicates the Cretaceous hinge line extracted from Karner and Gambôa (2007). The other lines indicate the continent-ocean boundary (COB) presented by different authors: (Karner, 2000; Meisling et al., 2001; Carminatti et al., 2008; Zalán et al., 2011). COB compilation extracted from Rigoti $(2015) . \ldots \ldots$. . . . . . . . . . . . 86 



\section{List of Tables}

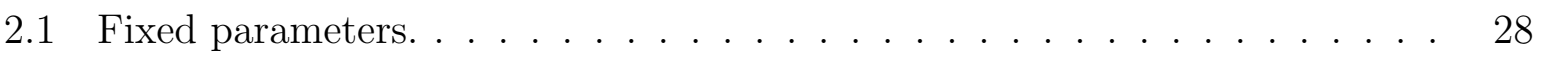

5.1 Physical parameters for the different layers of the numerical scenarios. $A$ is the pre-exponent constant, $n$ is the exponent of the power law, $Q$ is the activation energy, $V$ is the activation volume and $C$ is the scale factor adopted. Parameters extracted from Karato and $\mathrm{Wu}$ (1993) for olivine and Gleason and Tullis $(1995)$ for quartz. . . . . . . . . . . . . 67 67

5.2 Fixed parameters for the numerical scenarios. . . . . . . . . . 67 



\section{Contents}

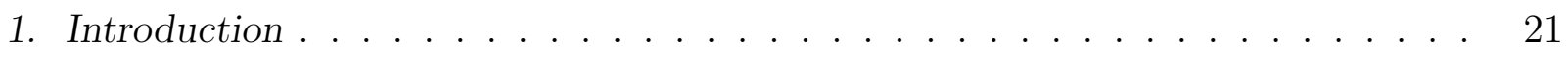

1.1 Tectonic and surface processes . . . . . . . . . . . . . . 21

1.2 Aim of the thesis . . . . . . . . . . . . . . 23

1.3 Outline of the Thesis . . . . . . . . . . . . . . 23

2. Erosion-induced stress field linked to continental rift: the origin of the Cenozoic basins in SE Brazil . . . . . . . . . . . . . . . . . . . . . . . . . . 25

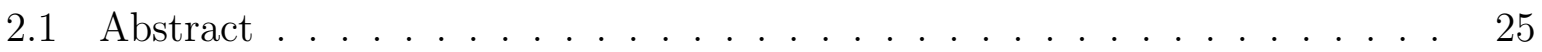

2.2 Introduction . . . . . . . . . . . . . . . . . . . . 26

2.3 Modeling description . . . . . . . . . . . . . . . . . . . . . . . 26

2.4 Results . . . . . . . . . . . . . . . . . . . 31

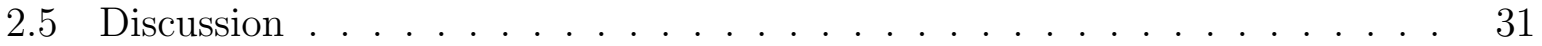

2.6 Conclusions . . . . . . . . . . . . . . . . . . 35

3. MANDYOC model description ........................ 37

3.1 Conservation equations and numerical approach . . . . . . . . . . . 37

3.2 Numerical implementation using the Finite Element Method . . . . . . . . 40

3.3 Free surface . . . . . . . . . . . . . . . . . . 44

3.4 Rheological behaviour of mantle and crust . . . . . . . . . . . . . 46

3.5 Space and time dependent boundary conditions . . . . . . . . . . . 46

3.6 Surface tracking . . . . . . . . . . . . . . . . . 47

3.7 Surface processes . . . . . . . . . . . . . . . . . . . . 47

3.8 Numerical techniques . . . . . . . . . . . . . . . . . . . . . . . . 48

3.9 Surface stabilization test . . . . . . . . . . . . . . . . . . 49 
4. Testing of diffusive erosion . . . . . . . . . . . . . . . . . . 53

4.1 Surface processes . . . . . . . . . . . . . . 53

5. Applications of the model to continental margins . . . . . . . . . . 63

5.1 The numerical model . . . . . . . . . . . . . . . . 64

5.2 Numerical setup . . . . . . . . . . . . . . . . . 65

5.3 Numerical results . . . . . . . . . . . . . . . . . . . . . . . . . 68

5.4 Discussion . . . . . . . . . . . . . . . . . . 82

5.4.1 The mechanism for post-rift tectonism induced by erosion . . . . 82

5.4.2 Comparison of the numerical results with continental divergent margins 85

6. Conclusions . . . . . . . . . . . . . . . . . . . . . . . . . 89

Bibliography ................................ 91

Appendix 101

A. Supporting information . . . . . . . . . . . . . . . . 103 
Chapter 1

\section{Introduction}

\subsection{Tectonic and surface processes}

Surface and tectonic processes are inherently coupled and feedback mechanisms exist that affect each other during periods of active tectonism or geodynamic quiescence $\mathrm{Be}-$ aumont et al., 2000). In the context of extensional settings (Figure 1.1), stretching of the lithosphere results in faulting of the upper crust and ductile flow in depth. In the same time, the margin is affected by magmatic activity and the base of the stretched lithosphere is affected by edge driven convection. All these processes perturb the surface, since mantle flow can induce the formation of dynamic topography, rifting induces rift flanks formation, and magmatism affects the landscape. Concomitantly, erosion of the escarpments provides sediments to adjacent sedimentary basins which induces the redistribution of surface load on the lithosphere. Additionally, these surface processes also can modify the thermal structure of the lithosphere, consequently affecting its rheology and rigidity through the geological time scale (Lavier and Steckler, 1997). Therefore, an integration of surface and Earth's interior processes are necessary to appropriately study the formation and evolution of divergent margins.

Due to the complexity of a coupled integrated model combining surface and geodynamic processes, a natural tool for this study is the numerical modelling. Tectonic deformation studies using numerical techniques has been applied since the 1980s (e.g. Beaumont et al., 1982; England and McKenzie, 1982). In the last two decades, many numerical models were further developed and applied to study rifting processes (e.g. Lavier and Manatschal, 2006; Huismans and Beaumont, 2011; Brune et al., 2014; Sharples et al., 2015, refer to Brune, 2016, to a extensive review). Although the rifting process and margin development 
is inherently a three-dimensional (3-D) problem in nature, two-dimensional (2-D) modelling has provided insightful conclusions on mechanics involved on these processes. 3-D modelling also imposes many challenges due to complexity and computational resources needed and simplified rheologies (e.g. Allken et al., 2012) or limited simulation time-spans (e.g. Naliboff et al., 2020) are often used to avoid inaccuracy of the numerical solution.

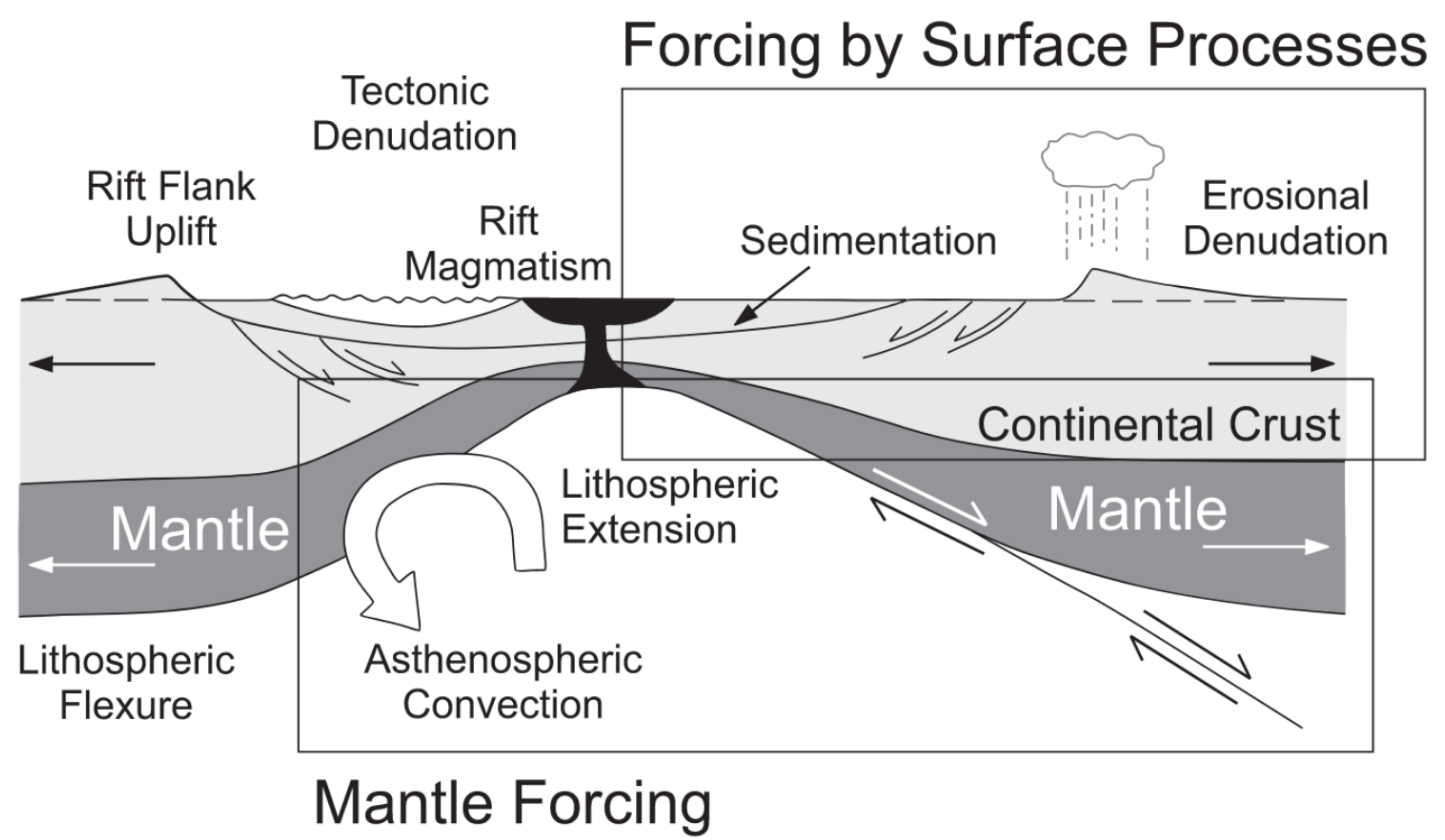

Figure 1.1: Processes acting on the formation and evolution of divergent margins. Extracted from Bishop (2007). Original figure from Beaumont et al. (2000).

Many of the models which analyzed the formation of divergent margin focused on the rifting process and early stage of the margin development. Hence, there is a lack of studies addressing the post-rift stages of the margin evolution, with time-spans of tens of millions of years after the continental breakup. The work of Burov and Cloetingh (1997) is a notable exception, showing an example of the interaction of surface and thermo-mechanical processes during and after the rifting phase (Figure 1.2). The authors showed the feedback between erosion and sedimentation of the surface, ductile flow of lower crust and the flexural response of the lithosphere. Following this work, other models showed the importance of surface processes affecting the thermal, and hence, rheological structure of the lithosphere (Andrés-Martínez et al., 2019: Pérez-Gussinyé et al., 2020), even influencing the magmatic activity (Sternai, 2020). Recently, Theunissen and Huismans (2019) identified feedbacks between erosion and deposition and tectonic processes on structural style of rift and divergent margin formation due to the efficiency of surface processes. 


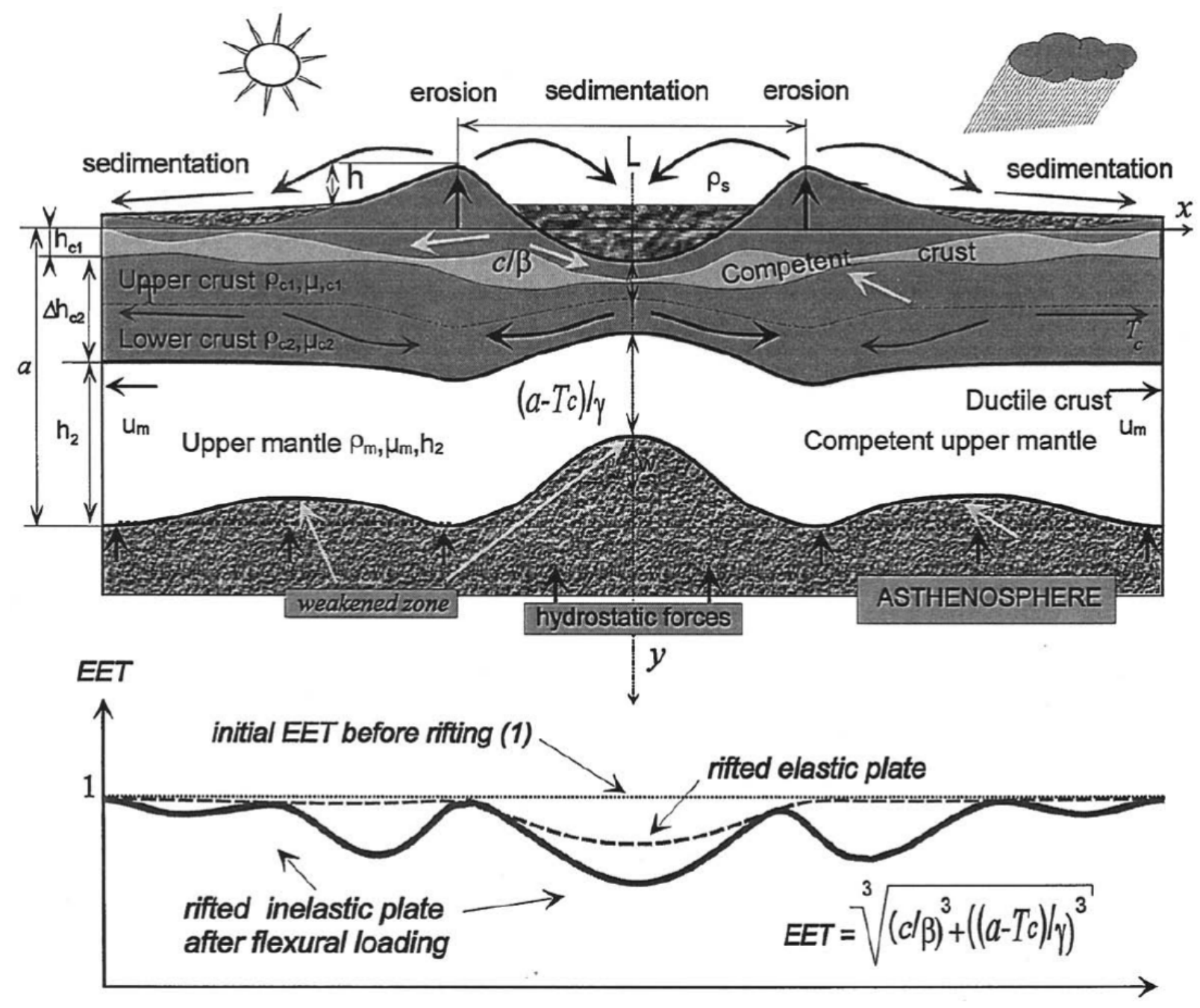

Figure 1.2: Post-rift interaction of surface and Earths interior's processes. Extracted from Burov and Cloetingh (1997).

\subsection{Aim of the thesis}

The primary aim of this thesis is to evaluate in detail how surface processes may affect the stress field in the continental hinterland of divergent margin. Despite previous works have addressed the role of surface processes in the context of extensional settings, they focused mainly on the stretched lithosphere. Instead, this work focuses on adjacent onshore region of the margin in time-spans that corresponds to the post-rift phase.

\subsection{Outline of the Thesis}

This thesis is structured as follows:

Chapter 2 presents the initial study of how surfaces processes affects the onshore re- 
gion of a divergent margin. This study used a viscoelastic numerical model to quantify the stresses within the lithosphere and its variability as a function of the necking depth, onshore erosion, offshore sedimentation, regional uplift and compressional stresses based on numerical simulation of the southeastern Brazilian margin evolution. This chapter is presented as a published article.

Chapter 3 describes the mathematical and numerical formulation of a thermo-mechanical viscoplastic model called MANDYOC. This model implements features that overcome some of the limitations of the previous model showed on Chapter 2, including the incorporation of plastic deformation and the direct simulation of the rifting phase of the divergent margin. Additionally, the chapter presents a numerical benchmark, showing the correct implementation of the free surface in the numerical code as part of this thesis. This was a fundamental step of the project, allowing the correct representation of the evolving Earth's surface in contact with air or water.

In the following chapter, Chapter 4, this model is tested on scenarios where the erosive process affects the surface of the model, consequently affecting the strain and stress regime in the interior of the Earth.

The Chapter 5 is the main part of this thesis and presents the results of simulations of the evolution of a divergent margin using the code MANDYOC. These chapter presents numerical experiments for the evolution of divergent margins since the onset of lithospheric extension, showing how the post-rift tectonism in the continental interior is affected by different rheological structure for the lithosphere and surface processes regimes.

Finally, Chapter 6 summarizes the study and points suggestions for future work. 
Chapter 2

\section{Erosion-induced stress field linked to continental rift: the origin of the Cenozoic basins in SE Brazil}

This Chapter presents the article ${ }^{1}$ Shallow necking depth and differential denudation linked to post-rift continental reactivation: The origin of the Cenozoic basins in southeastern Brazil published in Terra Nova (Silva and Sacek, 2019).

\subsection{Abstract}

The southeastern Brazilian margin presents post-breakup Cenozoic tectonism that created a series of grabens and small sedimentary basins, known as the Continental Rift of Southeastern Brazil. The formation of this rift occurred long after the South Atlantic ocean opening and has been attributed to different mechanisms like regional uplift induced by hotspot activity, pulses of Andean orogeny and reactivation of pre-existing faults. However, the proposed models lack an analytical or numerical verification from a geodynamic point of view. Based on finite element modelling of the lithospheric stress field evolution we conclude that a shallow necking depth, consistent with the hyperextended southeastern Brazilian margin, combined with differential denudation of the continent, resulted in an extensional stress field in the upper crust that induced the observed Cenozoic tectonism.

\footnotetext{
${ }^{1}$ The numbering of equations, figures, tables and the references citations format were adapted in this document.
} 


\subsection{Introduction}

The Continental Rift of Southeastern Brazil (CRSB) is characterized by several Cenozoic sedimentary basins (Figure 2.1 a) along a narrow valley flanked by the Serra do Mar and the Serra da Mantiqueira escarpments. The rift extends for about $900 \mathrm{~km}$ along the continental margin preserving Paleogene to Quaternary sedimentation with maximum sedimentary thickness of $800 \mathrm{~m}$ (Riccomini, 1989), following the direction of dextral strike-slip shear zones (NE-trending) of Precambrian rocks of the Ribeira Belt (e.g., Trouw et al. 2000). The formation of the CRSB during the Paleocene (e.g., Cobbold et al. 2001, Sant'Anna et al. 2004) cannot be explained as a natural consequence of the South Atlantic opening during the Early Cretaceous, with a time interval of more than 60 Ma between these two events. Different mechanisms were invoked to explain the CRSB formation, like gravitational sliding through reactivation of weak shear zones (e.g., Almeida, 1976; Riccomini et al., 2004), far-field stresses related to Andean orogeny and consequent reactivation of the pre-existing shear zones in a transtensional context (e.g., Cobbold et al., 2001; Cogné et al., 2013), and regional uplift of the margin related to the passage of the Trindade-Martin Vaz hotspot under the continental margin, which resulted in Late Cretaceous-Paleogene alkaline intrusions (Cobbold et al., 2001, Figure 2.1 a). In spite of the various proposed mechanisms to explain the CRSB generation, there is a lack of quantitative studies to analyse their viability.

Using a finite element model to simulate the stress field evolution during the postrift phase, in the present work we conclude that a shallow necking depth Braun and Beaumont, 1987) during the Cretaceous opening of the South Atlantic ocean combined with differential denudation, i.e. high erosion rate along the onshore margin relative to the interior hinterland (Figure 2.1 b), created a state of stress in the upper crust favourable to normal faulting near the margin at the time of CRSB formation. Deeper necking depth delays the timing in which normal faulting occurs, whereas regional uplift and horizontal compressive stresses represented secondary factors in the Cenozoic tectonism.

\subsection{Modeling description}

Here we used a mechanical, two-dimensional finite element model Assumpção and Sacek, 2013) in which the rheology of the lithosphere is described by a Maxwell viscoelastic 

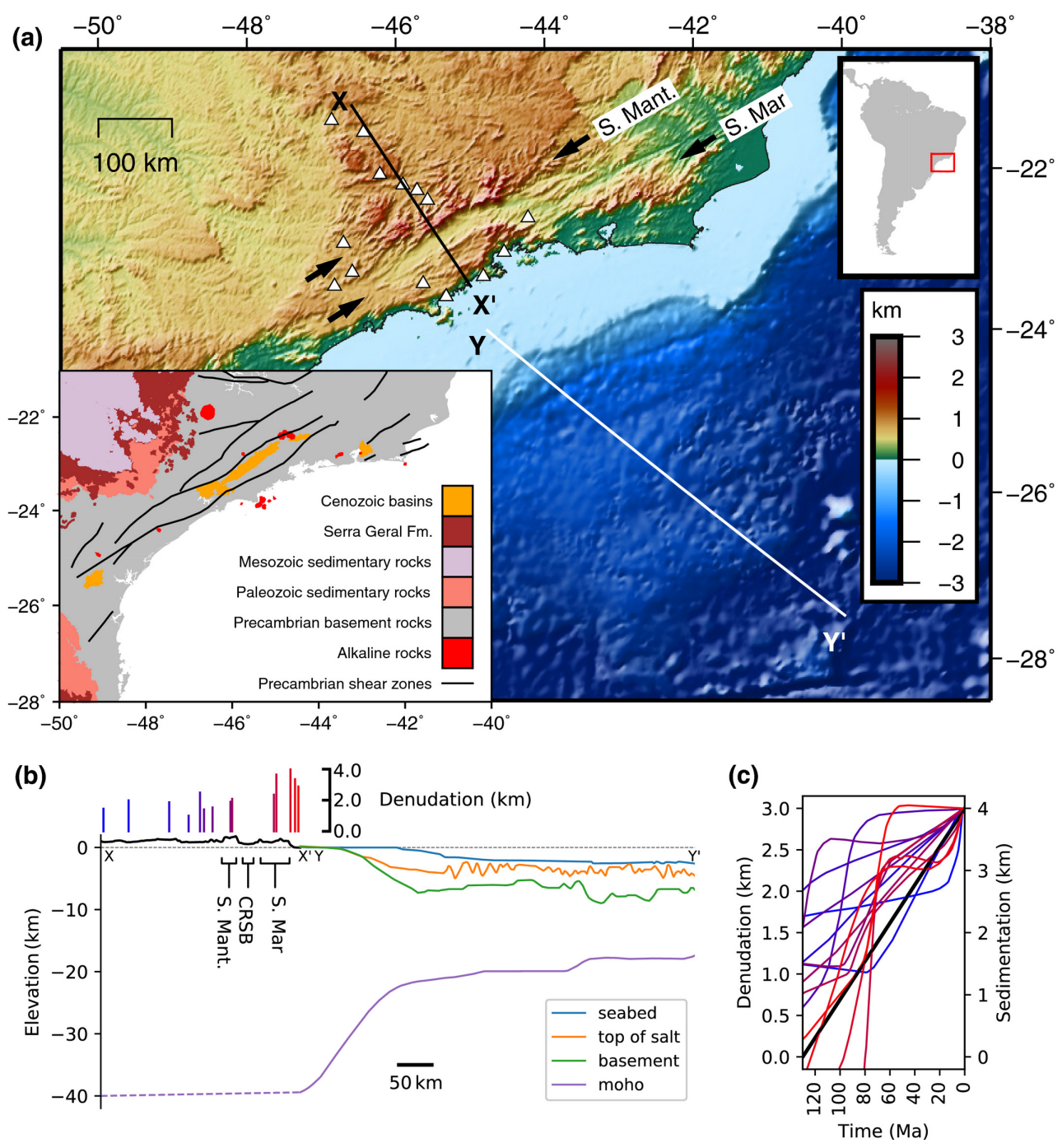

Figure 2.1: (a) Map of southeastern Brazil. Black arrows indicate the Serra da Mantiqueira and the Serra do Mar escarpments. Triangles are locations of thermochronological data (Cogné et al., 2011). Lower inset shows the geological context of the CRSB. Orange areas are the CRSB basins and solid traces are main Precambrian shear zones (redrawn from Cogné et al. (2011)). (b) Elevation profile showed in (a) as XX'. Sedimentary stratigraphic profile YY' in (a) was obtained from (Evain et al., 2015). Upper panel are the maximum post-rift denudation inferred from the thermochronological data considering a geothermal gradient of $30^{\circ} \mathrm{C} / \mathrm{km}$. (c) Representative denudation and sedimentation evolution patterns used in the model (black curve). The maximum magnitude varied across the model as shown in Figure 2.2 (upper panel). The coloured curves represent the thermal histories obtained from (Cogné et al. 2011) with the respective colours of total denudation shown in (b).

material with a nonlinear power-law viscosity (Melosh and Raefsky, 1980) in plane-strain deformation. The effective viscosity $\eta_{\text {eff }}$ is a function of pressure $P$ and absolute temperature $T$ :

$$
\eta_{\text {eff }}=\exp \left(\frac{E_{a}+P V_{a}}{R T}\right) / 2 A \sigma_{I I}^{n-1}
$$


where $\sigma_{I I}$ is the square root of the second invariant of the deviatoric stress tensor and the other parameters are defined in Table 2.1. The model domain is 2000-km-long by a 150-km-thick lithosphere $\left(L_{z}\right)$. In the continental side of the model, the crust is $40-\mathrm{km}$ thick, while for the thinned continental crust we assumed a stretching factor $\beta$ (McKenzie, 1978) of 3, which is representative for the distal southeastern Brazilian margin (Chang et al., 1992). Between the continental and oceanic domains, the crustal thickness varies linearly in a transition zone 100-km-long near the centre of the model (Figure 2.2). For the reference model, in the onset of the simulation, the lithosphere is in isostatic equilibrium assuming densities of $2,800,3,250$ and $3,300 \mathrm{~kg} / \mathrm{m}^{3}$ for crust, lithospheric mantle and asthenosphere respectively. The temperature profile initially varies linearly from $0^{\circ} \mathrm{C}$ at the surface to $1,300^{\circ} \mathrm{C}$ at the base of the lithosphere in the continental part. In the oceanic part, the profile varies linearly from $0^{\circ} \mathrm{C}$ at the bottom of the water layer to $1,300^{\circ} \mathrm{C}$ at depth $L_{z} / \beta$ (thinned lithosphere) and is constant below this depth. The temperature evolves by thermal diffusion, influencing the density structure and the effective viscosity during the numerical simulation (see Data $\mathrm{S}_{1}^{2}$ ). The upper and bottom boundaries were left free while the lateral boundaries were kept fixed in the horizontal direction. Winkler's foundation (e.g., Burov and Poliakov, 2001) was used to keep isostatic equilibrium.

\begin{tabular}{ccc}
\hline & Crust & Mantle \\
& $($ Ranalli, 1987) & $($ Karato and Wu, 1993) \\
\hline \hline$A \mathrm{~Pa}^{-n} \mathrm{~s}^{-1}$ & $2.1 \times 10^{-23}$ & $2.2 \times 10^{-16}$ \\
$E_{a}(\mathrm{~kJ} / \mathrm{mol})$ & 238 & 540 \\
$V_{a}\left(\mathrm{~m}^{3} \mathrm{~mol}^{-1}\right)$ & 0 & $2 \times 10^{-5}$ \\
$n$ & 3.2 & 3.5 \\
$R$ & \multicolumn{2}{c}{$8.314 \mathrm{~J} \mathrm{~K}^{-1} \mathrm{~mol}^{-1}$} \\
\cline { 2 - 3 }$E$ (Young's modulus) & \multicolumn{2}{c}{$70 \mathrm{GPa}^{2} 0.25$} \\
$v$ (Poisson's ratio) & \multicolumn{2}{c}{$9.8 \mathrm{~m} / \mathrm{s}^{2}$} \\
$g$ (gravity)
\end{tabular}

Table 2.1 - Fixed parameters.

We performed numerical experiments varying the necking depth of the lithosphere, the denudation and sedimentation rates, the effect of a regional uplift and compressional stresses in the model. In the numerical scenarios, the total amount of erosion in the

\footnotetext{
${ }^{2}$ Data S1. Descriptions of the horizontal compressive stress, necking depth concept and the numerical model. See Appendix A
} 


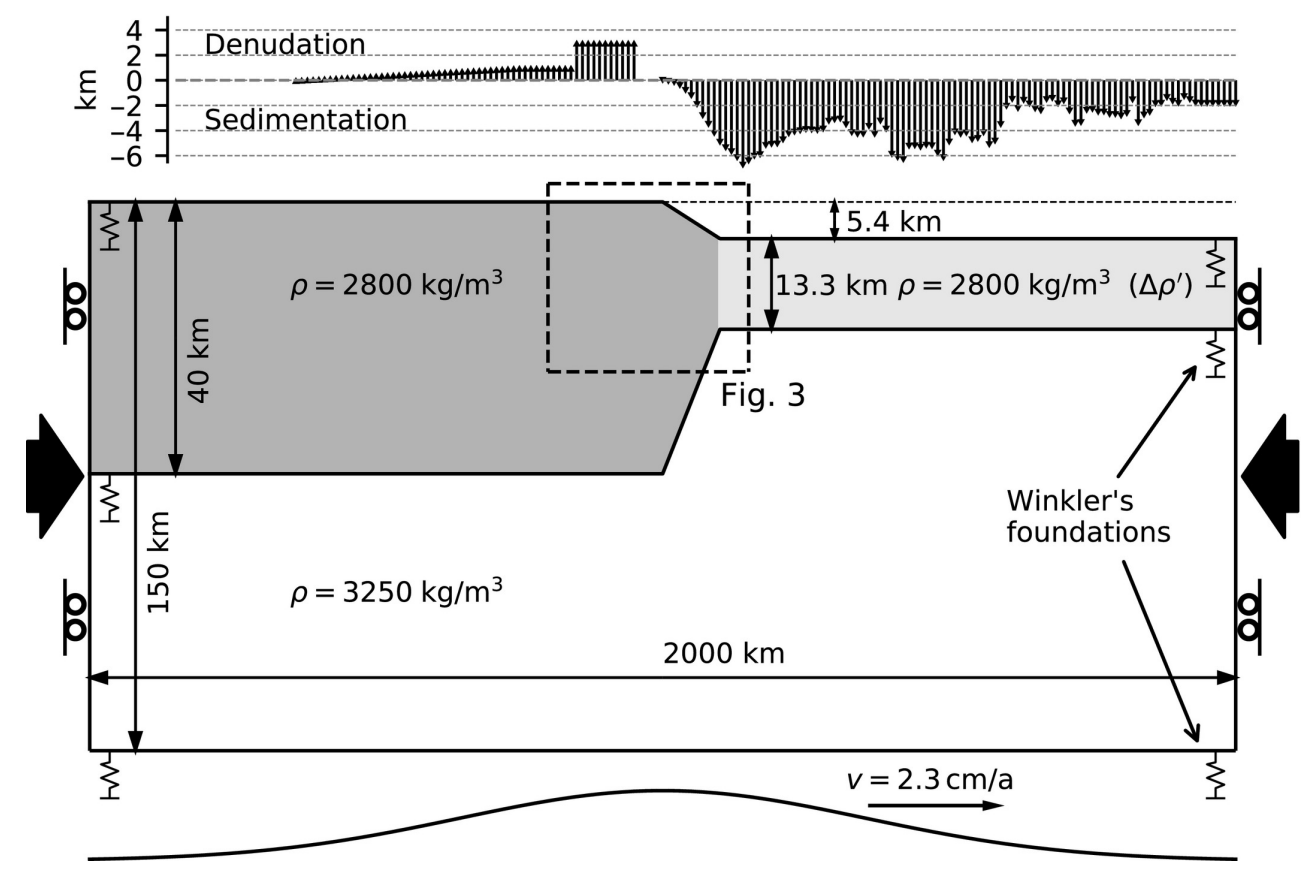

Figure 2.2: Model setup. Density contrasts were calculated based on reference densities for the crust and mantle of 2,800 and $3,250 \mathrm{~kg} / \mathrm{m}^{3}$ respectively. The dashed rectangle indicates the sections shown in Figure 2.3 . The swell profile in the bottom part represents a thermal anomaly moving rightward with velocity of $v=2.3 \mathrm{~cm} /$ a and initial position $x_{0}=-897.5 \mathrm{~km}$. These values were chosen to be in accordance with the magmatic history presented in the work of Ferrari and Riccomini (1999). Arrows in the upper panel represent the maximum load variation across the model. $\Delta \rho^{\prime}$ is a fictitious density contrast used to obtain the equivalent flexural load for a given necking depth. The denudation/sedimentation rate follows the linear pattern shown in Figure 2.1.

continent since the opening of the Atlantic margin was $3 \mathrm{~km}$ over $100 \mathrm{~km}$ near the coastal area, and $1 \mathrm{~km}$ in the hinterland, decreasing smoothly to zero landward, and the offshore sedimentation is based on the total sedimentary thickness presented by Evain et al. (2015) (Figure 2.2, vertical arrows in the upper panel). This denudation/sedimentation pattern corresponds to setup a and half of these amplitudes represent setup b. For simplicity, we simulated denudation/sedimentation with a constant rate (Figure 2.1k, black line). The total simulated time was $130 \mathrm{Ma}$, equivalent to the age of SE Brazilian margin. The erosion and sedimentation was incorporated in the numerical model as nodal forces at the top of the finite element mesh (Braun and Beaumont, 1987).

Additionally, we tested the effect of a regional uplift that would be caused by a thermal anomaly under the base of the continental lithosphere moving toward the right side of the model, simulating the relative movement of the South American plate over the TrindadeMartin Vaz hotspot. To simulate the uplift, we applied a vertical stress at the bottom 
nodes of the model resulting in a vertical displacement $s$ :

$$
s(x, t)=A_{s} \exp \left(-\left(x-v t-x_{0}\right)^{2} / r^{2}\right)
$$

where $A_{s}$ is the maximum amplitude, $r$ is the swell radius, $v$ is the horizontal velocity, $t$ is the time and $x_{0}$ is the initial position of the swell centre. We used $A_{s}=1,000 \mathrm{~m}$ and $r=$ $600 \mathrm{~km}$, corresponding to the approximate dimensions of the present Trindade-Martin Vaz hotspot swell in the Atlantic ocean (Ito and van Keken, 2007) and $v=2.3 \mathrm{~cm} / \mathrm{a}$ based on Ferrari and Riccomini (1999). To simulate the flexural effect of different necking depths $\left(z_{n}\right)$ in the model, we applied a vertical load $q$ in the offshore domain given by (Braun et al., 2013):

$$
q=\left(1-\frac{1}{\beta}\right)\left[h_{c 0}\left(\rho_{m}-\rho_{c}\right)-\left(\rho_{m}-\rho_{w}\right) z_{n}\right] g
$$

where $h_{c 0}$ is the original crustal thickness, $\rho_{m}, \rho_{c}$ and $\rho_{w}$ are the mantle, crust and water densities respectively and $g$ is the gravitational acceleration. To mimic this $q$ load, we applied a fictitious density contrast $\Delta \rho^{\prime}$ (Figure 2.2) in the thinned crust relative to the reference model given by:

$$
\Delta \rho^{\prime}=\frac{\beta q}{h_{c 0} g}
$$

To simulate the ridge push force, a horizontal force was applied in the model

$$
F(t)=F_{R P}\left(1-\exp \left(-t / \tau_{R P}\right)\right)
$$

where $\tau_{R P}$ is a decaying control factor and $F_{R P}$ is the maximum force per unit length (see Data $\left.\mathrm{S}_{1}^{3}\right]^{\text {. }}$

To evaluate the brittle failure of rocks we used the Mohr-Coulomb criterion Ranalli, 1987)

$$
\tau=c+\mu \sigma_{n},
$$

where $\tau$ is the shear stress, $\mu=\tan \phi$ is the coeffcient of friction for the internal friction angle $\phi, \sigma_{n}$ is the normal stress and $c$ is the cohesion. The depth in which this condition is satisfied we defined as the maximum depth of brittle failure $\left(d_{\max }\right)$. Our viscoelastic model does not incorporate the brittle deformation mechanism in the constitutive equations and, therefore, cannot simulate faulting. However, we equate the limiting depth for brittle failure to the conditions required to allow extensional faulting for different cohesion values, assuming the stress field obtained in our viscoelastic model.

\footnotetext{
${ }^{3}$ See Appendix A
} 
We performed numerical experiments with different boundary conditions to simulate the effect of surface loads due to denudation and sedimentation $(S)$, regional uplift $(U)$ and horizontal compressive stresses $(C)$, resulting in models labelled $S, S U$ and $S C$, where more than one letter means combination of effects.

\subsection{Results}

In the model $S$ for $z_{n}=8 \mathrm{~km}$, in which the lithosphere is initially close to isostatic equilibrium (Figure 2.3a, reference model), the unloading caused by concentrated denudation resulted in large tensional horizontal deviatoric stresses in the upper continental crust. These stresses are amplified by the load in the offshore basin. The $d_{\text {max }}$ increases with time near the margin and is deeper for low cohesion values (Figure 2.3 3 ). For deeper necking depth $\left(z_{n}=12 \mathrm{~km}\right.$, Figure $\left.2.3 \mathrm{~b}\right), d_{\max }$ is shallower due to additional compressive stresses in the upper crust originated by upward flexure of the margin.

For different models, Figure 2.4 presents the timing $t_{f}$ when the $d_{\max }$ is deeper than a threshold depth, assumed here equal to $1 \mathrm{~km}$ below the eroded surface. The value of $t_{f}$ increases for deeper necking depths, varying more than $10 \mathrm{Ma}$ for a $1 \mathrm{~km}$ change in $z_{n}$. Additionally, the decrease in amplitude of the surface processes (models b) delayed the $t_{f}$ by up to $\approx 60$ Ma.

The regional uplift (models $S U$ ) changed $t_{f}$ by less than $15 \mathrm{Ma}$ in almost all the models, representing a secondary tectonic effect. In fact, the regional uplift did not significantly modify the deviatoric stress pattern in the upper crust. Regional compression (models $S C$ ) tends to delay the $t_{f}$, but this effect is significant only for models with low denudation rate (models b). Therefore, the main factors that control the timing of $t_{f}$ are the necking depth and the magnitude of the surface processes.

\subsection{Discussion}

The hyperextended SE Brazilian margin is marked by a distal continent-ocean boundary located more than $500 \mathrm{~km}$ far from the coast in the Santos Basin (Karner, 2000; Zalán et al. 2011), which is compatible with a shallow necking depth (Huismans and Beaumont, 2011) probably $<12 \mathrm{~km}$. This shallow necking depth combined with the high denudation concentrated along the margin predicted by themochronological data, reaching up to 4 

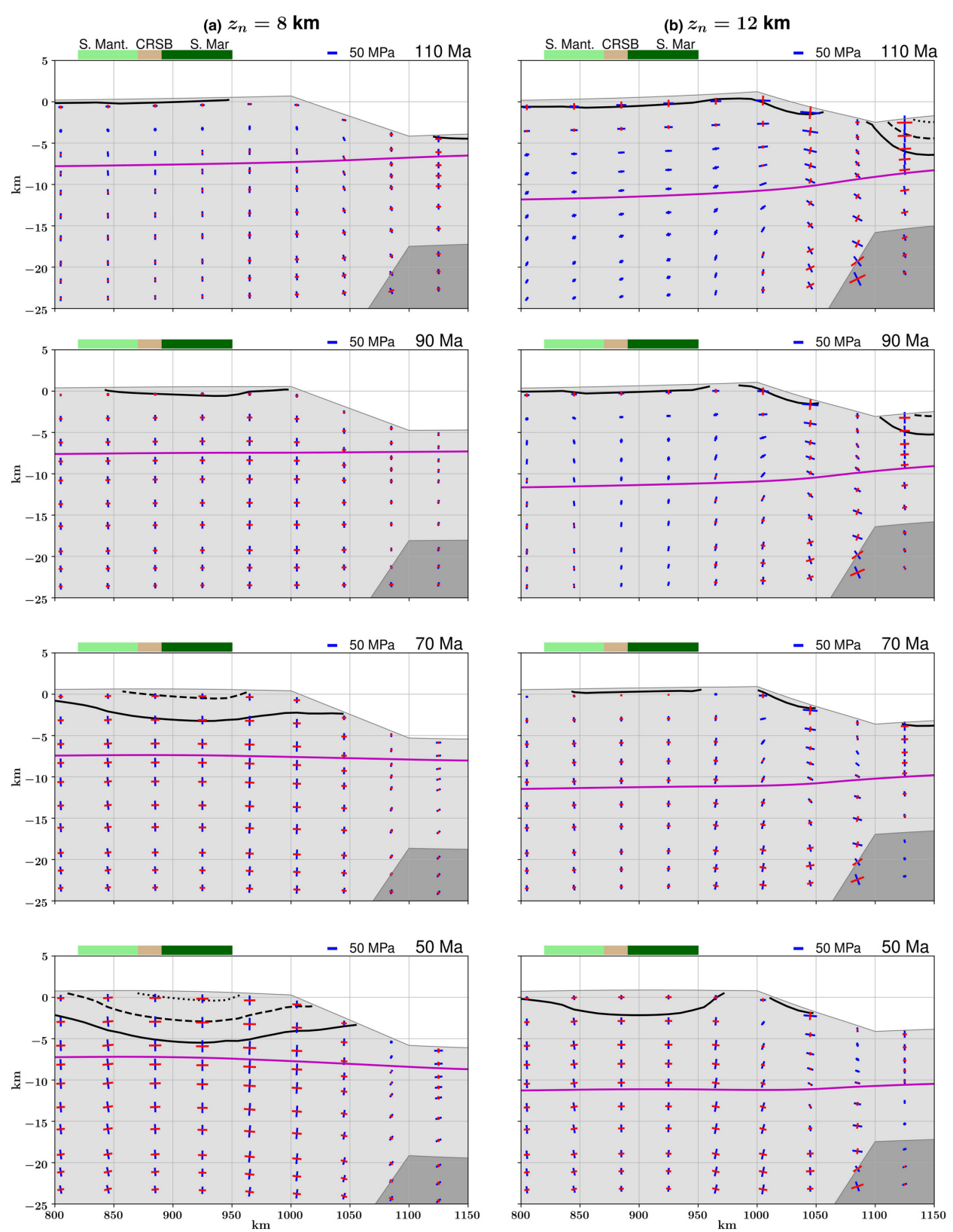

Figure 2.3: Deviatoric stress pattern along the continental margin for models with only surface processes (models $S$ and setup a). Only a section of the numerical domain is shown (see Figure 2.2 for location). Column A is for $z_{n}=8 \mathrm{~km}$ and column B for $z_{n}=12 \mathrm{~km}$. The purple lines indicate the necking depth zn in each scenario. Blue and red line segments represent principal compression and tension respectively. Solid, dashed and dotted black lines are the failure limit assuming rock cohesion of 0, 50 and $100 \mathrm{MPa}$ and with $\mu=\tan 30^{\circ}$. Top horizontal bar indicates the Serra da Mantiqueira (light green), the CRSB (light brown) and the Serra do Mar (dark green) areas. Dark grey area in the section corresponds to the mantle. See Figures S3-S16 in Data S1 (A) for a detailed evolution of the models.

$\mathrm{km}$ of post-breakup denudation (Cogné et al., 2011), can explain the origin of the CRSB during the Paleocene.

As our model does not incorporate the brittle rheology, the present viscoelastic model cannot simulate faulting in the upper part of the continental crust during the margin 


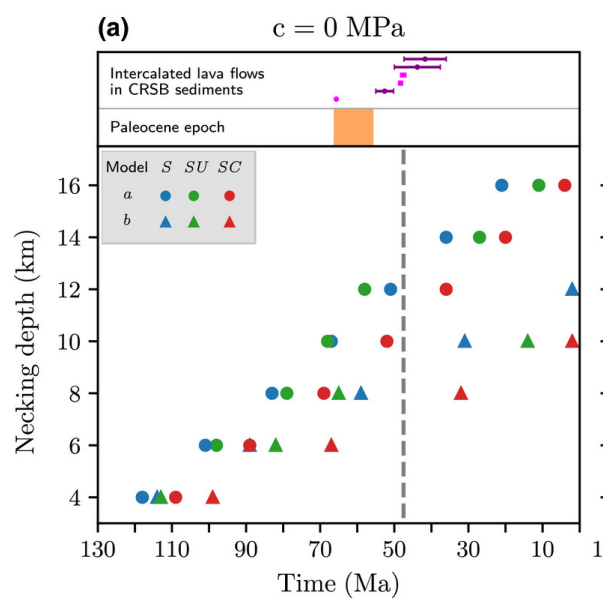

(b)

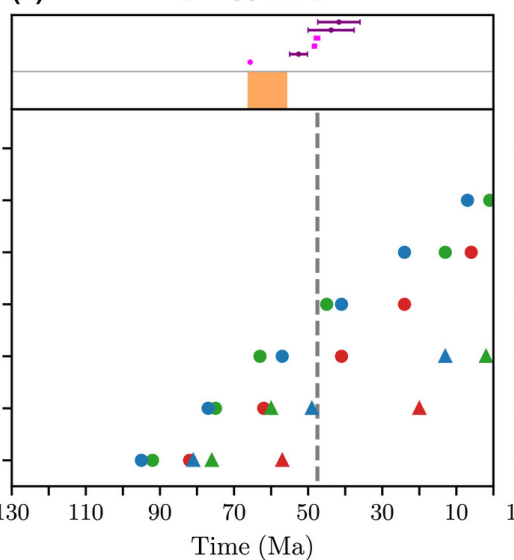

(c)

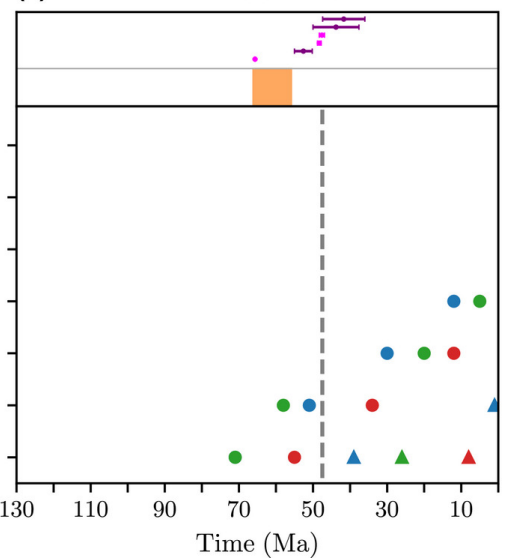

Figure 2.4: Timing when $d_{\max }$ is deeper than $1 \mathrm{~km}$ below the eroded surface for different necking depths and different cohesion values: (a) $\mathrm{c}=0 \mathrm{MPa},(\mathrm{b}) \mathrm{c}=50 \mathrm{MPa}$, (c) $\mathrm{c}=100 \mathrm{MPa}$. The purple (Ar-Ar ages) and magenta (K-Ar ages) bars represent interbedded lava flows with sediments in CRSB basins (Riccomini et al. 2004, and references therein). The onset of the numerical experiments started at 130 Ma, close to the end of the rifting phase in the Santos Basin, SE Brazilian margin (Moreira et al., 2007). The horizontal orange bar represents the Paleocene epoch, indicating the oldest sedimentation preserved in the central portion of the CRSB (Riccomini et al. 2004). The model keys are: $S$ - denudation and sedimentation; $S U$ - denudation, sedimentation and regional uplift; $S C$ - denudation, sedimentation and horizontal compression. Models a are the scenarios with the total denudation and sedimentation indicated in Figure 2.2. while models $\mathrm{b}$ are with half of the magnitude of models a. The vertical dashed line indicates the moment when the top of the moving swell reaches the margin at the position $\mathrm{x}=1,000 \mathrm{~km}$, only relevant for models $S U$.

evolution. However, the $d_{\max }$ gives the depth of the envelope where the brittle limit is achieved for different cohesion values, assuming the stress field in the viscoelastic model for each time step of the simulation. Incorporation of brittle rheology would modify the stress field mainly in the upper crust, localizing the deformation and, eventually, resulting in deeper faults. In fact, previous thermomechanical models with a nonlinear brittleelastic-ductile rheology showed that erosion indeed induces localization, increasing the deformation rate along major faults (e.g., Burov and Poliakov, 2001).

Although we employed a very simplified erosion history assuming a constant rate of erosion with total denudation up to $3 \mathrm{~km}$, representing a lower boundary for the total denudation in southeastern Brazil since the Early Cretaceous, thermochronological data (e.g., Cogné et al., 2011) indicate that denudation rate changed through time, with high cooling rates between 90 and $60 \mathrm{Ma}$ (Figure 2.1c). This period of high denudation rate along the margin probably contributed to create an extensional stress field that induced the formation of the CRSB by the reactivation of the Precambrian shear zones of the Ribeira Belt where the rocks of the upper crust possibly presented lower internal cohesion. 
Additionally, our results indicate that other geotectonic processes like regional uplift and inplane compression had only a secondary effect on the formation of these normal faults. However, a regional uplift can be indirectly related to the rift formation by the perturbation of surface processes dynamics, contributing to enhanced denudation. Braun et al. (2013) showed that long-wavelength topographic perturbation due to a mantle source can induce increased denudation rate even for a broad and smooth uplift. Thus, in spite of the apparently minor modification of the deviatoric stresses in the upper crust due to regional uplift, this perturbation probably increased the denudation rate in the onshore margin.

We conclude that important elements to create the CRSB are: (1) a shallow necking depth, (2) the high denudation concentrated along the continental margin, and (3) the preexistence of shear zones parallel to the coast. Other divergent margins around the world probably do not present these factors simultaneously, hence not inducing the formation of a continental rift. Thermochronological data (O'Sullivan et al., 1996) indicate that the divergent margin of southeastern Australia, formed at 100-90 Ma, had a low post-rift denudation rate, which might have contributed to the minor post-breakup tectonism of this margin (e.g., Bishop and Goldrick, 2000). In the margin between Namibia and South Africa the denudation was about the same magnitude observed in SE Brazil Gallagher and Brown, 1999). However, in this case, the width of the mobile belt parallel to coast is much narrower than the Ribeira Belt, hence not favouring the formation of a fault system on the belt. The Damara Belt, between Congo and Kalahari cratons, which extends inland for hundreds of kilometers, represents an exception. However, the direction of shear zones in this belt is essentially orthogonal to the margin and thus is unlikely that the onshore denudation resulted in flexural stresses that would induce the formation of normal faults parallel to the coast.

For narrow margins, necking depth is expected to be deeper, inducing upward flexure of the margin and precluding normal faulting occurrence. The Araçuaí Belt, northward of the Ribeira Belt, and the West Congo Belt in the African conjugate margin evolved to relatively narrow margins (Karner and Driscoll, 1999) and, therefore, probably related to deeper necking depths, which in turn contributed to suppress post-rift normal faulting reactivations. 


\subsection{Conclusions}

This study provides a numerical quantification of the stresses within the lithosphere due to variable necking depth, onshore erosion, offshore sedimentation, regional uplift and compressional stresses based on numerical simulation of the southeastern Brazilian margin evolution using a viscoelastic numerical model. Our results showed a dependence between the necking depth of the lithosphere and the timing in which normal faulting is expected to occur in the upper crust near the margin. A shallow necking depth $(\leq 12 \mathrm{~km})$ together with the high denudation rate of the onshore area, which resulted in more than $3 \mathrm{~km}$ of erosion along the margin since the opening of the South Atlantic ocean, combined with the pre-existing shear zones parallel to the margin contributed to form a suitable scenario for the formation of the Continental Rift of Southeastern Brazil. On the other hand, a regional uplift induced by the relative movement of the South American plate over the Trindade-Martin Vaz hotspot cannot explain the reactivation of deep normal faults by flexural stresses. 
Chapter 3

\section{MANDYOC model description}

This chapter presents the mathematical formulation of the MANDYOC (MANtle DYnamics simulatOr Code) thermo-mechanical model and its numerical implementation. The model was initially presented by Sacek (2017). As part of this project, I contributed in the implementation and testing of additional components on the code, namely: the free surface stabilization algorithm (Section 3.3), the surface tracking (Section 3.6) and the surface processes simulation (Section 3.7).

\subsection{Conservation equations and numerical approach}

To simulate mantle convection, the Non-Newtonian formulation with the incompressible Boussinesq approximation (Zhong et al., 2007) was adopted to solve the mass, momentum and energy conservation equations:

$$
\begin{gathered}
u_{i, i}=0 \\
\sigma_{i j, j}+g \rho_{0} \alpha T \delta_{i 3}=0 \\
\frac{\partial T}{\partial t}+u_{i} T_{, i}=\kappa T_{, i i}+H / c_{p}-\alpha T g u_{3} / c_{p}
\end{gathered}
$$

in which

$$
\sigma_{i j}=-P \delta_{i j}+\eta\left(u_{i, j}+u_{j, i}\right)
$$

where $t$ is time, $u_{i}$ is the $i$-th velocity component, $g$ is gravity acceleration, $\rho_{0}$ is a reference density, $\alpha$ is the volumetric expansion coefficient, $T$ is temperature, $\kappa$ is the thermal diffusivity, $H$ is the heat production per unit mass, $P$ is the dynamic pressure, $c_{p}$ is the specific heat, $\eta$ is the rock effective viscosity and $\delta_{i j}$ is the Kronecker delta. In this notation, repeated indices indicate the Einstein summation convention Barr $(1991)$ and $T_{, i}$ is the partial derivative of $T$ with the coordinate $x_{i}$. 
In equation 3.3, the terms in the right-hand side represent, respectively, the heat diffusion component, the radiogenic heat production and the adiabatic heat.

In the visco-plastic model, the effective viscosity $\eta$ is given by the formulation described by Moresi and Solomatov (1998), combining the viscous rheology and the Byerlee's law for plastic deformation.

The brittle fracture is achieved when the stress reaches, for example, the limit given by the Byerlee's law (Byerlee, 1968):

$$
\tau_{\text {yield }}=c_{0}+\mu \rho g z
$$

where $c_{0}$ is the internal cohesion, $\mu$ is the friction coefficient and $z$ is depth, but other plastic laws can be adopted.

The effective nonlinear viscosity is given by the following expression (Moresi and Solomatov, 1998):

$$
\eta_{\text {plast }}=\frac{\tau_{\text {yield }}}{2 \dot{\varepsilon}_{I I}}=\frac{c_{0}+\mu \rho g z}{2 \dot{\varepsilon}_{I I}}
$$

where $\dot{\varepsilon}_{I I}$ is the second invariant of the deviatoric strain rate tensor:

$$
\dot{\varepsilon}_{I I}=\left(\dot{\varepsilon}_{i j}^{\prime} \dot{\varepsilon}_{i j}^{\prime} / 2\right)^{1 / 2}
$$

The effective viscosity $\eta$ (equation 5.13) is taken as the minimum between $\eta_{\text {plast }}$ and $\eta_{v i s c}:$

$$
\eta=\min \left(\eta_{\text {plast }}, \eta_{\text {visc }}\right)
$$

where $\eta_{v i s c}$ is a power-law viscosity component, described in Section 3.4 .

The equations $3.1,3.2$ are numerically solved by the finite elements method (Zhong et al. 2007) either in tridimensional mesh using $Q_{1} P_{0}$ hexahedral elements or in a bidimensional mesh using $Q_{1} P_{0}$ quadrilaterals elements (Hughes, 2012). The equation 3.3 is solved in the same finite element mesh using the implicit formulation presented by Braun (2003).

To run the numerical simulation (Figure 3.1), the user initially specifies the initial conditions (I.C.) and boundary conditions (B.C.) for the temperature $T$ and velocity $u$, altogether with the reference density field $\rho_{0}$, radiogenic heat production $H$ and the compositional factor $C$, which is a viscosity scaling parameter. In each time step, $\eta_{v i s c}$ and $\eta_{\text {plast }}$ are evaluated using equations 3.38 and 3.6 , respectively. Then, the effective viscosity $\eta$ is determined using equation 3.8. Given the effective viscosity field $\eta$, the Uzawa scheme 


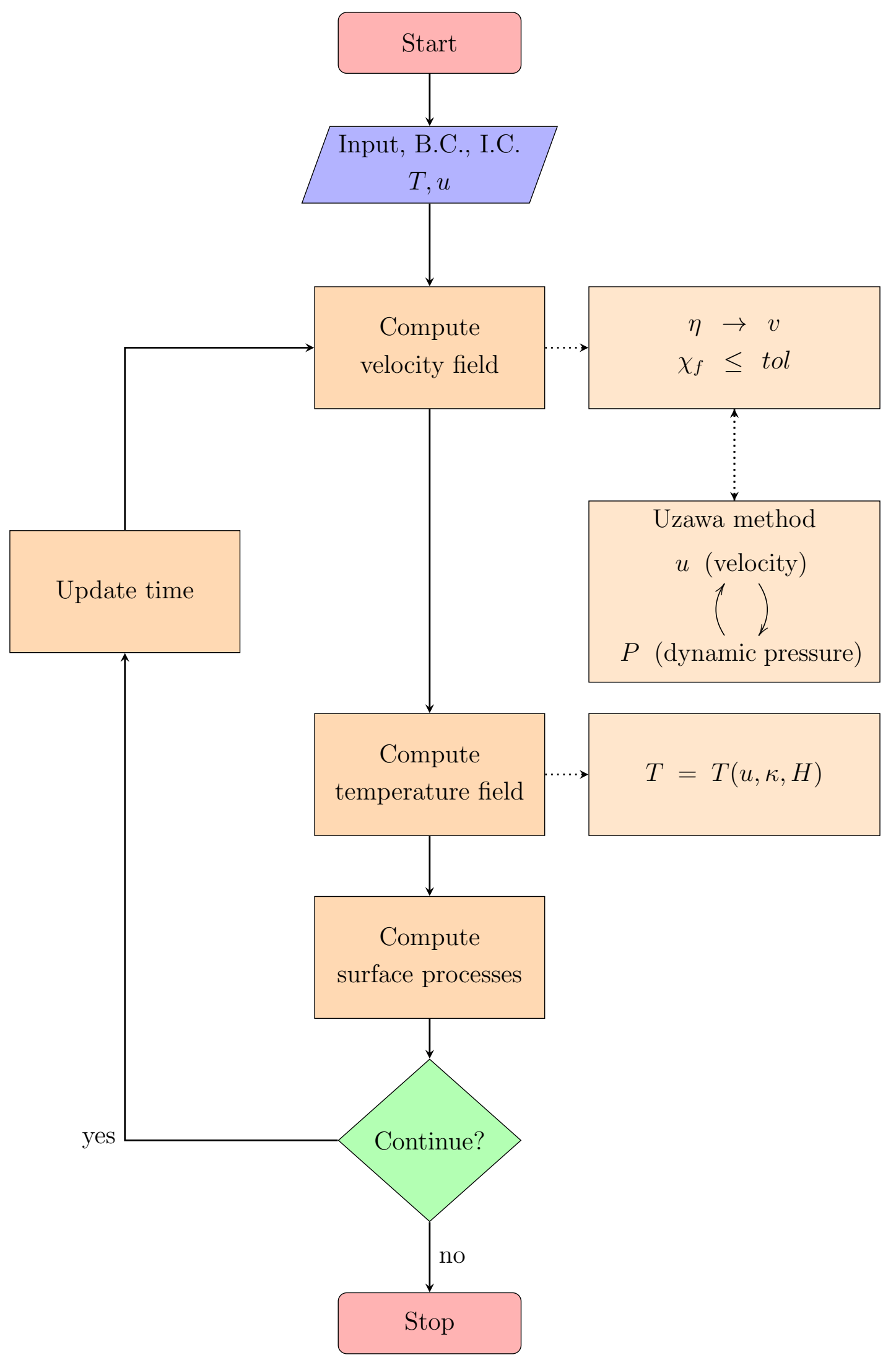

Figure 3.1: Flowchart picturing the evaluation of equations that represent conservation of mass, momentum, and energy. 
(Zhong et al., 2007) is used to iteratively solve equations 3.1 e 3.2 resulting in new states for the velocity $u$ and pressure $P$ fields. The updated velocity field modifies the effective viscosity $\eta$ which then also modifies the velocity field. These fields are evaluated until the following convergence condition is achieved (Thieulot, 2014):

$$
\chi_{f}=1-\frac{\left\langle\left(f^{i}-\left\langle f^{i}\right\rangle\right) \cdot\left(f^{i+1}-\left\langle f^{i+1}\right\rangle\right)\right\rangle}{\left|f^{i}-\left\langle f^{i}\right\rangle\right|\left|f^{i+1}-\left\langle f^{i+1}\right\rangle\right|} \leq \text { tol }
$$

in which $f$ represents a vector holding the velocity components $u$ for all nodes of the finite element mesh, tol is a tolerance parameter $\left(=10^{-6}\right)$ and $\langle f\rangle$ is the mean value of $f$. The superscripts $i$ and $i+1$ represents two consecutive iterations within the same time step. Given the velocity field $u$ the equation 3.3 is solved to obtain the temperature field.

Additionally, the compositional factor $C$ is evaluated using the following advection equation:

$$
\frac{\partial C}{\partial t}+u_{i} C_{, i}=0
$$

The last equation is solved explicitly using particles randomly distributed over the finite element mesh, mapped in the different mesh elements. The displacement of these particles is function of the adjacent nodes to each particle (Tackley and King, 2003), which is obtained via linear interpolation within each element.

The computational code was written in $\mathrm{C}$ language and is possible to be executed in parallel using modern techniques of parallel algebraic offered by PETSC - Portable, Extensible Toolkit for Scientific Computation - library (Balay et al., 1997, 2018a b).

The code is freely available at https://bitbucket.org/victorsacek/mandyoc/src/ master/.

\subsection{Numerical implementation using the Finite Element Method}

The equations 3.1 and 3.2 can be expressed equivalently in the Galerkin weak formulation (Bercovici, 2010) as

$$
\int_{\Omega} w_{i, j} \sigma_{i j} d \Omega-\int_{\Omega} q u_{i, i} d \Omega=\int_{\Omega} w_{i} f_{i} d \Omega+\sum_{i=1}^{n_{\text {sd }}} \int_{\Gamma_{h_{i}}} w_{i} h_{i} d \Gamma
$$

where $w_{i}$ and $q$ are weighting functions and the boundary conditions are given by

$$
u_{i}=\bar{u}_{i} \text { on } \Omega_{g}
$$




$$
\sigma_{i j} n_{j}=h_{i} \text { on } \Gamma_{h_{i}}
$$

where $\Omega_{g}$ and $\Gamma_{h_{i}}$ are the boundaries where the $i$-th components of velocity and forces are specified to be $\bar{u}_{i}$ and $h_{i}$, respectively, $n_{j}$ is the normal vector at the boundary $\Gamma_{h_{i}}$ and $f_{i}=g \rho_{0} \alpha T \delta_{i 3}($ Hughes, 2000).

The equation 3.11 can be expressed as

$$
\begin{aligned}
\int_{\Omega} w_{i, j} c_{i j k l} v_{k, l} d \Omega-\int_{\Omega} q v_{i, i} d \Omega & -\int_{\Omega} w_{i, i} P d \Omega \\
= & \int_{\Omega} w_{i} f_{i} d \Omega+\sum_{i=1}^{n_{\mathrm{sd}}} \int_{\Gamma_{h_{i}}} w_{i} h_{i} d \Gamma-\int_{\Omega} w_{i, j} c_{i j k l} \bar{u}_{k, l} d \Gamma
\end{aligned}
$$

where

$$
c_{i j k l}=\eta\left(\delta_{i k} \delta_{j l}+\delta_{i l} \delta_{j k}\right)
$$

is obtained from the constitutive equation 3.4 .

The pressure and velocity and the weighting functions are given by

$$
\begin{aligned}
\mathbf{v}=v_{i} \mathbf{e}_{i} & =\sum_{\mathrm{A} \in \Omega^{v}-\Gamma_{g_{i}}^{v}} N_{\mathrm{A}} v_{i \mathrm{~A}} \mathbf{e}_{i} \\
\mathbf{w}=w_{i} \mathbf{e}_{i} & =\sum_{\mathrm{A} \in \Omega^{v}-\Gamma_{g_{i}}^{v}} N_{\mathrm{A}} w_{i \mathrm{~A}} \mathbf{e}_{i} \\
\overline{\mathbf{u}} & =\sum_{\mathrm{A} \in \Gamma_{g_{i}}^{v}} N_{\mathrm{A}} \bar{u}_{i \mathrm{~A}} \mathbf{e}_{i} . \\
P & =\sum_{\mathrm{B} \in \Omega^{p}} M_{\mathrm{B}} P_{\mathrm{B}} \\
q & =\sum_{\mathrm{B} \in \Omega^{p}} M_{\mathrm{B}} q_{\mathrm{B}}
\end{aligned}
$$

where $N_{\mathrm{A}}$ is the shape function for velocity at node $\mathrm{A}, M_{\mathrm{B}}$ is the shape functions for pressure at node $\mathrm{B}, \Omega^{v}$ are the nodes for velocity, $\Omega^{p}$ are the nodes for pressure and $\Gamma_{g_{i}}^{v}$ are the nodes for velocity along the boundary $\Gamma_{g_{i}}$. Considering, as an example, in a 2-D grid with a 4-node bilinear element, the pressure can be defined at the center of the element and velocity can be defined at the corners of the elements, resulting in different sets of nodes and shape functions for velocity and pressure (Figure 3.2): linear interpolation for velocity between the element corners, and constant pressure in each element. This strategy to keep the interpolation function (shape functions) for velocity one order higher than those for pressure, commonly used in finite element modeling of incompressible media (Hughes, 2000), avoid spurious flow solutions and numerical instabilities (Bercovici, 2010). 


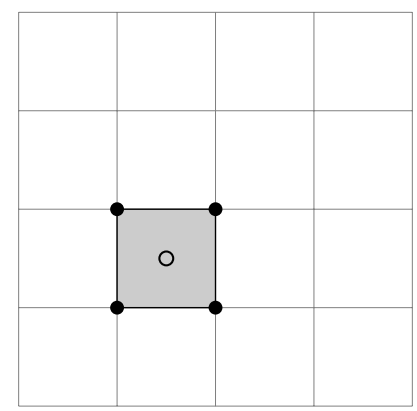

Figure 3.2: Finite element. Example of 2-D grid with 4-node bilinear element. Filled circles at corners indicate the nodes where velocity is defined and the centered open circle indicate where the pressure is defined.

From equations 3.163 .20 and 3.14 , the following two equations are derived:

$$
\begin{gathered}
\sum_{\mathrm{B} \in \Omega^{v}-\Gamma_{g_{j}}^{v}}\left(\mathbf{e}_{i}^{\mathrm{T}} \int_{\Omega} B_{\mathrm{A}}^{\mathrm{T}} D B_{\mathrm{B}} d \Omega \mathbf{e}_{j} v_{j \mathrm{~B}}\right)-\sum_{\mathrm{B} \in \Omega^{p}}\left(\mathbf{e}_{i} \int_{\Omega} N_{\mathrm{A}, i} M_{\mathrm{B}} d \Omega P_{\mathrm{B}}\right)= \\
=\int_{\Omega} N_{\mathrm{A}} \mathbf{e}_{i} f_{i} d \Omega+\sum_{i=1}^{n_{\mathrm{sd}}} \int_{\Gamma_{h_{i}}} N_{\mathrm{A}} \mathbf{e}_{i} h_{i} d \Gamma-\sum_{\mathrm{B} \in \Gamma_{g_{j}}^{v}}\left(\mathbf{e}_{i}^{\mathrm{T}} \int_{\Omega} B_{\mathrm{A}}^{\mathrm{T}} D B_{\mathrm{B}}^{\mathrm{T}} d \Omega \mathbf{e}_{j} g_{j \mathrm{~B}}\right) \\
\sum_{\mathrm{B} \in \Omega^{v}-\Gamma_{g_{j}}^{v}}\left(\int_{\Omega} M_{\mathrm{A}} N_{\mathrm{B}, j} d \Omega \mathbf{e}_{j} v_{j \mathrm{~B}}\right)=0
\end{gathered}
$$

which can be expressed in a matrix form

$$
\left[\begin{array}{cc}
K & G \\
G^{\mathrm{T}} & 0
\end{array}\right]\left\{\begin{array}{l}
V \\
P
\end{array}\right\}=\left\{\begin{array}{l}
F \\
0
\end{array}\right\}
$$

where $V$ is the vector with velocity values at all nodes, $P$ is the vector with pressure values at all pressure nodes, $F$ is the vector resulting from the terms of the right-hand side of equations 3.21 or $3.22, K$ is the stiffness matrix, $G$ is the discrete gradient operator, and $G^{\mathrm{T}}$ is the discrete divergence operator (Bercovici, 2010).

The $B$ operators in equations 3.21 and 3.22 represent matrix containing the spatial derivatives of the shape function $N$. In $2-\mathrm{D}, B$ is given by:

$$
B_{A}=\left[\begin{array}{cc}
N_{A, 1} & 0 \\
0 & N_{A, 2} \\
N_{A, 2} & N_{A, 1}
\end{array}\right]
$$

The matrix $D$ is related to the effective viscosity. In $2-\mathrm{D}, D$ is given by: 


$$
D=\left[\begin{array}{ccc}
2 \eta & 0 & 0 \\
0 & 2 \eta & 0 \\
0 & 0 & \eta
\end{array}\right]
$$

The stiffness matrix $K$ and the discrete gradient operator $G$ are given by

$$
\begin{aligned}
K_{l m} & =\mathbf{e}_{i}^{\mathrm{T}} \int_{\Omega} B_{A}^{\mathrm{T}} D B_{B} d \Omega \mathbf{e}_{j} \\
G_{l m} & =\mathbf{e}_{i} \int_{\Omega} N_{A} M_{B} d \Omega \mathbf{e}_{j}
\end{aligned}
$$

where subscripts $A$ and $B$ corresponds to the global nodes for velocity, $i$ and $j$ are the degree of freedom per node (ranging from 1 to $n_{\mathrm{sd}}$ ), $l$ and $m$ are the numbering in the global equation for velocity (ranging from 1 to $n_{v} n_{\mathrm{sd}}$, given that $n_{v}$ is the number of velocity nodes).

The finite elements representation of equation 3.3 is given by

$$
\mathbf{M} \dot{\mathbf{a}}_{T}+\left(\mathbf{K}_{a}+\mathbf{K}_{c}\right) \mathbf{a}_{T}=\mathbf{F}
$$

where

$$
\begin{gathered}
\mathbf{M}=\int_{\Omega_{V}} \mathbf{N}_{V}^{\mathrm{T}} \rho_{0} c_{p} \mathbf{N}_{V} d \Omega_{V} \\
\mathbf{K}_{a}=\int_{\Omega_{V}} \mathbf{N}_{V}^{\mathrm{T}} \rho_{0} c_{p} \mathbf{v} \cdot \mathbf{B}_{V} d \Omega_{V} \\
\mathbf{K}_{c}=\int_{\Omega_{V}} \mathbf{B}_{V}^{\mathrm{T}} \rho_{0} c_{p} \mathbf{v} \cdot \mathbf{B}_{V} d \Omega_{V} \\
\mathbf{F}=\int_{\Omega_{V}} \mathbf{N}_{V}^{\mathrm{T}}\left(H / c_{p}-\alpha T g u_{3} / c_{p}\right) d \Omega_{V}
\end{gathered}
$$

In the equations above, $T$ refer to the temperature and $\mathrm{T}$ designates the transpose of a matrix. $\Omega_{V}$ is the domain, $\mathbf{N}_{V}$ is a row vector of shape functions, $\mathbf{a}_{T}$ is a column vector of the unknowns parameters for temperature, $\dot{\mathbf{a}}_{T}$ is its time derivative and $\mathbf{B}_{V} \equiv \nabla \mathbf{N}_{V}$.

In equation 3.28, matrices $\mathbf{M}$ and $\mathbf{K}_{c}$ are symmetric while $\mathbf{K}_{a}$ is non-symmetric. In cases in which the transport of heat is dominated by advection the solution of equation 3.28 ca be unstable (Zienkiewicz et al., 2000, chapter 2) since the asymmetry of $\mathbf{K}_{a}$ reduces the accuracy of the solution. The accuracy and stability of the solution of equation 3.28 is improved by the streamline upwind Petrov-Galerkin process (Hughes, 1979, 1982, Zienkiewicz et al., 2000), which modifies equation 3.28 to

$$
\mathbf{M} \dot{\mathbf{a}}_{T}+\left(\mathbf{K}_{a}^{*}+\mathbf{K}_{c}\right) \mathbf{a}_{T}=\mathbf{F}
$$




$$
\mathbf{M} \dot{\mathbf{a}}_{T}+\left(\mathbf{K}_{T}\right) \mathbf{a}_{T}=\mathbf{F}
$$

where

$$
\begin{gathered}
\mathbf{K}_{a}^{*}=\int_{\Omega_{V}} \mathbf{N}_{V}^{* \mathrm{~T}} \rho_{0} c_{p} \mathbf{v} \cdot \mathbf{B}_{V} d \Omega_{V} \\
N_{V i}^{*}=N_{V i}+\frac{\alpha_{\mathrm{opt}} h^{e} \mathbf{v} \cdot \nabla N_{V i}}{2|\mathbf{v}|} \\
\alpha_{\mathrm{opt}}=\operatorname{coth} P e-\frac{1}{P e} \\
P e=\frac{|\mathbf{v}| h^{e}}{2 \kappa \rho_{0} c_{p}}
\end{gathered}
$$

and $h_{e}$ is the characteristic element size in the direction of the advection velocity $\mathbf{v}$. In the equations above, $P e$ is the Péclet number.

Following Braun (2003), the discretization in time is done by an implicit scheme:

$$
\frac{\mathbf{a}_{T}(t+\Delta t)-\mathbf{a}_{T}(t)}{\Delta t}=\theta \dot{\mathbf{a}}_{T}(t+\Delta t)+(1-\theta) \mathbf{a}_{T}(t)
$$

where $\theta$ is a weighting parameter $(=0.5)$. Multiplying equation 3.35 in both sides by $\mathbf{M}(t+\Delta t)$, assuming $\mathbf{M}(t+\Delta t) \approx \mathbf{M}(t)$ and taking equation 3.33 into account, one obtains

$$
\begin{aligned}
\mathbf{M}(t+\Delta t) \frac{\mathbf{a}_{T}(t+\Delta t)-\mathbf{a}_{T}(t)}{\Delta t}=\theta\left[\mathbf{F}(t+\Delta t)-\mathbf{K}_{T}(t+\Delta t) \mathbf{a}_{T}(t+\Delta t)\right]+ & \\
& +(1-\theta)\left[\mathbf{F}(t)-\mathbf{K}_{T}(t) \mathbf{a}_{T}(t)\right]
\end{aligned}
$$

The terms of equation 3.36 can be rearranged, resulting in the following equation, which is the numerical form to solve the energy equation 3.3

$$
\begin{aligned}
& {\left[\mathbf{M}(t+\Delta t)+\Delta t \theta \mathbf{K}_{T}(t+\Delta t)\right] \mathbf{a}_{T}(t)(t+\Delta t)=} \\
& \quad=\left[\mathbf{M}(t+\Delta t)-\Delta t(1-\theta) \mathbf{K}_{T}(t)\right] \mathbf{a}_{T}(t)+\Delta t[\theta \mathbf{F}(t+\Delta t)+(1-\theta) \mathbf{F}(t)] .
\end{aligned}
$$

\subsection{Free surface}

In numerical geodynamics, the representation of a free surface like the interface between crust-air or crust-water is a challenge task due to the large density difference between rocks and air or water on the interface. The main problem with the free surface is a numerically instability which causes up/down oscillations of the interface around a stead configuration. In the geodynamics modelling this effect is known as "sloshing instability" or "drunken 
sailor effect" (Kaus et al., 2010). The cause of this instability arises due to an imprecise time integration of the free surface which doesn't takes into account the displacement velocity of the surface during the time interval of the numerical integration. Since the error in this integral is proportional to the density contrast between the two medium, it is specially critical on the Earth's surface where the density contrast is $\Delta \rho \approx 2700 \mathrm{~kg} / \mathrm{m}^{3}$. This problem is less important for the interfaces on the interior of the Earth where the density contrast is smaller (for example, on the crust-mantle $\Delta \rho \approx 500 \mathrm{~kg} / \mathrm{m}^{3}$ ).

A strategy to avoid the "drunken sailor effect" is to have significantly smaller time steps than those normally used in geodynamics problems ( $c a$. 30 times smaller, as mentioned by Kaus et al., 2010), largely increasing the execution time of the model which turns prohibitive the simulation of geodynamic numerical settings for dozens or hundreds of millions of years.

A solution for this problem is the Free Surface Stabilization Algorithm proposed by Kaus et al. (2010) in which the numerical solution in finite elements of the Stokes equations is modified to include a free surface stabilization component. The modification is applied in the finite element stiffness matrices $K_{e}$ adding the term $L_{e}$ referred to a stabilization boundary integral:

$$
\tilde{K}_{e}=K_{e}+L_{e}
$$

In this case, the correction $L_{e}$ is given by

$$
L_{e}=\int_{\Gamma_{e}} \mathbf{N} \Theta \Delta \rho \Delta \operatorname{tg} \mathbf{n} d \Gamma
$$

in which the integration is evaluated on the boundary $\Gamma_{e}$ of each finite element, $\mathbf{N}$ is the element shape function, $\Theta$ is a weight factor of the correction term between 0 and 1 (taken to be 0.5 in the present work), $\Delta \rho$ is the density contrast between the two medium, $\Delta t$ is the numerical integration time step, $\mathbf{g}$ is gravity acceleration vector and $\mathbf{n}$ is the normal vector to the element.

This correction removes the oscillation in the free surface while keeping it stable during the evolution of the geodynamic model, without requiring a small time step $\Delta t$. 


\subsection{Rheological behaviour of mantle and crust}

In MANDYOC, the ductile rheology can be represented by the Frank-Kamenetskii approximation, as previously done by Sacek (2017):

$$
\eta_{v i s c}=C \eta_{r} b^{*} \exp [-\gamma T]
$$

in which $\eta_{r}$ is the reference viscosity, $C$ is a compositional factor to control the scaling of the effective viscosity, and $b^{*}$ and $\gamma=E_{a} / R T_{b}^{2}$ are constants.

In addition, the rheology can also be represented by a power law for the viscosity as a function of temperature, composition, pressure and strain rate:

$$
\eta_{v i s c}=C \cdot A^{-1 / n} \cdot \dot{\varepsilon}^{\frac{1-n}{n}} \cdot \exp \left(\frac{Q+V \cdot P}{n R T}\right)
$$

in which $A$ is a pre-exponential scale factor, $n$ is the power law exponent, $\dot{\varepsilon}$ is the second invariant of the strain rate tensor $\left(\dot{\varepsilon}_{i j}^{\prime} \dot{\varepsilon}_{i j}^{\prime} / 2\right), Q$ is the activation energy, $V$ is the activate volume, $P$ is the pressure, $T$ is the temperature and $R$ the gas constant.

The values of $A, n, Q$ and $V$ are obtained by measures under laboratory conditions (Karato and Wu, 1993; Gleason and Tullis, 1995).

\subsection{Space and time dependent boundary conditions}

The tectonic interaction between lithospheric plates vary along dozens of millions of years. The plates show pulses of acceleration and deceleration (Brune et al., 2016) depending on coupling degree between adjacent plates and the type of interaction. To simulate this kind of variation in the boundary velocity field in MANDYOC the user can add an input file indicating the time instants in which the velocity changes will occur.

In this case, the user provides a text file named scale_bcv.txt (bcv meaning boundary condition for velocity) indicating in the first line the number of episodes along the geologic evolution in which the velocity will be modified, and in the following lines a two column pattern: the first column indicates the time of change in millions of years since the beginning of simulation and the second column indicates the scale factor $s_{v}$ that will be applied to the velocity field, such that a new velocity field $u_{\text {new }}$ is obtained from the current field $u_{\text {current }}$ :

$$
u_{\text {new }} \leftarrow u_{\text {current }} \cdot s_{v}
$$


In this context, it is possible to simulate a tectonic inversion by using a negative scaling factor. For example, for a scenario in which the initial boundary condition specifies a lithospheric stretching with relatively velocity $v_{r e l}=2 \mathrm{~cm} /$ year between the plates and the scale_bcv.txt file with the following contents:

$$
\begin{array}{ll}
2 & \\
10.0 & -1.0 \\
20.0 & 0.5
\end{array}
$$

during the first 10 millions of years the relative velocity is kept at $2 \mathrm{~cm} /$ year, followed by a period of compression with relative velocity of $-2 \mathrm{~cm} /$ year until 20 million years. After 20 million years the relative velocity of convergence will be reduced by a factor of 2 , resulting in a relative velocity of $-1 \mathrm{~cm} /$ year.

\subsection{Surface tracking}

The free surface implementation (Section 3.3) allows the tracking of the surface with time. In MANDYOC, the surface is obtained from the particles that follows the advection equation 3.10, holding the rheological properties of the model. For each time step $\Delta t$, a search is made to determine the air and land particles (that is, a particle from the "sticky air" and a particle from the upper crust, respectively) which has the minimum distance between each other in a band with width $l_{x}$. The sequence of air and land particles obtained in this manner composes two interfaces, $y_{a i r}$ e $y_{l a n d}$, respectively, along the model horizontal extent. The model surface is given by the mean level between theses two interfaces:

$$
y_{s}=\frac{y_{a r}+y_{\text {terra }}}{2}
$$

The model surface, in this case, is proportional to the spacial density of particles and the band width $l_{x}$.

\subsection{Surface processes}

Following a similar approach by Silva and Sacek (2019), in MANDYOC, the user can provide a input file with a history of denudation and sedimentation along the model hori- 
zontal extent. The input file must be named topo_var.txt. The number of profiles with the erosion/sedimentation rates which will be applied must be specified in the first line. In each following line is specified the time in millions of years of start of the specified rates and the erosion rate (positive values) or sedimentation rate (negative value), in meters per year, for each point of the surface.

For example, consider the topo_var.txt file with the following contents:

$$
\begin{aligned}
& 2 \\
& \begin{array}{lllllllllll}
0.0 e+06 & 0.0 & 0.0 & \ldots & 1.0 \mathrm{e}-03 & 1.0 \mathrm{e}-03 & 1.0 \mathrm{e}-03 & \ldots & 0.0 & 0.0
\end{array}
\end{aligned}
$$

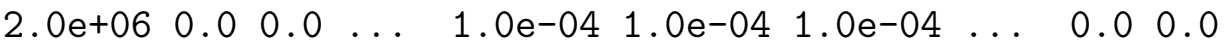

during the first 2 million years, a portion of the surface are eroded with a erosion rate of $10^{-3} \mathrm{~m} /$ year and then, after this period of time, the rate is reduced by a factor of 10 .

This approach allows to specify denudation and sedimentation obtained from thermochronological studies and stratigraphic analyses of sedimentary basins (e.g., Silva and Sacek, 2019).

Other approaches to simulate the surface processes are possible, including the simulation of diffusion on the top of the topography, resulting in the redistribution of mass at the surface.

Once the tracked surface is updated by the surface processes, each particle is updated based on its original properties and the position relative to the updated surface: (1) if one air particle is now under the updated tracked surface (due to sedimentation) this particle is updated to have the properties of the sedimentary layer. (2) if one rock particle is above the updated surface (due to erosion) this particle is updated to have the properties of the air. This scheme can be also modified to take into account air and water at the top of the free surface.

\subsection{Numerical techniques}

In the Uzawa method represented on the flowchart in Figure 3.1, the velocity field $u$ is evaluated by solving a large system of linear equations, with thousands to millions of unknowns depending on the number of nodes of the finite element mesh. These equations are solved in parallel using PETSC (Balay et al., 1997, 2018b a) library, on a system of 
MPI distributed-memory.

In addition, in MANDYOC it is possible to solve the system of linear equations using direct methods involving LU decomposition or domain decomposition like the multigrid technique.

\subsection{Surface stabilization test}

To evaluate the implementation of the surface stabilization algorithm, the experiment "Case 2" presented by Crameri et al. (2012) was reproduced and presented here. This experiment analyses the change in topography due to the rising of a mantle plume. The model setup (Figure 3.3) consists of a $2800 \mathrm{~km}$ by $850 \mathrm{~km}$ box with a $150 \mathrm{~km}$ "sticky air" layer on the top of the model. The mantle thickness is $600 \mathrm{~km}$ with a $100 \mathrm{~km}$ thick lithosphere. The lithosphere density is $3300 \mathrm{~kg} / \mathrm{m}^{3}$ with viscosity $10^{23} \mathrm{Pas}$, the mantle density is $3300 \mathrm{~kg} / \mathrm{m}^{3}$ with viscosity $10^{21} \mathrm{Pas}$ and the mantle plume density is $3200 \mathrm{~kg} / \mathrm{m}^{3}$ with viscosity $10^{20} \mathrm{Pas}$. Initially, the center of the plume is horizontally centered and 300 $\mathrm{km}$ above the base of the model. At the top, the "sticky air" layer has density $0 \mathrm{~kg} / \mathrm{m}^{3}$ with viscosity $10^{19} \mathrm{Pas}$. The free slip boundary condition is applied to the upper boundary of the "sticky air" layer and the vertical sides of the model and the base is kept fixed. There is no temperature difference, and the geodynamic evolution is guided solely by compositional density differences.

\section{(b) 2-D Stokes cylinder:}

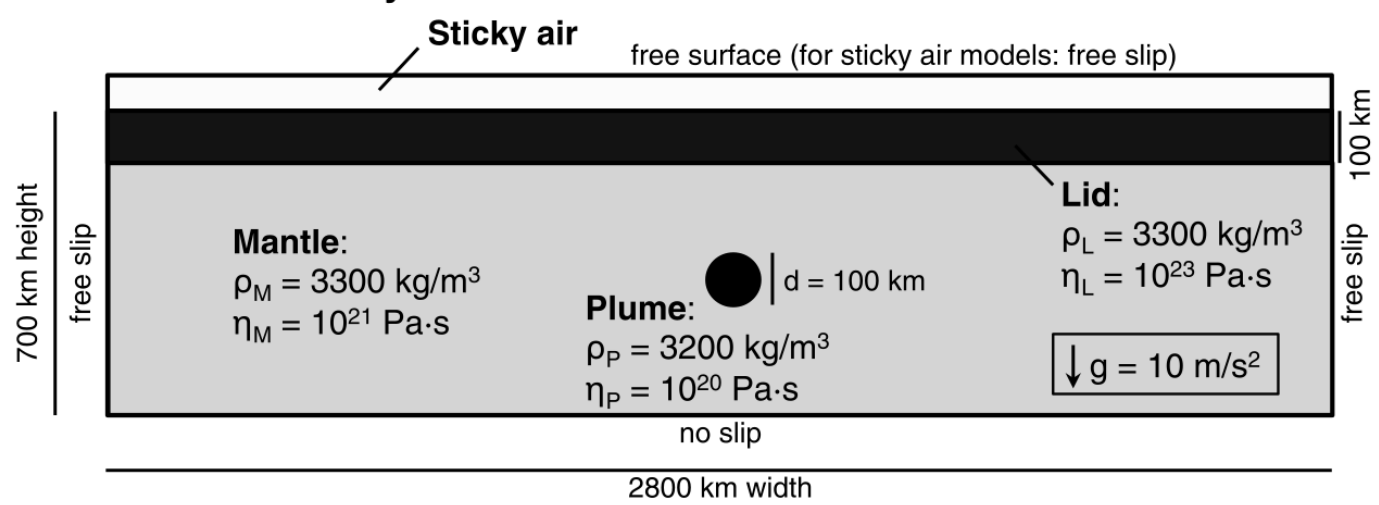

Figure 3.3: "Case 2" model setup to evaluate the "sticky air" method. Extracted from Crameri et al. (2012).

The results of this experiment reproduced in MANDYOC is the maximum topography with time, similar to Fig. 6a of Crameri et al. (2012), is depicted in Figure 3.6. The models 
used for comparison are: UNDERWORLD (Moresi et al., 2003), STAGYY (Tackley, 1993) and I2VIS (Gerya and Yuen, 2003a).

This result validates the "sticky air" method and the surface stabilization algorithm since the results are equivalent to other numerical geodynamic models. The larger discrepancy in results was the UNDERWORLD solution, in which the maximum topography was more than $900 \mathrm{~m}$. Despite this difference, Crameri et al. (2012) did not discuss a possible explanation for that difference between UNDERWORLD and the other models. 


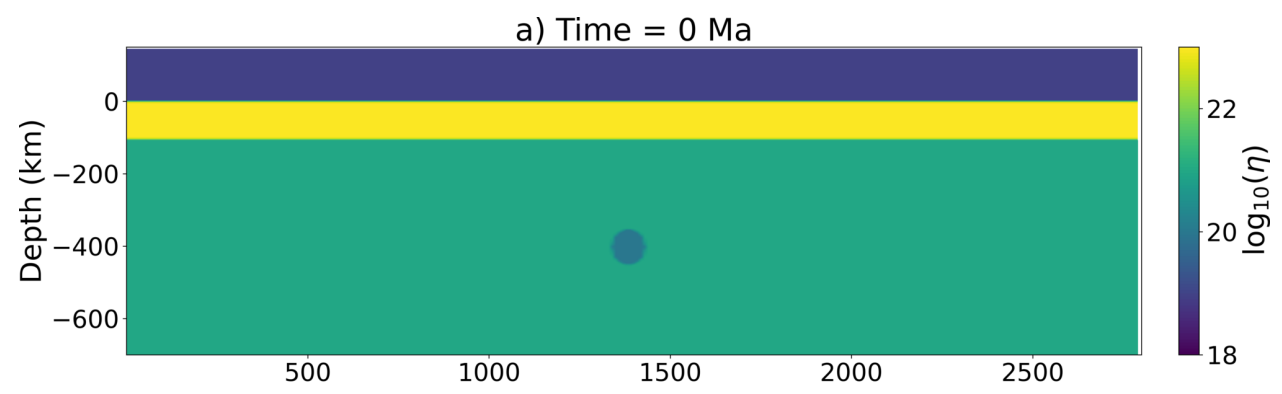

b) Time $=4 \mathrm{Ma}$

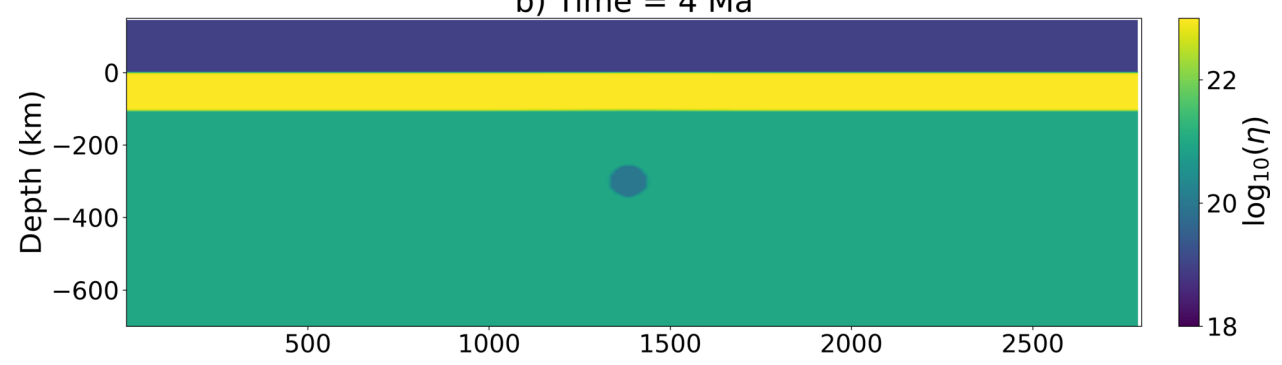

c) Time $=8 \mathrm{Ma}$

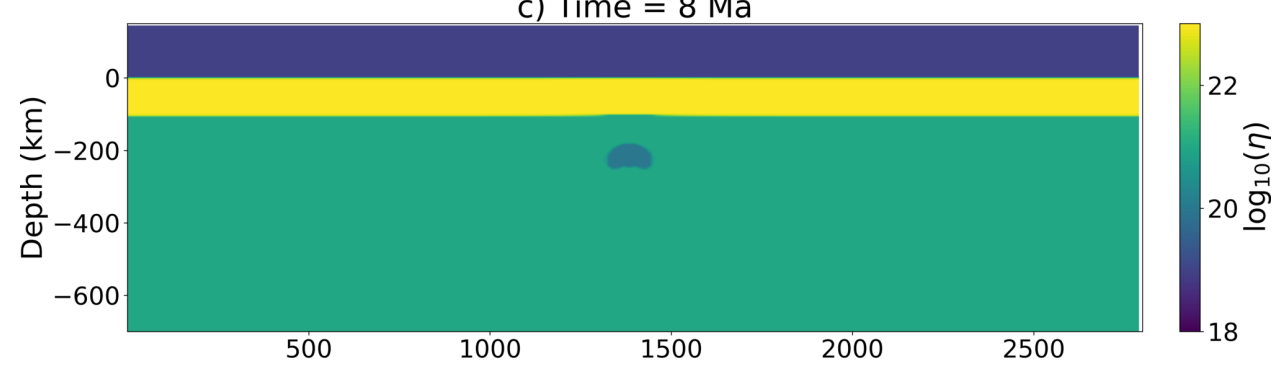

d) Time $=12 \mathrm{Ma}$

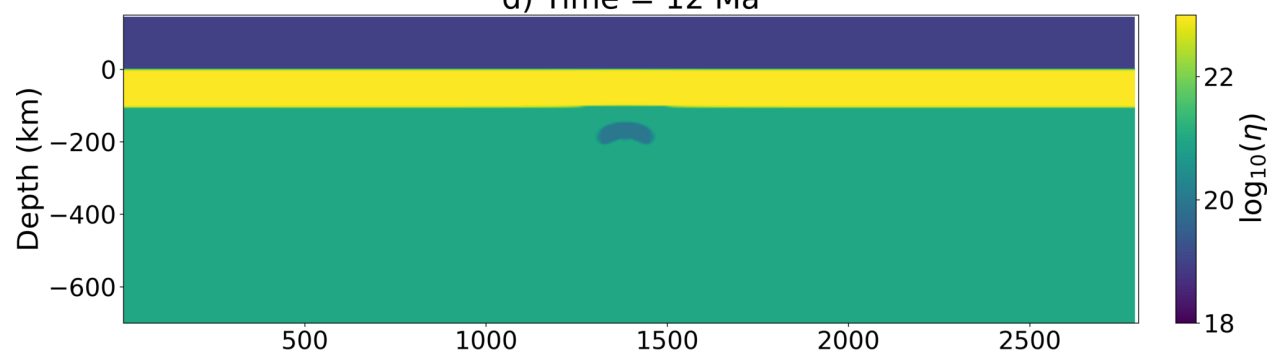

e) Time $=16 \mathrm{Ma}$
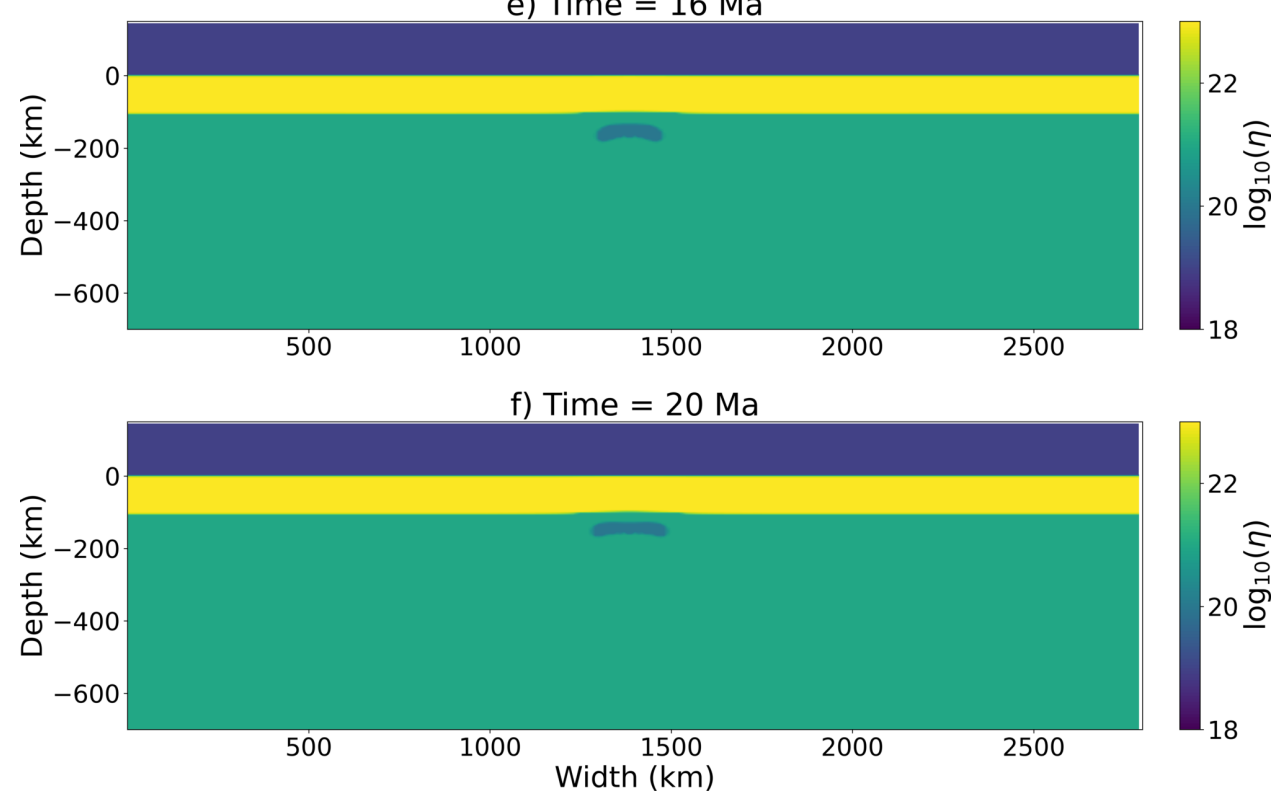

Figure 3.4: Temporal evolution of the "Case 2" (Crameri et al., 2012) obtained with MANDYOC. 


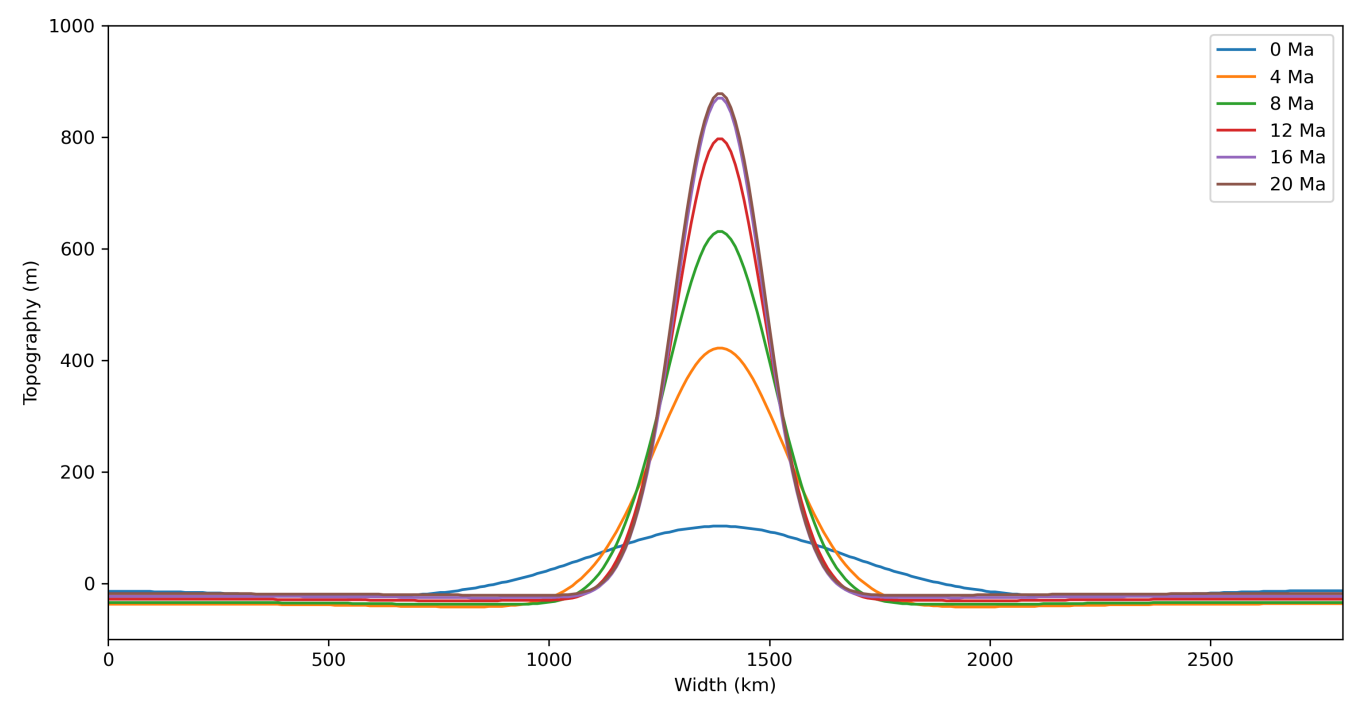

Figure 3.5: Temporal evolution of the surface for results shown on Figure 3.4

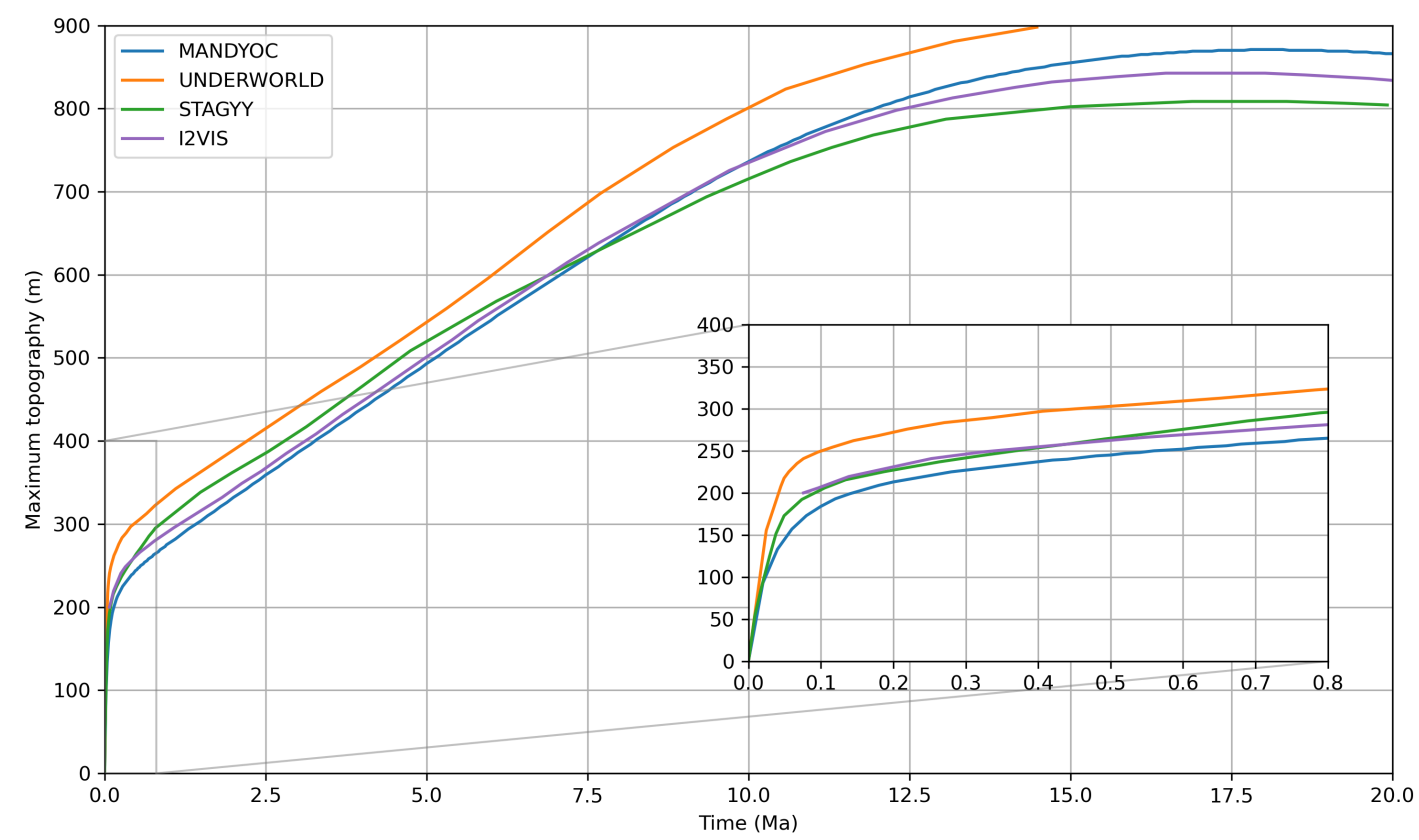

Figure 3.6: Comparison of the maximum topography with time for the "Case 2" (Figure 3.3) model setup (Crameri et al., 2012). 
Chapter 4

\section{Testing of diffusive erosion}

This chapter presents the results of a simple diffusive model of erosion incorporated in MANDYOC. The analysis shows the effects of the surface processes on the initial results of the benchmark where no erosion takes place, and the differences caused on the topography and lithosphere deformation.

\subsection{Surface processes}

The modelling of short-range surface processes can be quantified by a diffusive equation. In nature, these processes occur on hillslope such as weathering and soil creep. Assuming that the transport is linearly proportional to the slope, the change in topography through time is given by a linear diffusion equation (Dietrich et al., 2003)

$$
\frac{\partial h}{\partial t}=k_{d} \nabla^{2} h
$$

where $h$ is the topography, $t$ is time, and $k_{d}$ is a coefficient related to the diffusive transport.

To test the diffusive erosion, the "Case 2" of the benchmark presented by Crameri et al. (2012) was used as a reference scenario. It is important to highlight that this reference scenario extracted from Crameri et al. (2012) has no surface processes model coupled to the geodynamic code. To my knowledge, no benchmark study combining surface processes and thermomechanical simulation is available in the scientific literature. The model setup is the same described in Section 3.9. The domain is $2800 \mathrm{~km} \mathrm{x} 850 \mathrm{~km}$ comprising a sticky air layer of $150 \mathrm{~km}$ thick with a mesh composed of 281 x 169 nodes. In each element, 1200 randomly distributed particles was used. The amount of particles in vertical direction was 3 times as many as the horizontal direction. The greater density in vertical direction improves the determination of the surface level. Numerical experiments tested values of 
$k_{d}=1 \times 10^{5} \mathrm{~m}^{2} / \mathrm{s}$ and $k_{d}=2 \times 10^{4} \mathrm{~m}^{2} / \mathrm{s}$. The benchmark case with $k_{d}=0$ was used as the reference model.

Due to the rise of the mantle plume an uplift of the surface occurs. On models with $k_{d} \neq 0$, the diffusive process erodes the topography and sediments are accumulated on both sides from the center of the model. The higher the value of $k_{d}$ more effective is the diffusive process and hence the erosion of the surface, limiting the maximum elevation the topography can reach. The difference in the maximum topography observed for the different models is presented on Figure 4.1 and Figure 4.2 shows the effect of erosion on the surface in different moments.

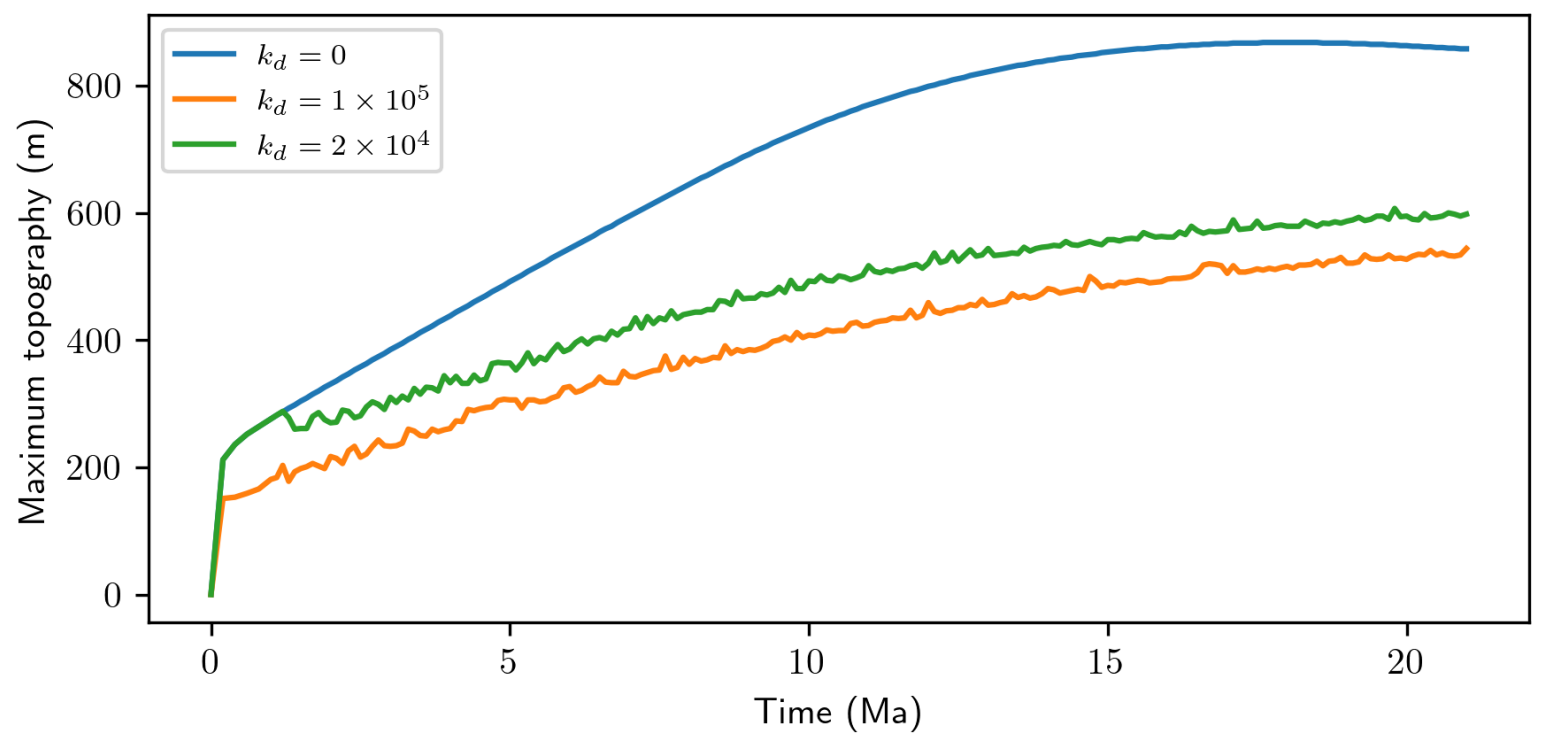

Figure 4.1: Comparison of maximum topography for models with erosion.

The Figures 4.3, 4.4 and 4.5 show the evolution of the models $k_{d}=0, k_{d}=1 \times 10^{5} \mathrm{~m}^{2} / \mathrm{s}$ and $k_{d}=2 \times 10^{4} \mathrm{~m}^{2} / \mathrm{s}$, respectively. The sedimentary packages are shown in yellow for the models with erosion. The sediments accumulated for lower $k_{d}$ value produces a relatively small package compared with higher $k_{d}$ as expected. The difference in sedimentary packages is shown in Figures 4.6 and 4.7 .

Another difference on models with erosion is observed at the base of the lithosphere. The removal of material causes a isostatic adjustment of the lithosphere and hence the base of the lithosphere deforms, which can be seen on Figures 4.4 and 4.5 . This deformation is higher for the model with higher amount of erosion.

Additionally, it is possible to observe an asymmetry of the sedimentary package on each 


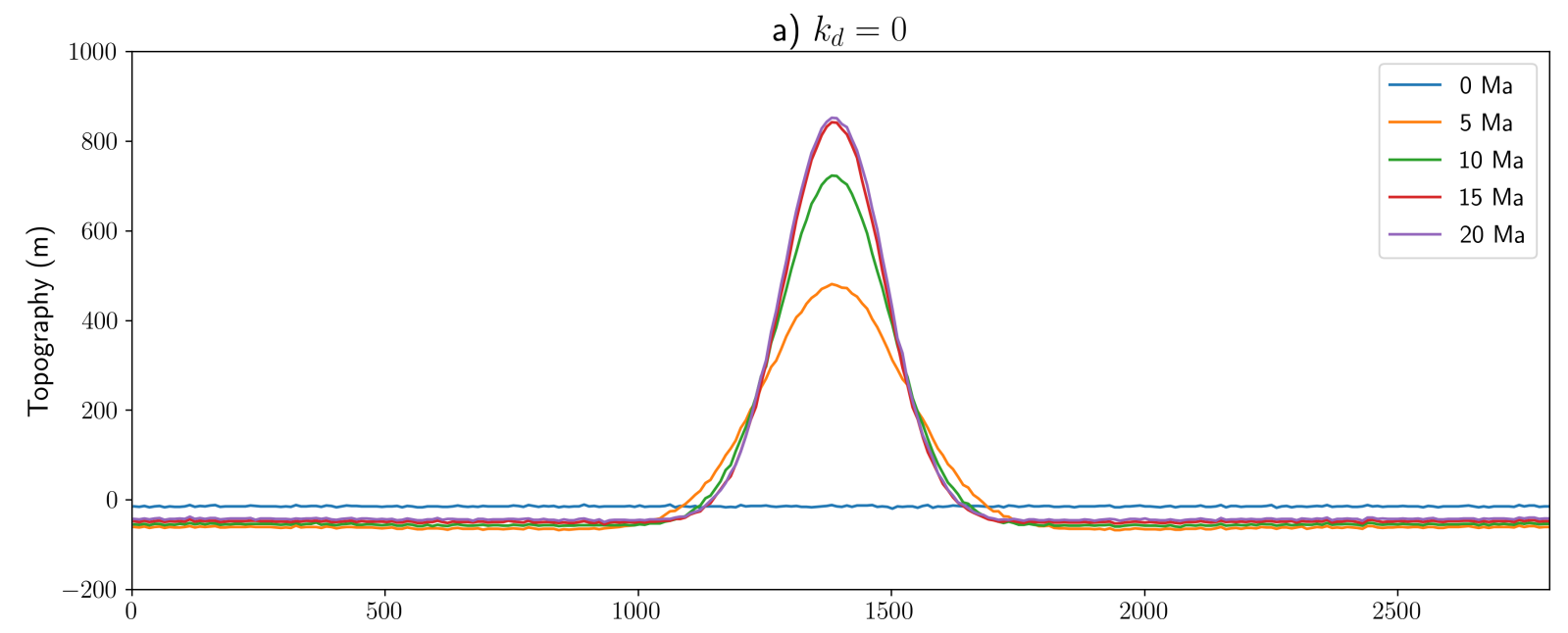

b) $k_{d}=2 \times 10^{4}$

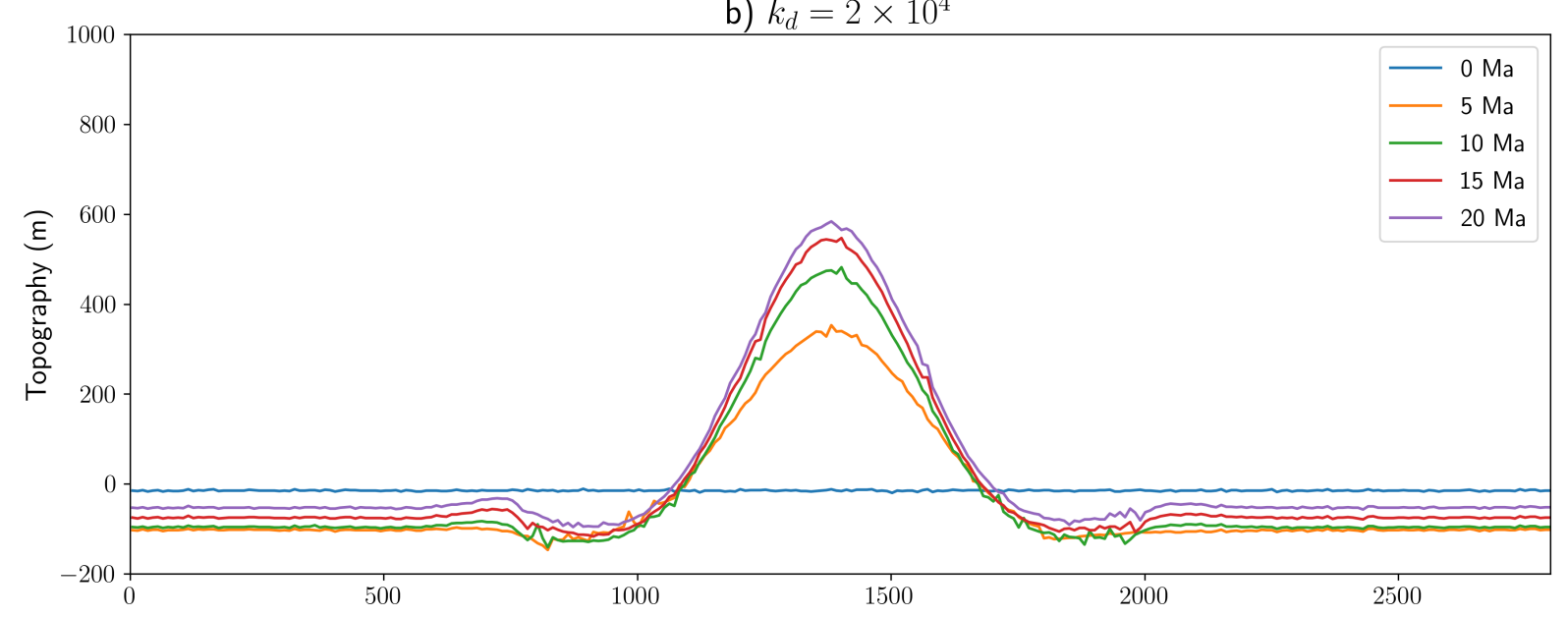

c) $k_{d}=1 \times 10^{5}$

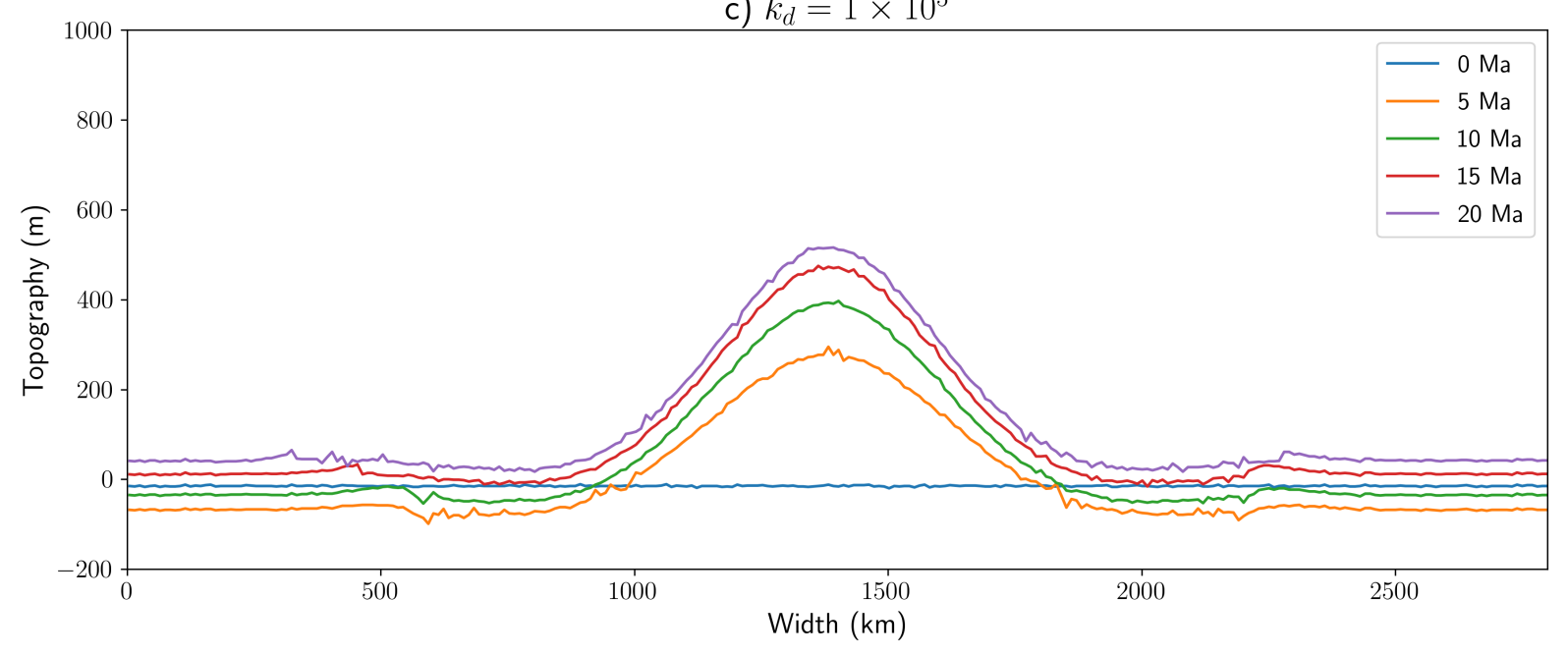

Figure 4.2: Comparison of topography for different $k_{d}$.

side of the swell (Figures 4.6 and 4.7). One possible explanation for this asymmetry is the positive feedback between regional uplift and the erosion of the landscape: the higher the regional uplift, the higher is the rate of erosion; conversely, the higher the magnitude of 
Time: $0 \mathrm{Ma}$
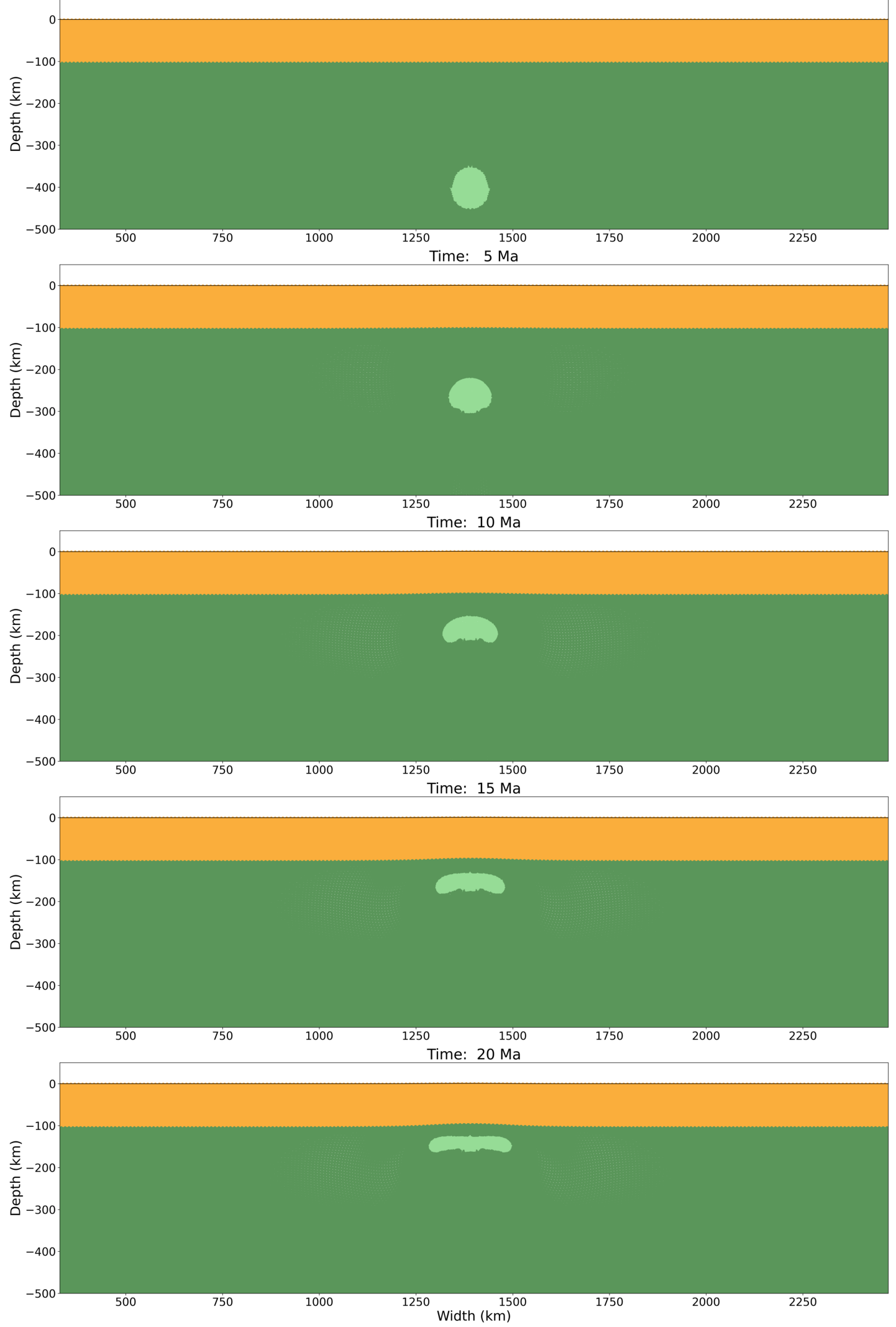

Figure 4.3: Evolution of the model with erosion and sedimentation for $k_{d}=0 \mathrm{~m}^{2} / \mathrm{s}$. Colors represent differences in density and viscosity (refer to Figure 3.3) 
Time: $0 \mathrm{Ma}$
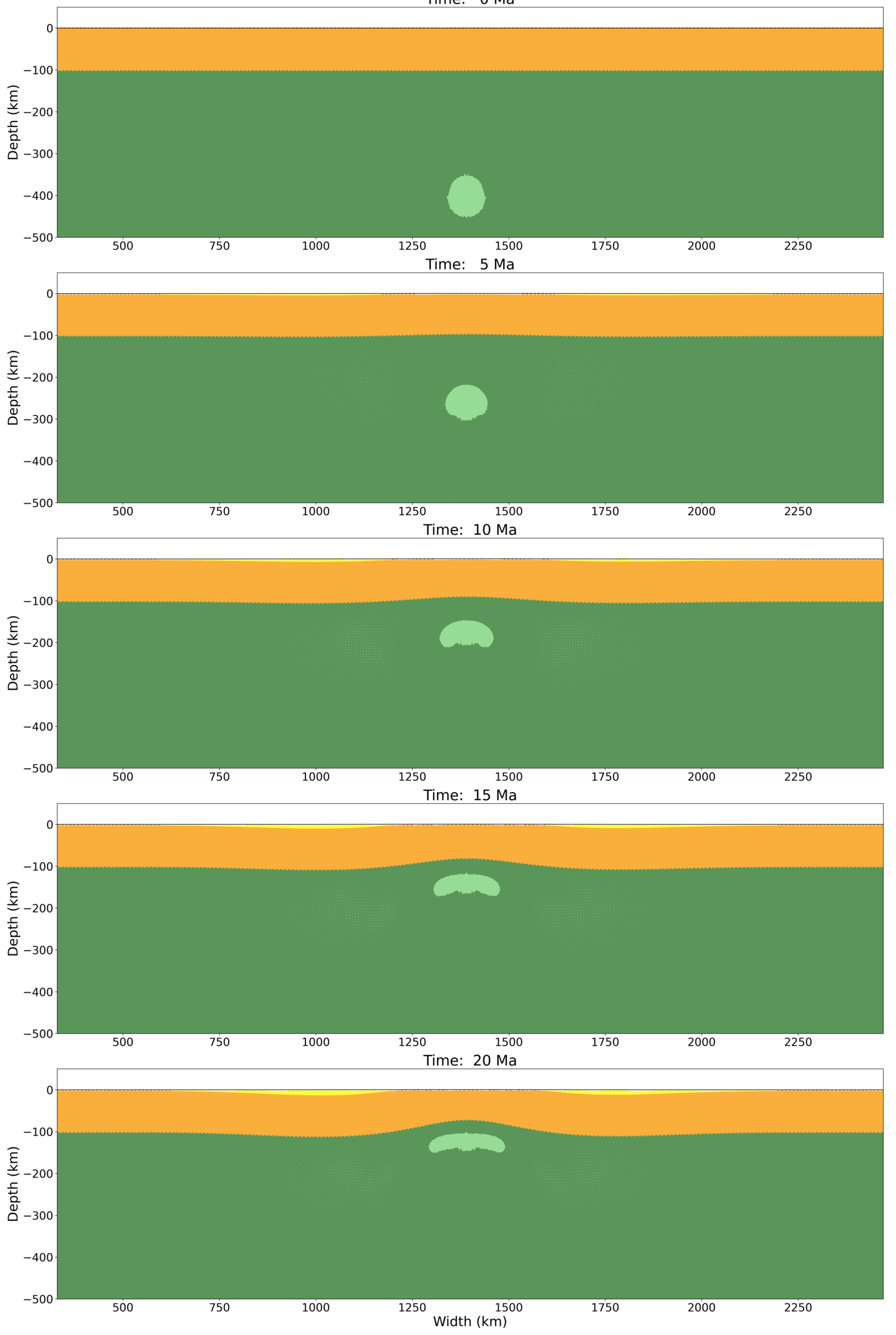

Figure 4.4: Evolution of the model with erosion and sedimentation for $k_{d}=1.0 \times 10^{5} \mathrm{~m}^{2} / \mathrm{s}$. Colors represent differences in density and viscosity (refer to Figure 3.3 
Time: $0 \mathrm{Ma}$
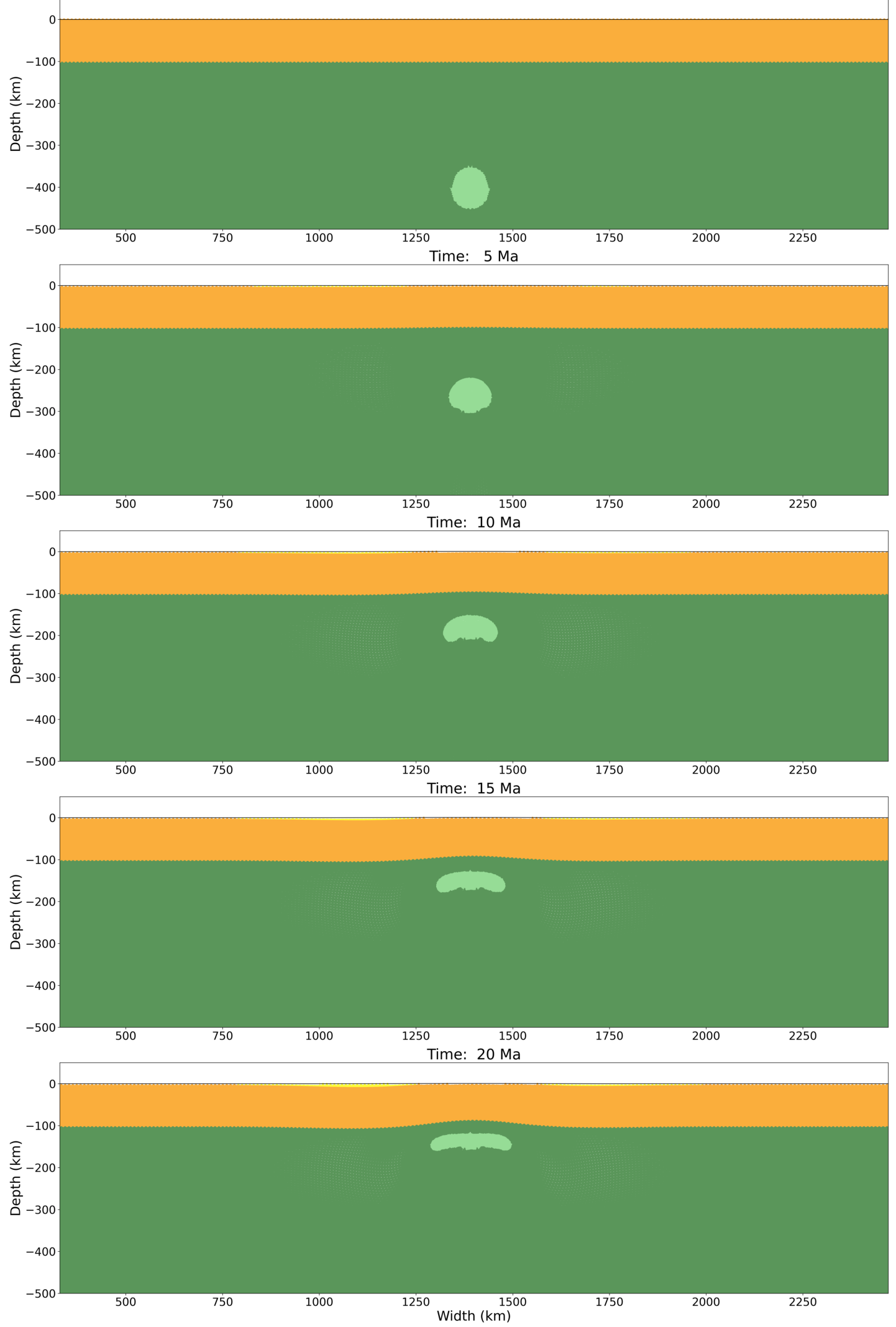

Figure 4.5: Evolution of the model with erosion and sedimentation for $k_{d}=2.0 \times 10^{4} \mathrm{~m}^{2} / \mathrm{s}$. Colors represent differences in density and viscosity (refer to Figure 3.3 . 
Time: $0 \mathrm{Ma}$
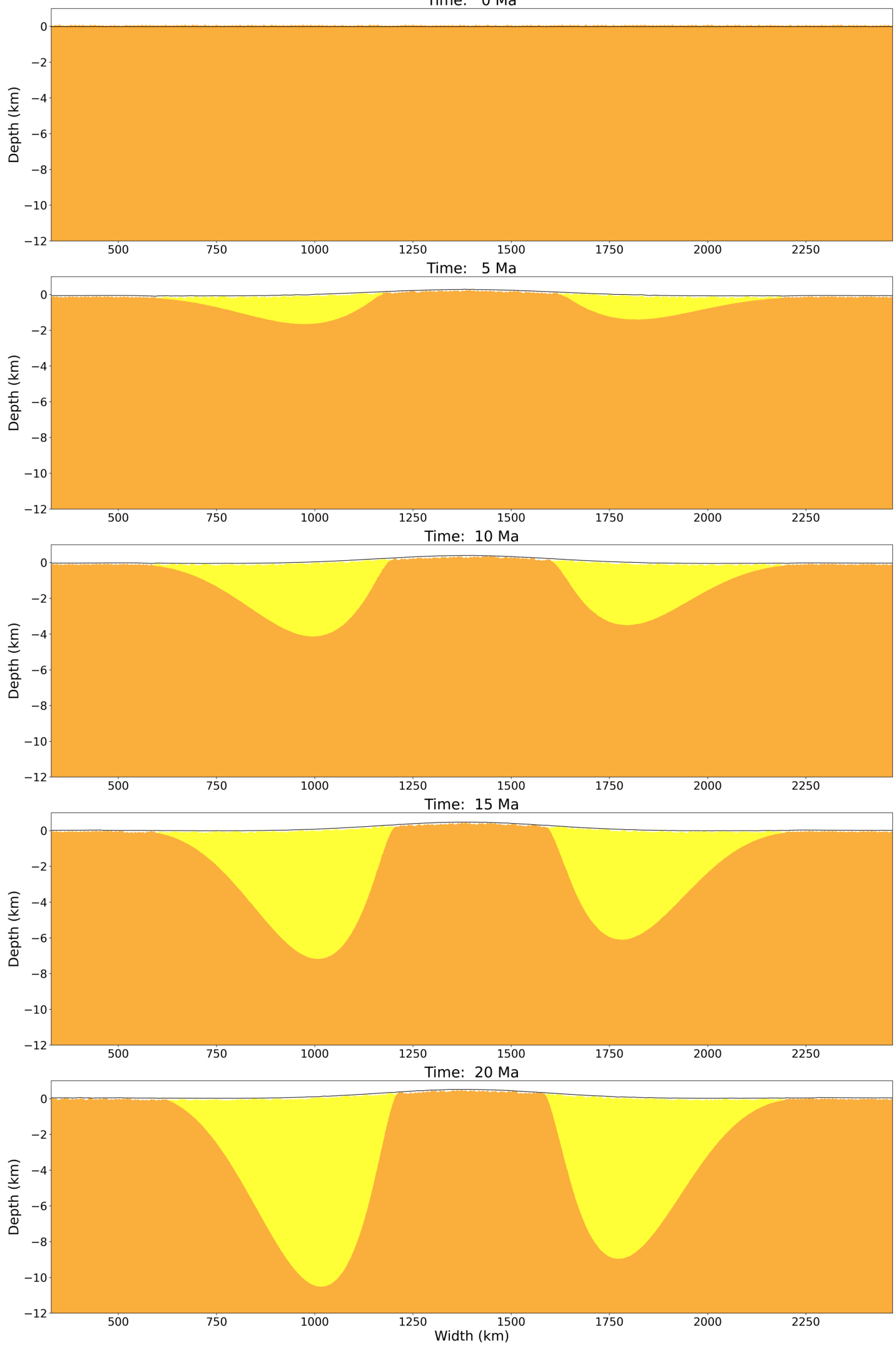

Figure 4.6: Package of sediments corresponding to the model of Figure 4.4 with $k_{d}=1.0 \times 10^{5} \mathrm{~m}^{2} / \mathrm{s}$. 
Time: $0 \mathrm{Ma}$
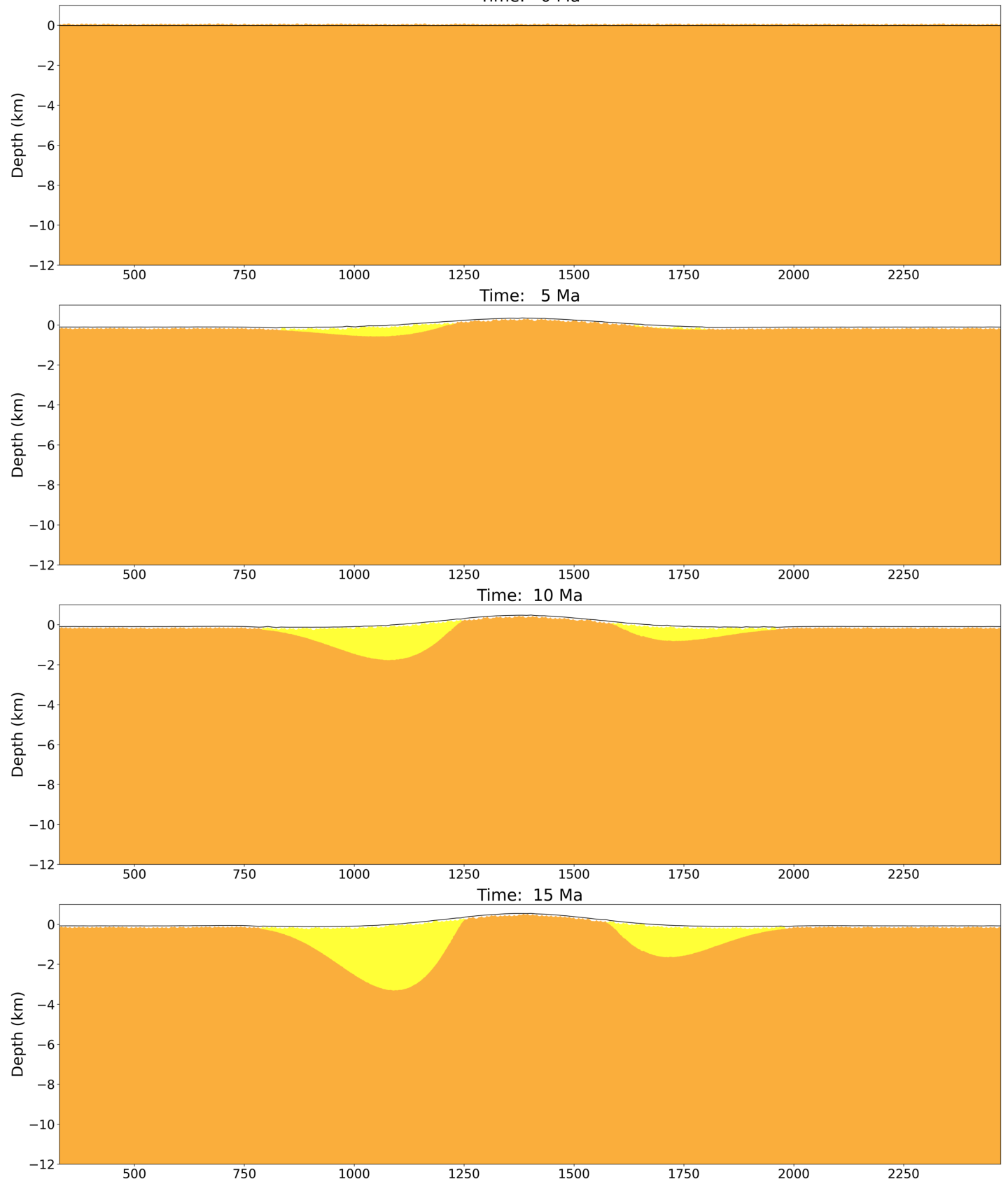
Time: $20 \mathrm{Ma}$

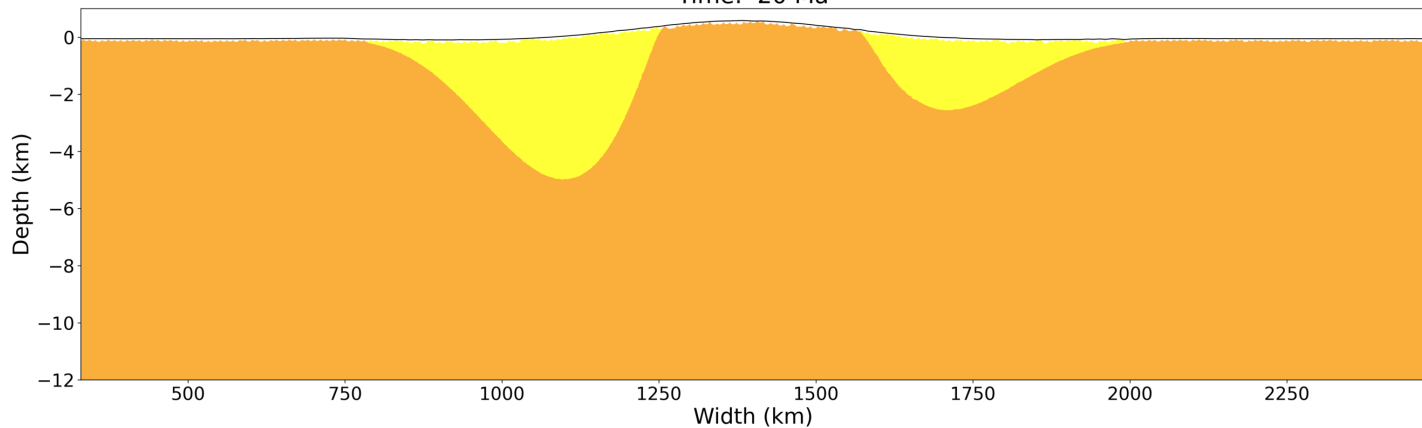

Figure 4.7: Package of sediments corresponding to the model of Figure 4.5 with $k_{d}=2.0 \times 10^{4} \mathrm{~m}^{2} / \mathrm{s}$. 
cumulative erosion, the higher the uplift of the lithosphere-asthenosphere boundary (LAB), perturbing the shape and flow of the head of the mantelic plume under the lithosphere. Any small lateral perturbation of the rising plume can be amplified through time during the numerical simulation, resulting in the amplification of the asymmetry in the sedimentary basins.

However, this numerical experiment based on the model proposed by Crameri et al. (2012) is synthetic, with the rising plume being purely represented by a chemical heterogeneity, without thermal contrasts between the plume and the surrounding mantle and therefore the density difference does not dissipate through time between the two media. In the case of a thermal plume, the temperature contrast tends to decrease and be diffused through time, probably inducing a more symmetrical perturbation of the surface. 
Chapter 5

\section{Applications of the model to continental margins}

The numerical model presented in Chapter 2 showed the importance of the surface processes on the evolution of the stress state along divergent margins. However, some simplifications on the numerical formulation limit the analysis and application to real divergent margins:

- The numerical code does not take the plastic deformation into account. Therefore, the brittle deformation in the upper crust cannot be directly observed but only inferred by post-processing procedures.

- The surface processes are approximated as boundary stresses. The rocks at the top of the domain are not removed or added by erosion or sedimentation.

- The initial numerical scenarios starts at a moment in the post-rift phase, after the lithospheric stretching.

Therefore, to better represent the evolution of divergent margins, taking into account the plastic rheology, the explicit representation of surface processes, and the sin-rift geodynamics, this chapter presents new thermo-mechanical simulations using the MANDYOC code. The results obtained in this "more realistic" geodynamic model agrees with the conclusion presented in Chapter 2, but give more details about the spatial evolution of the faulting in the upper crust and the relationship between onshore and offshore post-rift tectonism.

Different elements presented in the previous chapters are repeated here to preserve the coherence of the chapter as an independent manuscript. 


\subsection{The numerical model}

To simulate the formation and evolution of continental margins during and after lithospheric stretching, we used the finite element code MANDYOC to solve the equations for conservation of mass, momentum and energy.

$$
\begin{gathered}
u_{i, i}=0 \\
\sigma_{i j, j}+g \rho_{0} \alpha T \delta_{i 3}=0 \\
\frac{\partial T}{\partial t}+u_{i} T_{, i}=\kappa T_{, i i}+H / c_{p}-\alpha T g u_{3} / c_{p}
\end{gathered}
$$

in which

$$
\sigma_{i j}=-P \delta_{i j}+\eta\left(u_{i, j}+u_{j, i}\right)
$$

where $t$ is time, $u_{i}$ is the $i$-th velocity component, $g$ is gravity acceleration, $\rho_{0}$ is a reference density, $\alpha$ is the volumetric expansion coefficient, $T$ is temperature, $\kappa$ is the thermal diffusivity, $H$ is the heat production per unit mass, $P$ is the dynamic pressure, $c_{p}$ is the specific heat, $\eta$ is the rock effective viscosity and $\delta_{i j}$ is the Kronecker delta. In this notation, repeated indices indicate an addition and $T_{, i}$ is the partial derivative of $T$ relative to the coordinate $x_{i}$.

We adopted a visco-plastic rheology, where the effective viscosity $\eta$ combines nonlinear power law viscous rheology and a plastic yield criterion.

The viscous component is given by:

$$
\eta_{v i s c}=C \cdot A^{-1 / n} \cdot \dot{\varepsilon}_{I I}^{\frac{1-n}{n}} \cdot \exp \left(\frac{Q+V \cdot P}{n R T}\right)
$$

in which $A$ is a pre-exponential scale factor, $n$ is the power law exponent, $\dot{\varepsilon}_{I I}$ is the square

root of the second invariant of the deviatoric strain rate tensor $\left(\dot{\varepsilon}_{i j}^{\prime} \dot{\varepsilon}_{i j}^{\prime} / 2\right)^{1 / 2}, Q$ is the activation energy, $V$ is the activation volume, and $R$ is the gas constant. The values of $A, n, Q$ and $V$ were extracted from Karato and $\mathrm{Wu}(1993)$ and Gleason and Tullis (1995) and are presented in Table 5.1 .

In the plastic regime, the brittle fracture is achieved when the stress reaches the limit given by the Drucker-Prager criterion:

$$
\sigma_{\text {yield }}=c_{0} \cdot \cos \phi+P \cdot \sin \phi
$$


where $\phi$ and $c_{0}$ are the internal angle of friction and the internal cohesion of the rock, respectively. To facilitate the formation of localized deformation during lithospheric stretching, we adopted strain-softening effects, where the values of $\phi$ and $c_{0}$ varies as a function of cumulative strain $\varepsilon$ (Huismans and Beaumont, 2003). We used the procedure adopted by Salazar-Mora et al. (2018), where $c_{0}$ and $\phi$ linearly decrease from 20 to $4 \mathrm{MPa}$ and from $15^{\circ}$ to $2^{\circ}$, respectively, for accumulated strain values between 0.05 to 1.05 . Below and above these limits, $c_{0}$ and $\phi$ are assumed constant.

The effective nonlinear viscosity is given by the combination of the plastic and the viscous components (Moresi and Solomatov, 1998):

$$
\eta=\min \left(\eta_{\text {plast }}, \eta_{\text {visc }}\right)=\min \left(\frac{\sigma_{\text {yield }}}{2 \dot{\varepsilon}_{I I}}, \eta_{\text {visc }}\right)
$$

\subsection{Numerical setup}

The numerical domain comprises $1600 \times 300 \mathrm{~km}^{2}$ (Figure 5.1), composed of a regular mesh with square elements of $1 \times 1 \mathrm{~km}^{2}$, resulting in 480,000 elements. The boundary conditions for the velocity field simulate the lithospheric stretching assuming a reference frame fixed on the lithospheric plate on the left side of the model, and the plate on the right side moves rightward with a velocity $v_{\text {rift }}=1 \mathrm{~cm} /$ year (Figure 5.1). The velocity field in the left and right boundaries of the model is chosen to ensure conservation of mass and is symmetrical if the adopted reference frame movies to the right with a velocity $v_{\text {rift }} / 2$ relative to the left plate. Additionally, free slip condition was assumed on the top and bottom of the numerical domain.

To simulate the free surface, we adopted the "sticky air" approach (e.g. Gerya and Yuen, 2003b), taking into account a 40-km thick layer with a relatively low viscosity material but with a compatible density with the atmospheric air (see Table 5.1).

The initial temperature structure is only depth dependent and is $0^{\circ} \mathrm{C}$ at the surface and $1300^{\circ} \mathrm{C}$ at the base of the lithosphere at $130 \mathrm{~km}$. With these boundary conditions, the initial temperature structure in the interior of the lithosphere is given by the solution of the following equation:

$$
\kappa \frac{\partial^{2} T(z)}{\partial z^{2}}+\frac{H(z)}{c_{p}}=0
$$

where $H(z)$ is the internal heat production of the different layers, as indicated in Table 5.1. Under the lithosphere, the temperate follows an adiabatic increase up to the bottom 
of the model:

$$
T=T_{p} \exp \left(g \alpha z / c_{p}\right)
$$

where $T_{p}=1262^{\circ} \mathrm{C}$ is the adopted potential temperature for the mantle. Additionally, the temperature in all the boundaries was maintained fixed during all the numerical simulation.

To avoid artifacts created by a homogeneous rheology, usually inducing the development of perfectly symmetric rifting not observed in reality, we introduced a random perturbation of the initial strain in each finite element of the model (e.g. Brune et al., 2014). This random perturbation follows a normal distribution in which the mean initial strain is 0.25 with a standard deviation of $\approx 0.08$. Additionally, to ensure the nucleation of rifting at the center of the numerical domain, we introduced a weak seed (e.g. Huismans and Beaumont, 2003) in the lithospheric mantle (Figure 5.1) with a constant initial strain of 0.3. Other two weak seeds were introduced in the upper crust in part of the numerical scenarios to represent the preexistence of crustal weakness before the lithospheric stretching (Figure 5.1) with initial strain of 1.0 .

The denudation on the top of the model was simulated by the imposition of a prescribed erosion rate variable in space and time. Other procedures can be adopted, like the assumption of a diffusion equation or a power law equation to simulate surface processes (e.g. Andrés-Martínez et al., 2019). However, here we adopted the prescribed erosion rate to have the control on the timing and extent of the erosion, facilitating the comparison of the different numerical scenarios with the same escarpment retreat amount.

The rate of erosion $\dot{e}=\dot{e}(x, t)$ is given by the following expression:

$$
\dot{e}=k_{s p} e_{f}(x) c_{f}(t)
$$

where $e_{f}$ is a spatial control on denudation, given by

$$
e_{f}(x)=\exp \left(-\frac{\left(x-x_{c}\right)^{6}}{x_{\sigma}^{6}}\right)
$$

with $x_{\sigma}$ controlling the spatial extent of the denudation from the position $x_{c}$, while $c_{f}$ is a climate function that re-scale the magnitude of the denudation rate through time. The values of the different parameters of the surface processes are indicated in Table 5.2. The denudation rate $\dot{e}$ is only active if the topography $h$ is above sea level $h_{s l}$. For the points at the surface below the sea level $\left(h<h_{s l}\right)$ no surface processes was imposed. 
We adopted two types of climate scenarios: one reference model without erosion, where $c_{f}=0$, and another one in which the denudation starts only $25 \mathrm{Myr}$ after the onset of the lithospheric stretching:

$$
c_{f}= \begin{cases}0, & \text { if } t<25 \mathrm{Myr} \\ 1, & \text { if } t \geq 25 \mathrm{Myr}\end{cases}
$$

With these two climate scenarios, we try to evaluate the impact of the denudation on the post-rift evolution of divergent margins. In these cases, both models present the same behavior until $t=25 \mathrm{Myr}$. After this moment, we can compare the impact of denudation on the lithospheric deformation in comparison with the reference model, i.e. without erosion.

\begin{tabular}{llllll}
\hline & Air & Upper Crust & Lower Crust & $\begin{array}{l}\text { Lithospheric } \\
\text { Mantle }\end{array}$ & Asthenosphere \\
\hline $\begin{array}{l}\text { Reference } \\
\text { density }\end{array}$ & 1 & 2700 & 2800 & 3354 & 3378 \\
$\left(\mathrm{~kg} / \mathrm{m}^{3}\right)$ & & & & & \\
$\mathrm{Creep} \mathrm{flow} \mathrm{law}$ & - & Quartz & Quartz & Dry olivine & Wet olivine \\
$A\left(\mathrm{~Pa}^{-n} / \mathrm{s}\right)$ & $1.0 \times 10^{-18}$ & $8.574 \times 10^{-28}$ & $8.574 \times 10^{-28}$ & $2.4168 \times 10^{-15}$ & $1.393 \times 10^{-14}$ \\
$Q(\mathrm{~kJ} / \mathrm{mol})$ & 0 & 222 & 222 & 540 & 429 \\
$n$ & 1 & 4 & 4 & 3.5 & 3 \\
$V\left(\mathrm{~m}^{3} / \mathrm{mol}\right)$ & 0 & 0 & 0 & $25 \times 10^{-6}$ & $15 \times 10^{-6}$ \\
$C$ & 1 & 1 & 1,40 & 1 & 1 \\
$H(\mathrm{~W} / \mathrm{kg})$ & 0 & $9.26 \times 10^{-10}$ & $2.86 \times 10^{-10}$ & $9.0 \times 10^{-12}$ & 0 \\
\hline
\end{tabular}

Table 5.1 - Physical parameters for the different layers of the numerical scenarios. $A$ is the pre-exponent constant, $n$ is the exponent of the power law, $Q$ is the activation energy, $V$ is the activation volume and $C$ is the scale factor adopted. Parameters extracted from Karato and $\mathrm{Wu}(1993)$ for olivine and Gleason and Tullis (1995) for quartz.

\begin{tabular}{lll}
\hline \hline$\alpha$ & Volumetric expansion coefficient & $3.28 \times 10^{-5}{ }^{\circ} \mathrm{C}$ \\
$\kappa$ & Thermal diffusivity & $10^{-6} \mathrm{~m}^{2} / \mathrm{s}$ \\
$c_{p}$ & Specific heat capacity & $1250 \mathrm{~J} / \mathrm{kg} / \mathrm{K}$ \\
$x_{\sigma}$ & Half-width for the denudation function & $200 \mathrm{~km}$ \\
$x_{c}$ & Position of maximum denudation & $800 \mathrm{~km}$ \\
$k_{s p}$ & Maximum denudation rate & $8 \times 10^{-4} \mathrm{~m} /$ year \\
$h_{s l}$ & Sea level relative to the initial altitude & $-1500 \mathrm{~m}$ \\
\hline
\end{tabular}

Table 5.2 - Fixed parameters for the numerical scenarios. 


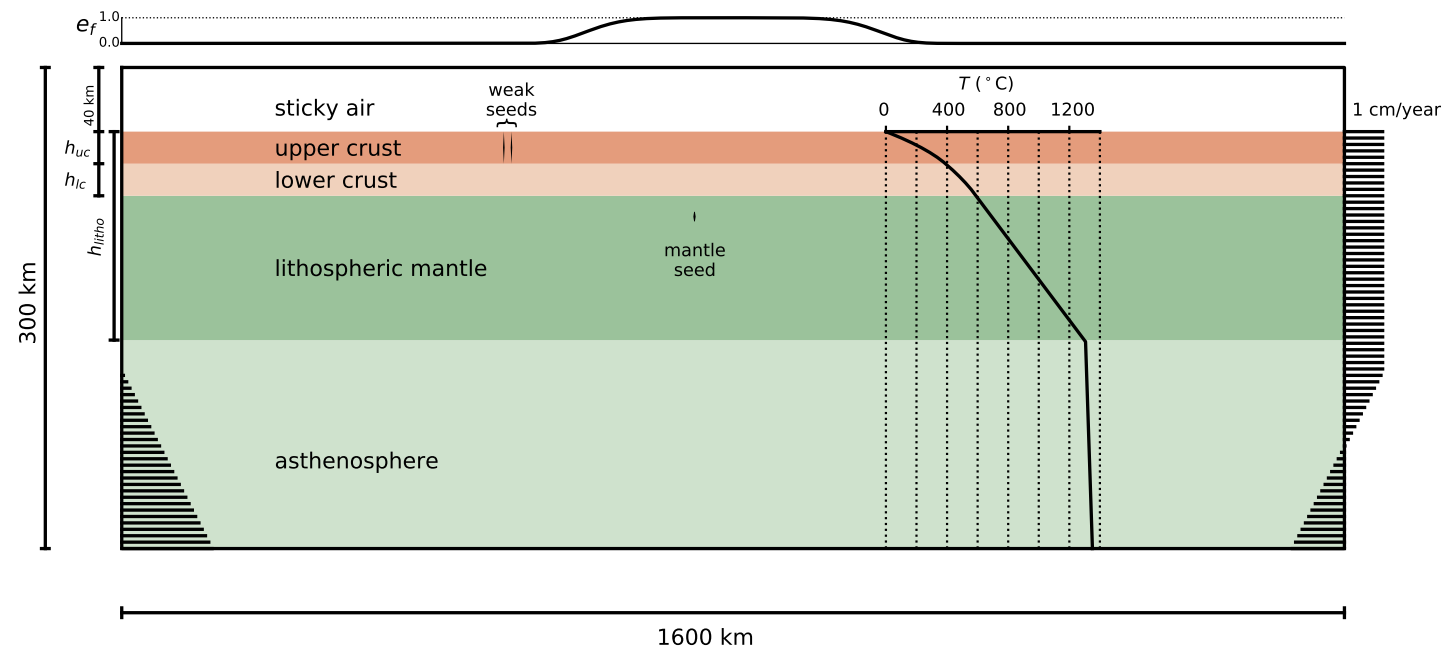

Figure 5.1: Numerical model setup for the simulation of the lithospheric stretching. The thickness of the upper and lower crust is equal $h_{u c}=h_{l c}=20 \mathrm{~km}$ and the thickness of the lithosphere is $h_{\text {litho }}=130$ $\mathrm{km}$. The series of horizontal black lines on the left and right boundaries of the model indicate the boundary condition adopted for the velocity field. The upper curve indicates the denudation function $e_{f}$ adopted, indicating that the maximum denudation occurs in the center of the domain, decreasing to the borders. Details about the function $e_{f}$ is indicated in the text. The small mark close to the center of the lithospheric mantle is the mantle seed, necessary to localize the lithospheric stretching in the center of the domain. Additionally two vertical weak seeds were introduced in the upper crust in some of the numerical experiments.

\subsection{Numerical results}

Initially, we present the results of the reference models, where no erosion is affecting the model and only the lithospheric mantle presents a weak seed in the center of the domain to nucleate the rifting process. The two reference scenarios are named as "coupled lithosphere" and "decoupled lithosphere" (Figure 5.2), where the only difference between them is the scale factor for viscosity $C$ for the lower crust: in the decoupled model $C=1$, while in the coupled model $C=40$, assuming the quartz rheology for the entire crust. This means that for $C=40$ this layer is 40 times more viscous at the same temperature, pressure and strain rate regime compared with $C=1$. The use of these nomenclatures represent an oversimplification, because both scenarios present a certain degree of coupling between the upper crust and lithospheric mantle, and part of the stress can be vertically transmitted through the different layers depending on the stress and temperature state of the entire lithosphere. However, to facilitate the reading of the text, we preferred to 
define "coupled lithosphere" the scenario with a higher degree of coupling and "decoupled lithosphere" the one with lower degree of coupling.
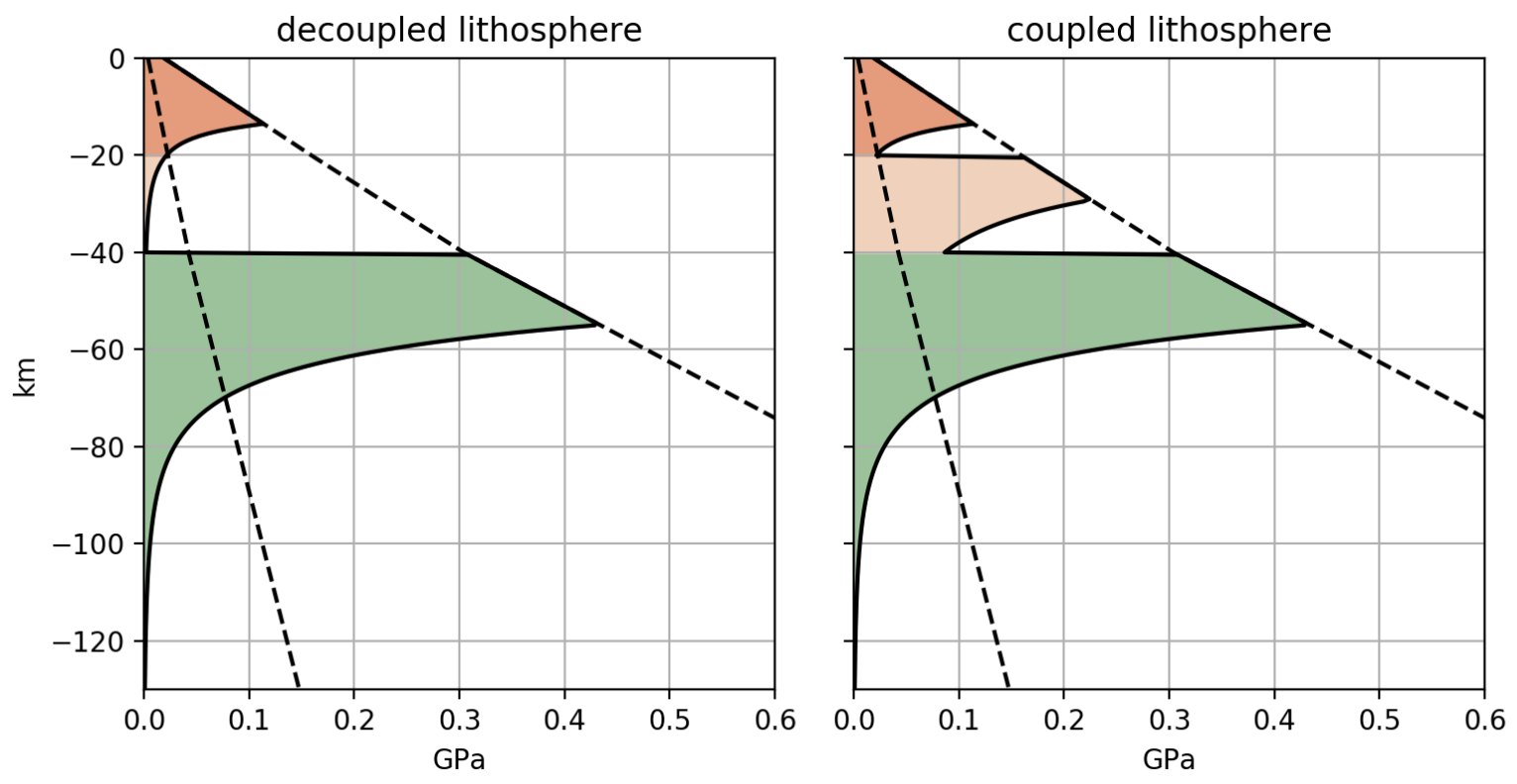

Figure 5.2: Yield strength envelope for the two reference numerical scenarios. The difference between the two scenarios is the scale factor $C$ for the lower crust: $C=1$ for decoupled lithosphere and $C=40$ for coupled lithosphere. The dashed lines represent the plastic yield criterion for the maximum and minimum internal angle of friction $\phi$ and internal cohesion $c_{0}$ adopted in this work. In these diagrams, the viscous stress was calculated assuming that $\dot{\varepsilon}_{I I}=10^{-15} \mathrm{~s}^{-1}$.

In the reference decoupled scenario, the lower crust flows laterally during the lithospheric stretching, while the upper crust is thinned essentially by a series of faults (Figure 5.3). This occurs because the lower crust is mainly in the viscous regime while the upper crust is in the plastic (brittle) regime. In this scenario, the continental breakup occurs at $\approx 28$ Myr after the onset of lithospheric extension, resulting in a broad region with thinned crust, with more than $400 \mathrm{~km}$ wide when both conjugate margins are combined.

On the other hand, in the reference coupled scenario, the lower crust is mainly in the plastic regime, and the stretching and thinning of the crust are essentially accommodated by normal faults (Figure 5.4. In this case, the zone of lithospheric thinning is narrower, resulting in a stretched continental crust zone of nearly $200 \mathrm{~km}$ (Figures 5.4 and 5.5), with the continental breakup at $\approx 18$ Myr.

In both reference scenarios (Figures 5.6 and 5.7), during the first $\sim 6 \mathrm{Myr}$, the strain rate is distributed throughout the lithosphere, and starts to localize in the center of the model only after this period and the thinning of the lithospheric mantle occurs mainly between 6 and 18 Myr. 

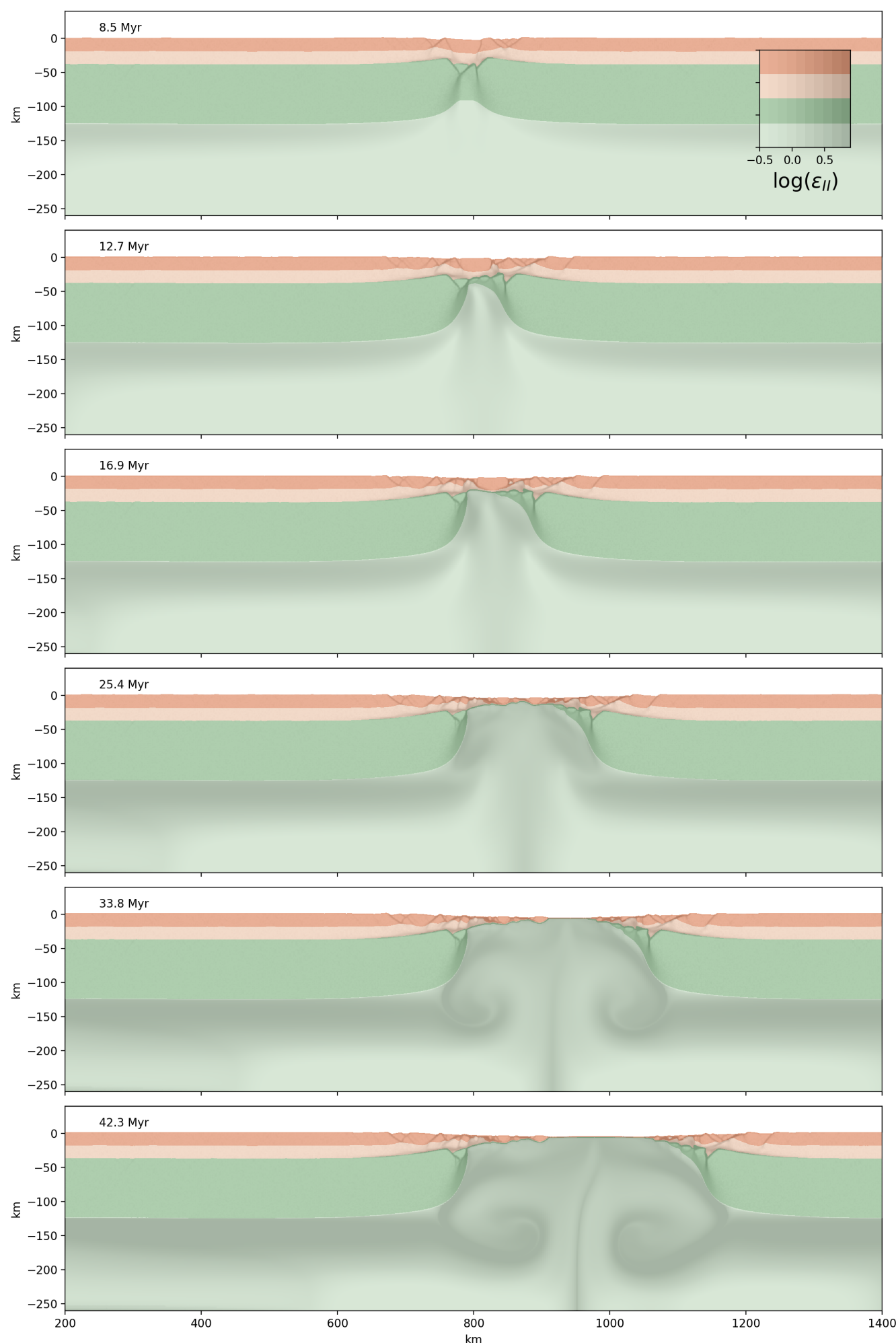

Figure 5.3: Evolution of the reference numerical scenario with decoupled lithosphere, with $C=1$ for the lower crust and without surface processes. Dark and light orange represent the upper and lower crust, while dark and light green represent lithospheric and sublithospheric mantle. Shades of gray indicate the magnitude of cumulative strain. 

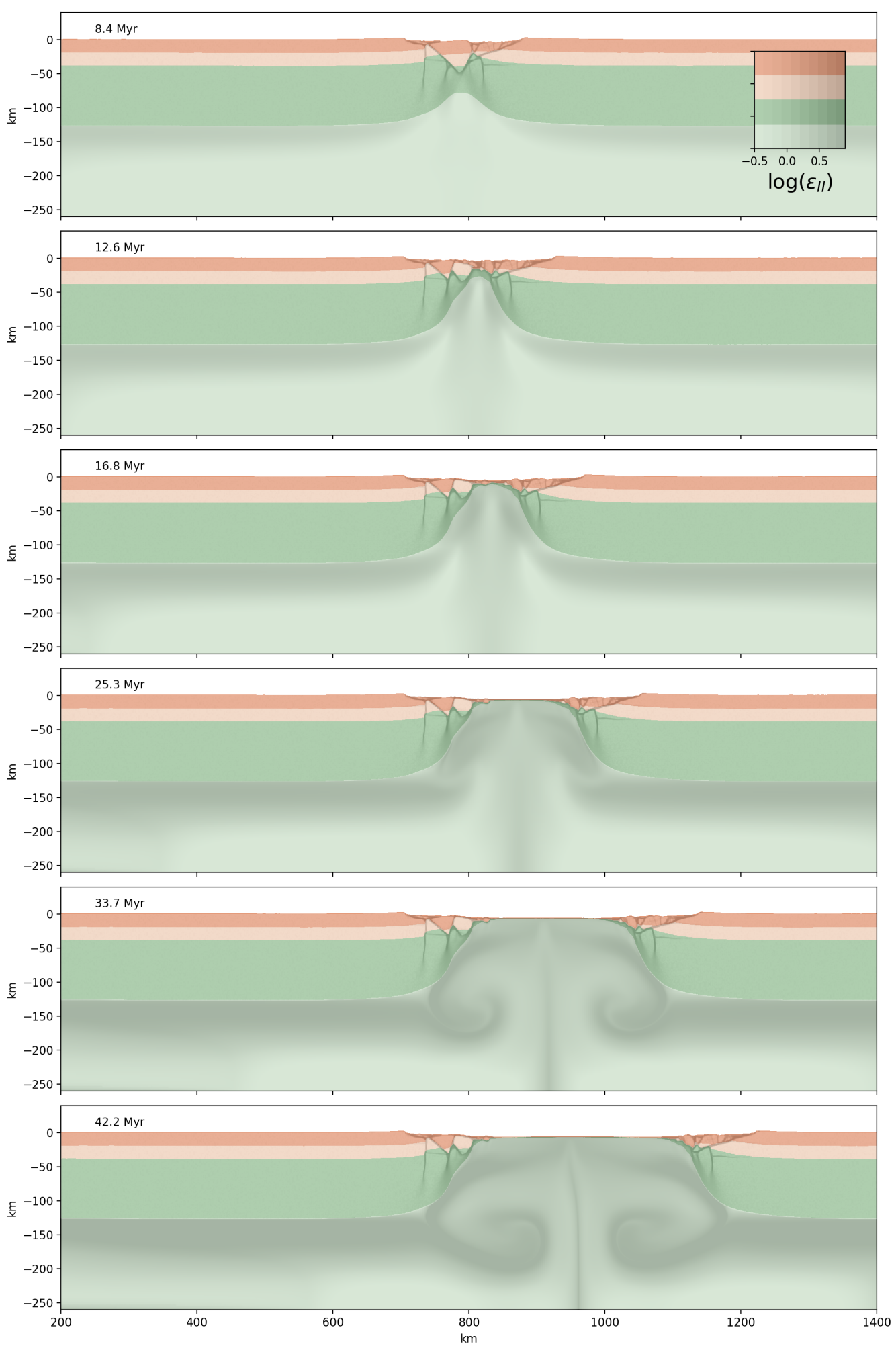

Figure 5.4: Evolution of the reference numerical scenario with coupled lithosphere, with $C=40$ for the lower crust and without surface processes. Dark and light orange represent the upper and lower crust, while dark and light green represent lithospheric and sublithospheric mantle. Shades of gray indicate the magnitude of cumulative strain. 


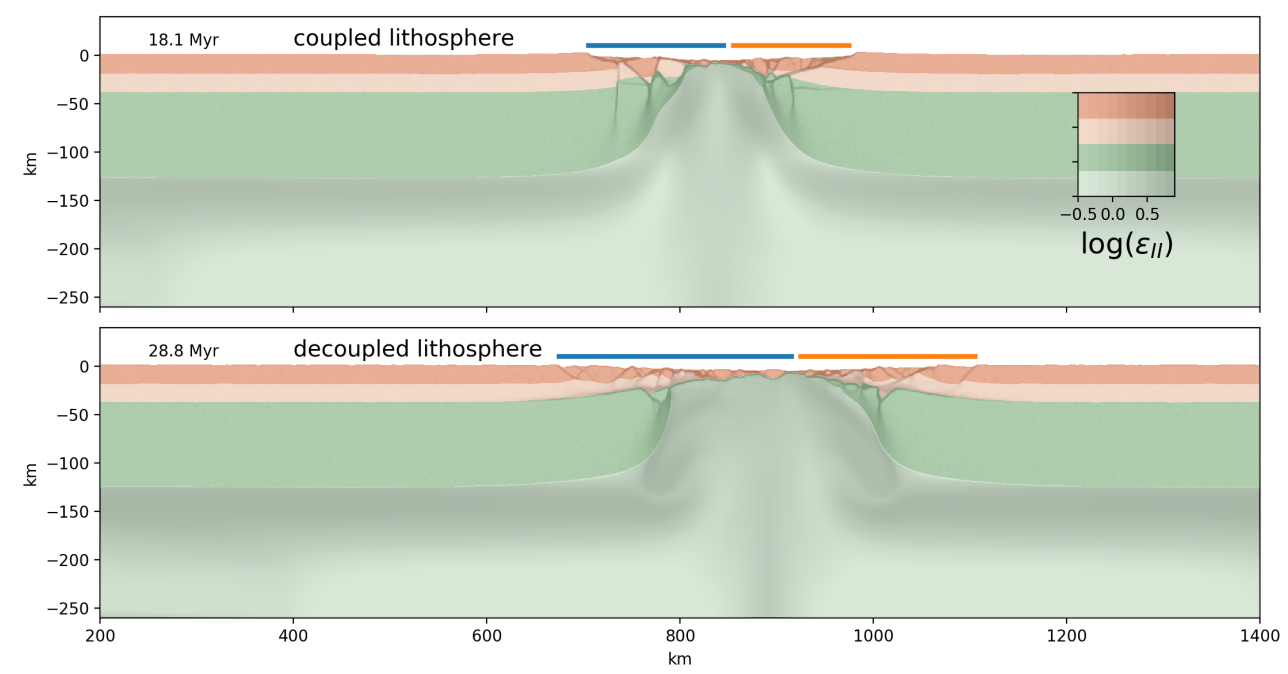

Figure 5.5: Comparison between the two reference scenarios, both without surface processes. Both images were selected to be close to the moment of crustal breakup. Coupled lithosphere: scenario with the $C=40$ for the lower crust. Decoupled lithosphere: scenario with the $C=1$ for the lower crust. The blue and orange bars indicate the width of the extended continental crust in both conjugate margins.

The strain rate decreases a few order of magnitude in both conjugate margins after the breakup (Figures 5.6 and 5.7, last panels at $t=33.8,42.3 \mathrm{Myr}$ ). The strain rate is preserved relatively high only at the base of the lower crust in the decoupled lithosphere, where the base of the crust has a low viscosity and continues to flow during the geologic timescale. Additionally, the magnitude of the strain rate along faults in the upper crust decreases through time, clearly observed in the decoupled scenario (Figure 5.6, 25.4-42.3 Myr).

However, in the scenario with the imposed erosion after $25 \mathrm{Myr}$ the onset of the lithospheric stretching, the crustal unloading perturbs the stress state in the lithosphere (Figure 5.8, right column). The erosion concentrated mainly along the continental margins creates flexural stresses not only under the eroded portion of the margin but also in adjacent domains. For the decoupled scenario, the erosion induces regional uplift, creating a flexural bending of the crust with downward concavity. Due to the decoupled behavior of the lithosphere in this scenario, the upper crust and the lithospheric mantle behave as two plates separated by a low viscosity lower crust, a condition known as "jelly sandwich" lithosphere (Burov et al., 2006). In this case, the stresses induced by erosional unloading are concentrated in the crust and are not efficiently transmitted to the lithospheric mantle. The erosion of the coastal escarpment and its progressive retreat toward the continent induces the bending of the crust with downward concavity, creating extension at the upper 


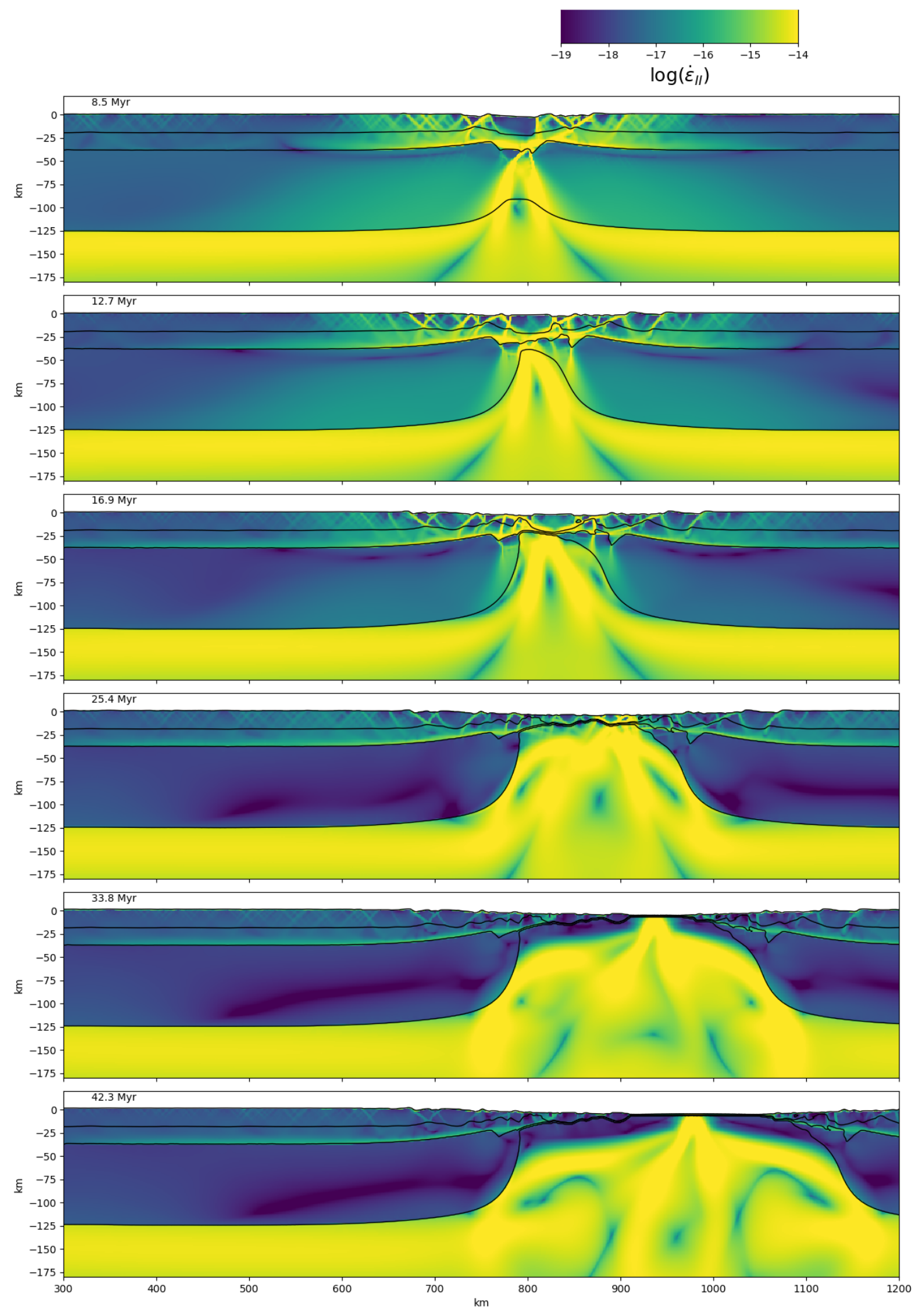

Figure 5.6: Evolution of the strain rate for the reference scenario with decoupled lithosphere $(C=1$ for the lower crust). The strain rate $\dot{\varepsilon}_{I I}$ is in $1 / \mathrm{s}$. 

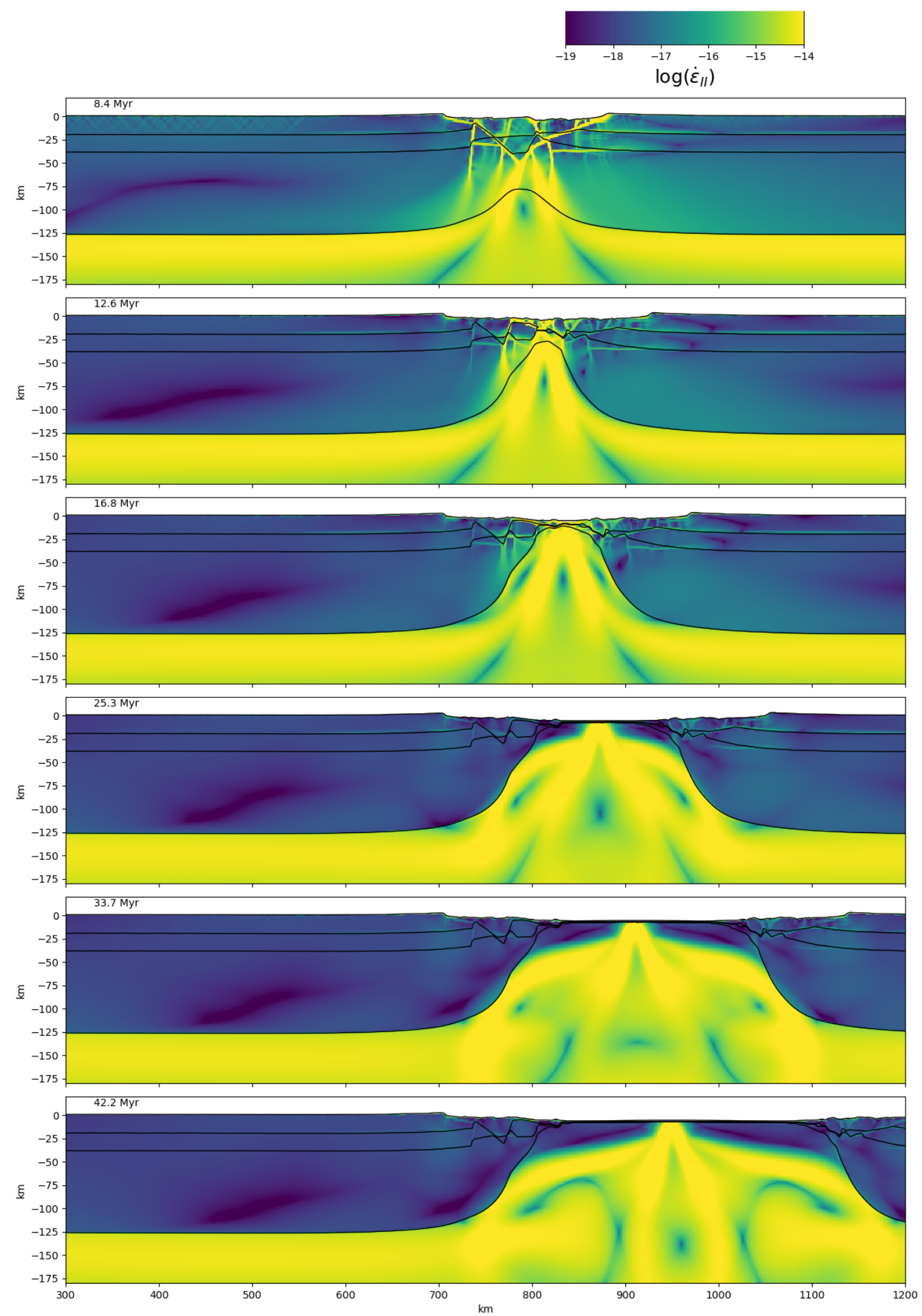

Figure 5.7: Evolution of the strain rate for the reference scenario with coupled lithosphere $(C=40$ for the lower crust). The strain rate $\dot{\varepsilon}_{I I}$ is in $1 / \mathrm{s}$. 

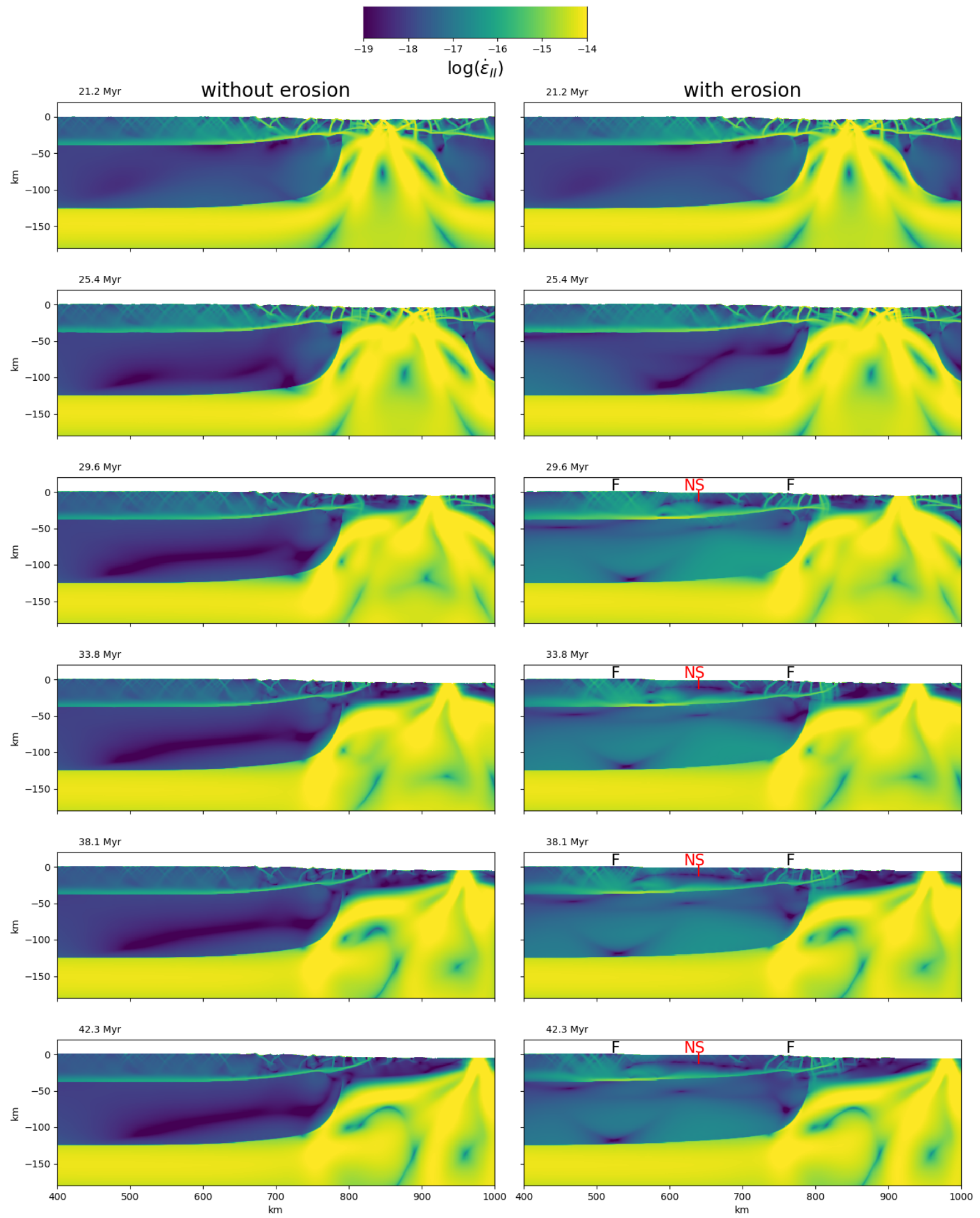

Figure 5.8: Comparison of the strain rate field for the scenarios with and without erosion for the decoupled lithosphere $(C=1)$ for the lower crust. The strain rate $\dot{\varepsilon}_{I I}$ is in $1 / \mathrm{s}$. The letters $\mathrm{F}$ indicate zones in the upper crust with active faults and NS indicate the flexural neutral surface. 


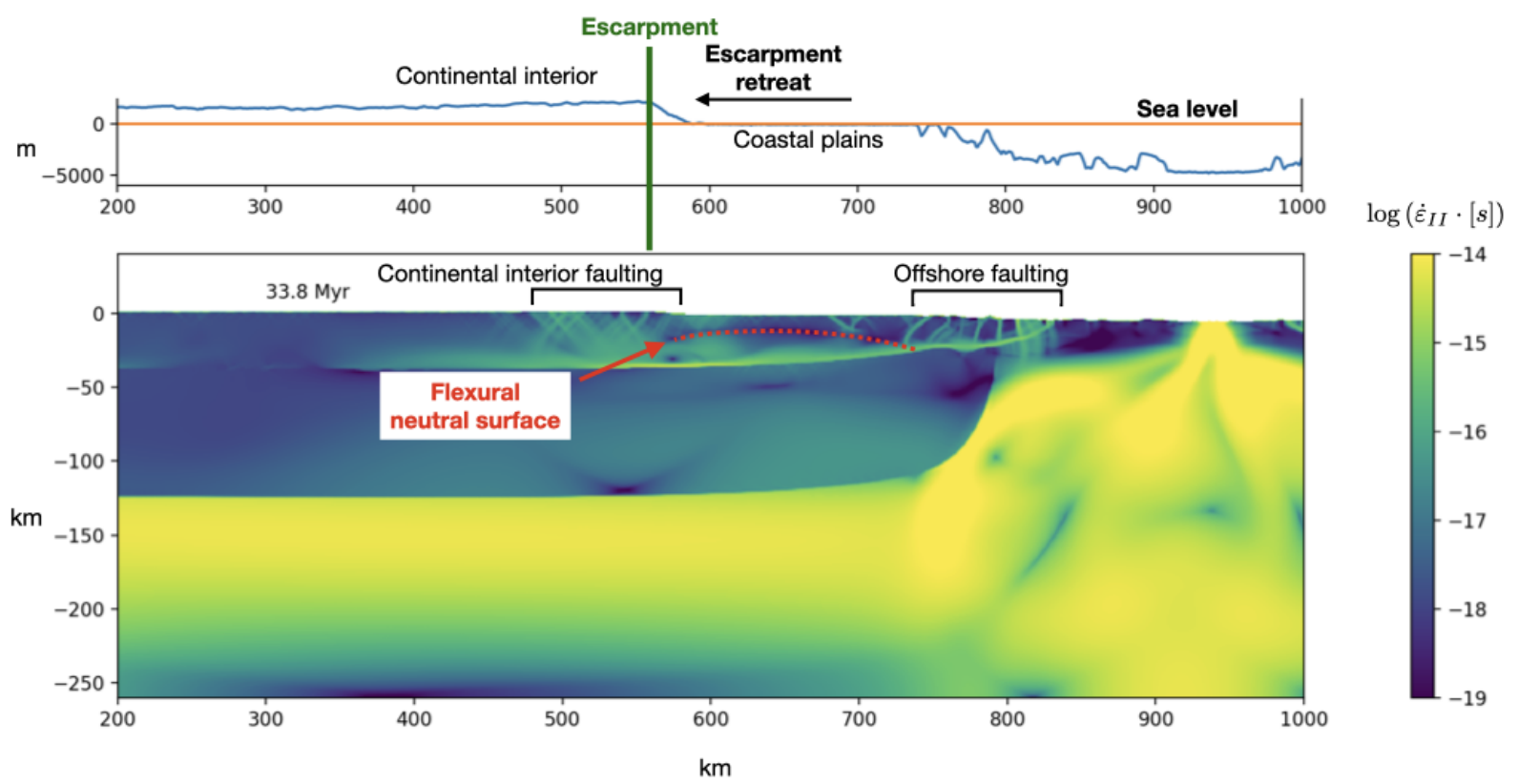

Figure 5.9: Topographic profile and strain rate pattern in the lithosphere for the decoupled scenario ( $C=1$ for the lower crust) and with erosion. The upper panel presents the topographic profile in blue, indicating the position of the escarpment separating the coastal plain from the continental interior. The flexural neutral surface in shown as a red dashed line in the lower panel.

portion of the crust, accommodated by normal faults, observed not only under the domain under imposed erosion (between 550-750 km) but occurs mainly in the offshore domain and in the continental interior (Figure 5.9 and letters $\mathrm{F}$ in Figure 5.8). At the middle of the upper crust, it is possible to observe the flexural neutral surface (Figure 5.9 and NS in Figure 5.8), marked by extremely low strain rate. Below this surface, the flexural compression in the crust is accommodated by viscous deformation.

On the other hand, the erosion of the margin in the coupled scenario induces a different stress pattern in the lithosphere (Figures 5.10 and 5.11). Due to the partial coupling of the crust with the lithospheric mantle, the flexural rigidity of the lithosphere increases significantly (Burov and Diament, 1995). As a consequence, the wavelength of the flexural bending increases and the curvature of the lithosphere decreases, resulting in flexural stresses with smaller magnitude in the upper crust. In this scenario, the faulting in the continental interior is negligible, and post-rift faulting occurs essentially in the coastal plain and in the proximal offshore domain (Figures 5.10 and 5.11). 

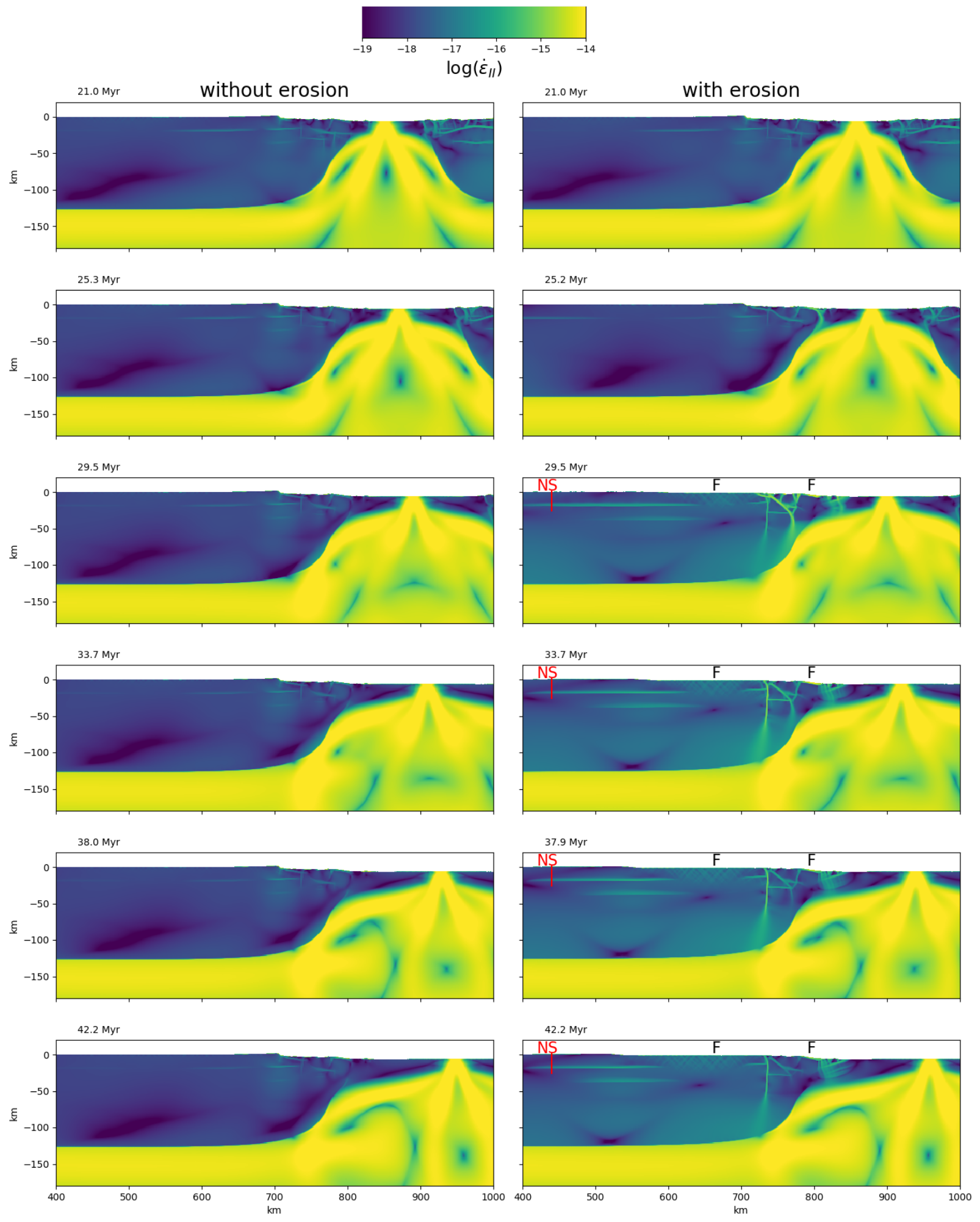

Figure 5.10: Comparison of the strain rate field for the scenarios with and without erosion for the coupled lithosphere $(C=40)$ for the lower crust. The strain rate $\dot{\varepsilon}_{I I}$ is in $1 / \mathrm{s}$. The letters $\mathrm{F}$ indicate zones in the upper crust with active faults and NS indicate the flexural neutral surface. 


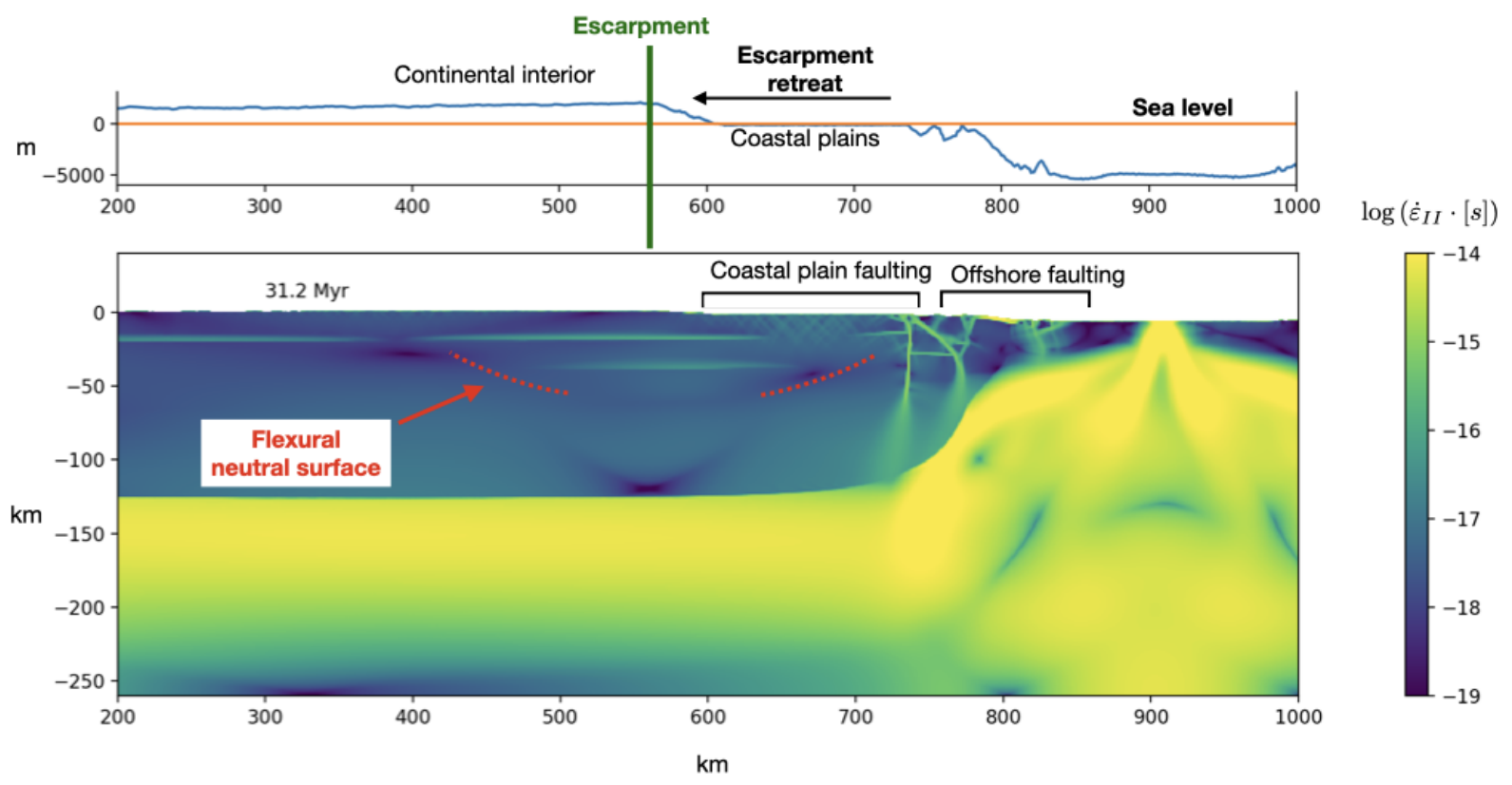

Figure 5.11: Topographic profile and strain rate pattern in the lithosphere for the coupled scenario ( $C=40$ for the lower crust) and with erosion. The upper panel presents the topographic profile in blue, indicating the position of the escarpment separating the coastal plain from the continental interior. The flexural neutral surface in shown as a red dashed line in the lower panel.

As a final set of numerical experiments, we considered scenarios where the upper crust has two preexisting weakness, as indicated in Figure 5.1. The initial position of these two upper crust weakness were chosen as $x=500$ and $510 \mathrm{~km}$. For the decoupled scenarios with surface erosion and with the presence of crustal weakness, the post-rift tectonism in the upper crust induced in the continental interior is concentrated close to the weakness seed and, consequently, presents larger strain rates (Figure 5.12 right column) than in the scenario without crustal weakness (Figure 5.12 left column). Due to the concentrated strain in the region close to the crustal weakness, the faulting is evident at the surface of the model (Figure 5.13, right column) generating an initial graben during the onset of lithospheric stretching in the first $6 \mathrm{Myr}$ of simulation that is reactivated during the denudation phase of the margin. This graben is not observed in the scenario without the preexistence of the upper crustal weakness, where the post-rifting faulting is more diffuse in the continental interior (Figure 5.13, left column).

In our numerical experiments, the maximum strain rate in the upper crust in the 

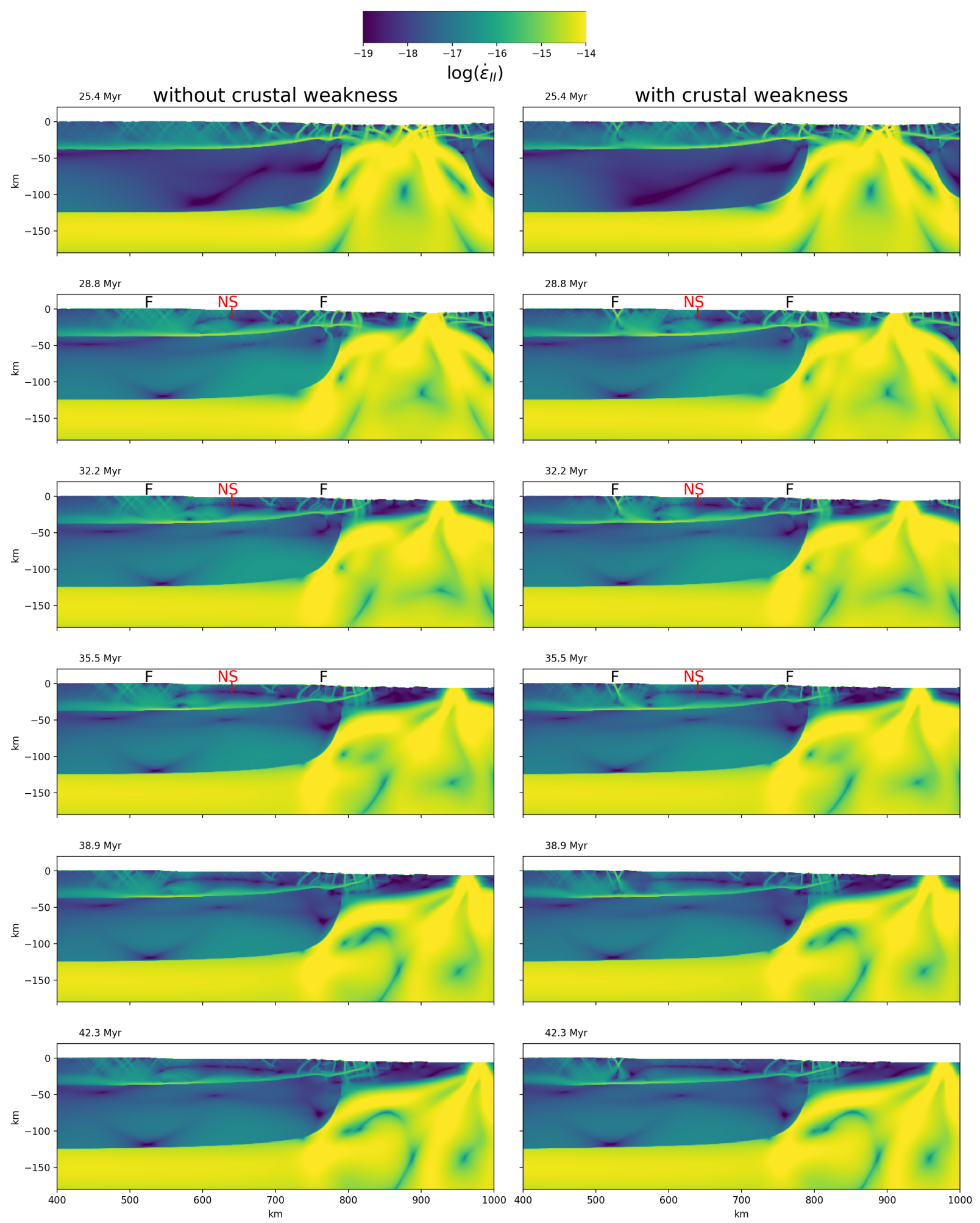

Figure 5.12: Comparison of the strain rate field for the scenarios with and without weak seeds in the upper crust for the decoupled lithosphere $(C=1)$ for the lower crust. Both models have erosion acting on the surface. The strain rate $\dot{\varepsilon}_{I I}$ is in $1 / \mathrm{s}$. The letters $\mathrm{F}$ indicate zones in the upper crust with active faults and NS indicate the flexural neutral surface. Both axes are in $\mathrm{km}$. 

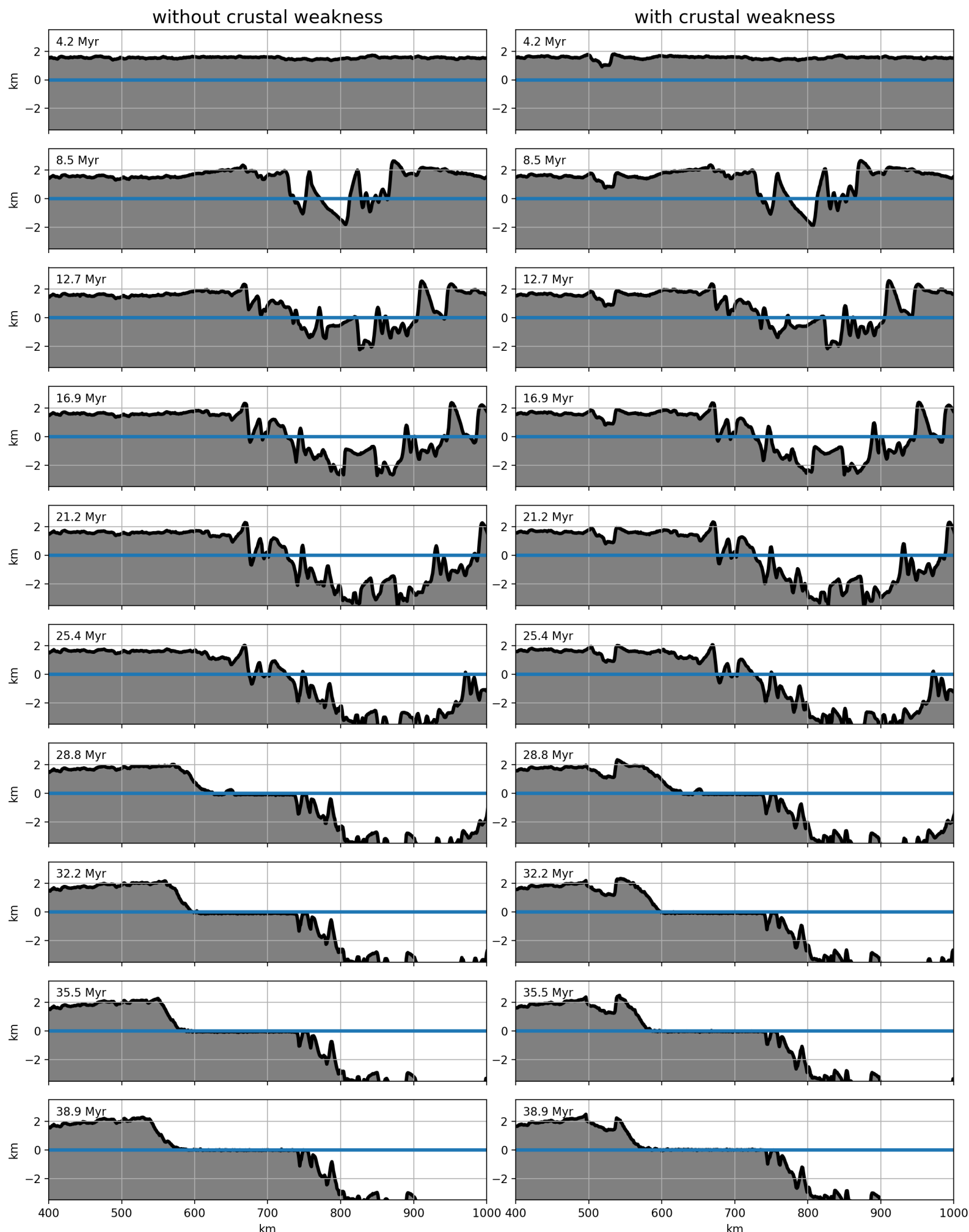

Figure 5.13: Topographic evolution for the scenarios shown in Figure 5.12 The blue line represents the sea level.

continental interior occurs during the initial stage of lithospheric stretching $(\lesssim 6 \mathrm{Myr})$, where the strain is distributed through the entire domain (Figure 5.14). After this time 


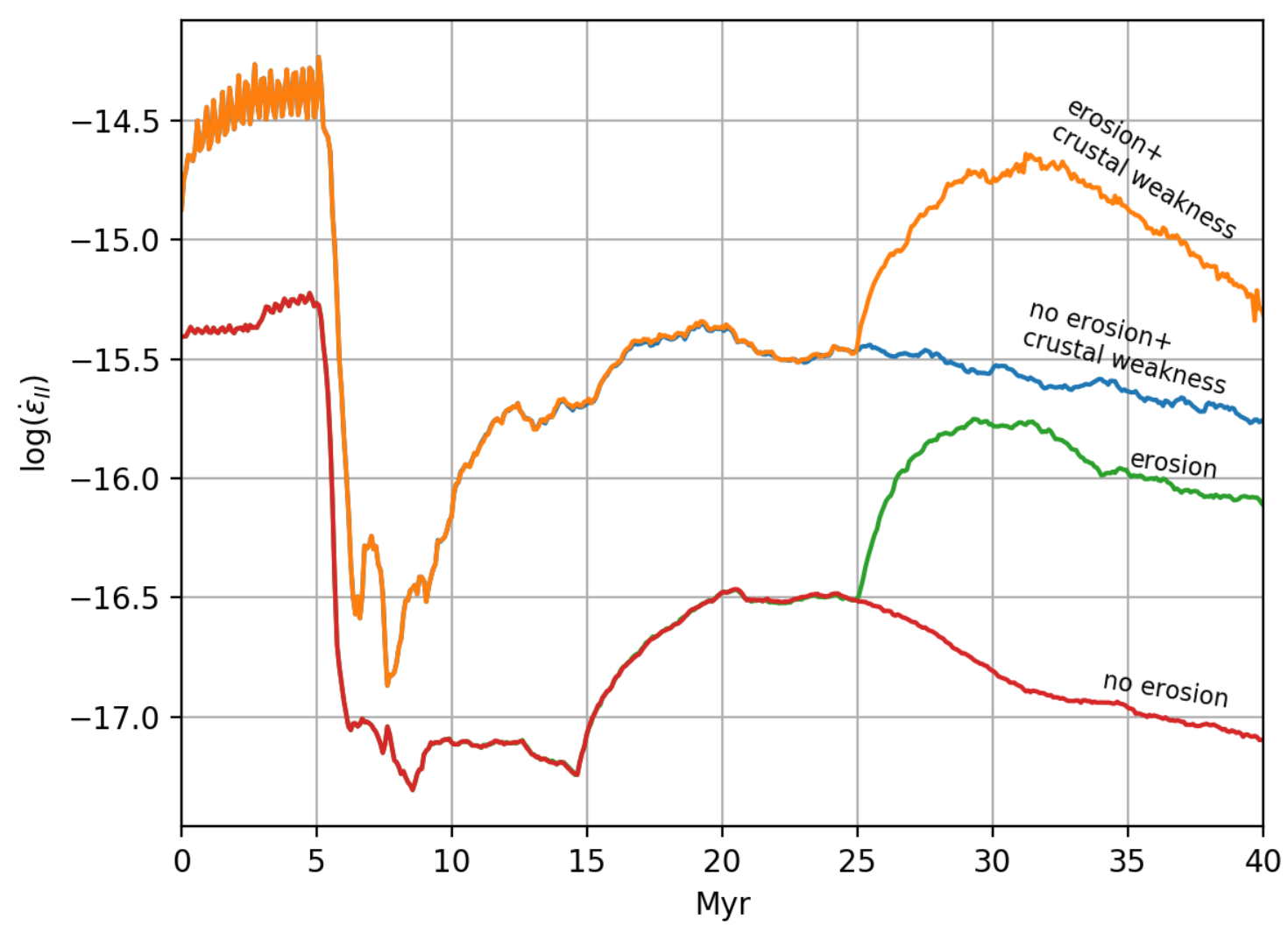

Figure 5.14: Maximum strain rate in the upper crust along the interval between $x=500$ and $550 \mathrm{~km}$ for four scenarios. The erosion of the continent starts at $25 \mathrm{Myr}$ in the scenarios with erosion (green and orange curves).

interval, the strain rate drops nearly two orders of magnitude in the continental interior due to the localization of the stretching in the center of the numerical domain. The strain rate increases slowly during the final stage of lithospheric stretching until $\sim 25$ Myr, period marked by expressive thinning of the lithospheric mantle and concentration of the stretching in the continental crust. In the scenarios without erosion, the strain rate in the continental interior decreases almost monotonically after the end of the rifting phase and through all the post rift phase. However, in the scenarios with imposed erosion at $t=25 \mathrm{Myr}$, the strain rate increases nearly one order of magnitude relative to the scenarios without erosion (Figure 5.14). When the erosion is applied in combination with the presence of weakness in the upper crust, the strain rate can be more than 100 times larger than the one observed in the same scenario but without crustal weakness and no erosion (Figure 5.14). Additionally, in the scenario with erosion, the strain rate after the onset of erosion at $25 \mathrm{Myr}$ is of the same order of the strain rate during the initial 
lithospheric stretching $(<6 \mathrm{Myr})$.

\subsection{Discussion}

\subsubsection{The mechanism for post-rift tectonism induced by erosion}

Based on simple analytical expressions assuming pure elasticity, it is well known that the uniform erosion of the crust can induce compressive stresses at the surface due to the elastic behavior of the rocks, inducing horizontal compressive stresses $\sigma_{h}$ at the surface given by (Turcotte and Schubert, 2002)

$$
\sigma_{h}=\left(\frac{1-2 \nu}{1-\nu}\right) \rho_{c} g h_{\text {erod }}
$$

where $\nu$ is the Poisson's ratio, $\rho_{c}$ is the crust density, and $h_{\text {erod }}$ is the thickness of the eroded layer. Assuming $\nu=0.25, \rho_{c}=2700 \mathrm{~kg} / \mathrm{m}^{3}$ and $h_{\text {erod }}=3 \mathrm{~km}$, the horizontal stress is $\sigma_{h}=54 \mathrm{MPa}$.

However, this expression is only valid if we consider the uniform erosion of a horizontal layer with constant thickness. If the erosion is localized and therefore geographically finite, flexural extensional stresses will be generated at the surface that can easily surpass the magnitude of compressive stresses obtained in the previous analytical solution. For example, assuming a simple elastic rheology, the magnitude of the horizontal stress $\sigma_{x x}$ along the axis $x$ generated by the bending of an elastic plate with effective elastic thickness $T_{e}$ is given by (Turcotte and Schubert, 2002):

$$
\sigma_{x x}=\frac{E}{1-\nu^{2}} \varepsilon_{x x}=\frac{E}{1-\nu^{2}} \frac{T_{e}}{2} \frac{d^{2} w}{d x^{2}}
$$

where $E$ is the Young's modulus, $\varepsilon_{x x}$ is the strain along the $x$ axis, and $\frac{d^{2} w}{d x^{2}}$ is the curvature of the plate. In this expression, $\sigma_{x x}$ is calculated at the surface of the plate at a distance $T_{e} / 2$ from the flexural neutral surface. Assuming reasonable values for the plate curvature due to flexural effects $\left(\frac{d^{2} w}{d x^{2}}=10^{-7}-10^{-6} \mathrm{~m}^{-1}\right.$, Lavier and Steckler, 1997) and $T_{e}=20$ $\mathrm{km}$, the resulting extensional stresses is $\sigma_{x x} \approx 100-1000 \mathrm{MPa}$. Obviously, this analysis is a simplification, assuming a perfect elastic plate, but gives an idea of the importance of the flexural stresses relative to the stresses induced only by erosive exhumation.

Keeping in mind the simplicity and limitation of the elastic plate approach, here we present a simplified analogous model for the thermo-mechanical model presented in the 
previous section, showing the physical explanation for the difference in the stress pattern obtained in the coupled and decoupled scenarios. Considering an infinite thin elastic plate with rigidity $D=E T_{e}^{3} / 12\left(1-\nu^{2}\right)$ floating on an inviscid fluid with density $\rho_{m}$ and under the load $q$ uniformly distributed over the segment $A-B$ of the plate, the deflection $w(x)$ of the plate at the point $x$, which is a distance $a$ from $A$ and a distance $b$ from $B$ is given by (Hetényi and Hetbenyi, 1946)

$$
w(x)= \begin{cases}\frac{q}{2 \rho_{m} g}\left(e^{-\lambda a} \cos \lambda a-e^{-\lambda b} \cos \lambda b\right), & \text { if } x \leq A \\ \frac{q}{2 \rho_{m} g}\left(2-e^{-\lambda a} \cos \lambda a-e^{-\lambda b} \cos \lambda b\right), & \text { if } A<x<B \\ \frac{-q}{2 \rho_{m} g}\left(e^{-\lambda a} \cos \lambda a-e^{-\lambda b} \cos \lambda b\right), & \text { if } B \leq x\end{cases}
$$

where $\lambda=\sqrt[4]{\rho_{m} g / 4 D}$.

Assuming that the load $q=\rho_{c} g h_{\text {erod }}$ is upward, representing the unloading due to the erosion of a layer of the crust with thickness $h_{\text {erod }}=3 \mathrm{~km}$, density $\rho_{c}=2700 \mathrm{~kg} / \mathrm{m}^{3}$, and width of $200 \mathrm{~km}$ (Figure 5.15a), the flexural response of the lithosphere depends on the flexural rigidity of the plate. Using the equation 5.14, for an effective elastic thickness $T_{e}=40 \mathrm{~km}$, the long-wavelength upward movement of the plate occurs over a segment of the plate of nearly $500 \mathrm{~km}$, while for a $T_{e}=10 \mathrm{~km}$ the upward movement occurs in a narrower region in a segment of nearly $300 \mathrm{~km}$ (Figure 5.15b). For these two cases, the maximum uplift coincides with the center of the (un)load.

However, the curvature of the plate $\frac{d^{2} w}{d x^{2}}$, which is proportional to the horizontal stress $\sigma_{x x}$ (see equation 5.13), presents different patterns for the locations of maxima and minima in these two cases (Figure 5.15). For the case with $T_{e}=40 \mathrm{~km}$, the maximum curvature with downward concavity (Figure 5.15k, symbol I), is in the center of the load, generating the maximum extension at the surface exactly under the eroded area. On the other hand, in the case with $T_{e}=10 \mathrm{~km}$, the maximum curvature with downward concavity occurs close to the limits of the eroded area (Figure 5.15k, symbols II) while in the center the concavity is close to zero. Therefore, in this case, the extension is maximum on the borders of the eroded area.

These flexural patterns are similar to what was observed in the thermo-mechanical scenarios of the previous section. The case with $T_{e}=40 \mathrm{~km}$ is compatible with the scenario with coupled lithosphere, where the unloading of the margin due to the escarpment erosion resulted in the development of normal faults mainly in the coastal plain, the center of the 
a)

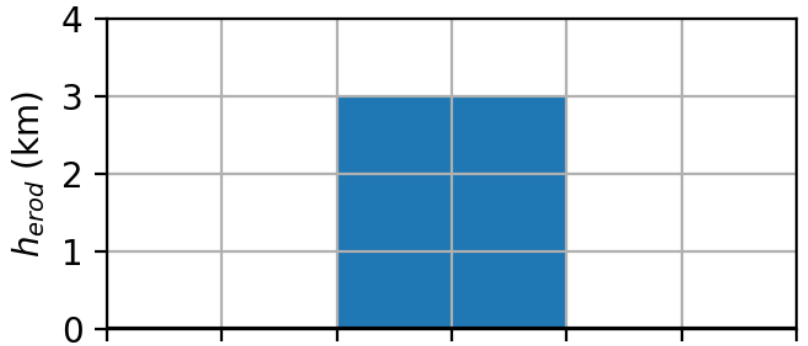

b)
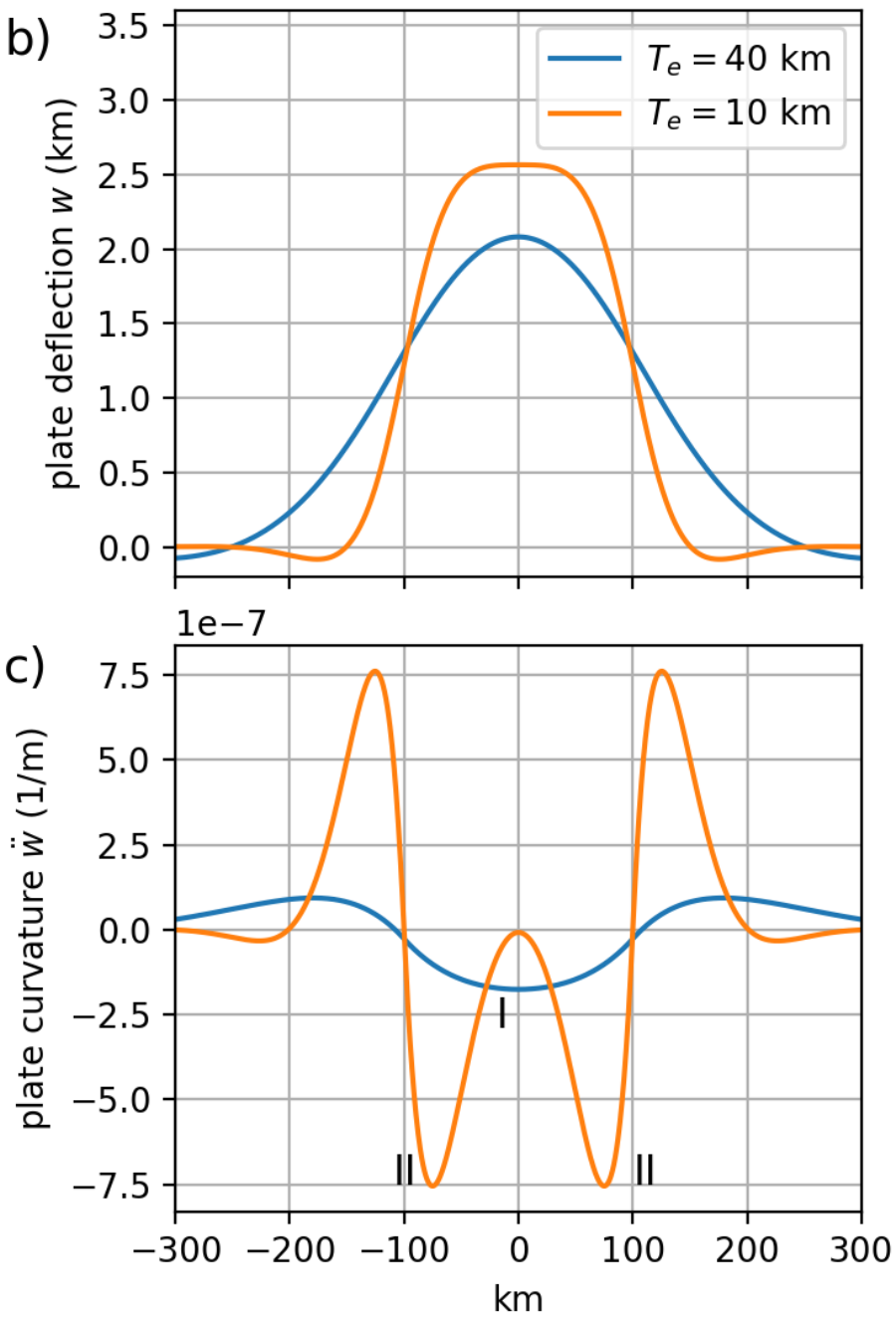

Figure 5.15: Analytical solution for the flexure of a thin elastic plate under the load of a uniform load distributed in the interval between $-100 \mathrm{~km}$ and $100 \mathrm{~km}$. a) thickness $h_{\text {erod }}$ of the eroded crust, resulting in the unload of the lithosphere. b) Flexural response of the elastic plate for two different effective elastic thickness: $T_{e}=10$ and $40 \mathrm{~km}$. c) Curvature of the plate for the two cases shown in b. The symbols I and II indicate the locations of maximum curvature with downward concavity for $T_{e}=40$ and $10 \mathrm{~km}$, respectively.

unloading of the margin. On the other hand, the case with $T_{e}=10 \mathrm{~km}$ is similar to the scenario with decoupled lithosphere, where the erosion of the escarpment induced faulting mainly in the continental interior and along the offshore margin previously stretched.

It is important to highlight that the effective elastic thickness used in the analogous 
experiments does not represent any physical layer in the interior of the lithosphere, but represents a integrative contribution of the flexural rigidity of the crust and lithospheric mantle (see Burov and Diament, 1995, for a detailed analysis of the meaning of the effective elastic thickness in the continental lithosphere). For the scenario with uncoupled lithosphere, the effective elastic thickness is essentially calculated based on the rigidity of the upper crust, with a negligible contribution of the lithospheric mantle. On the other hand, in the case with coupled lithosphere, the effective elastic thickness combines the rigidity of the crust and the lithospheric mantle.

\subsubsection{Comparison of the numerical results with continental divergent margins}

The two groups of scenarios tested in the present work, defined here as coupled and decoupled models for simplicity, resulted in different geometries for the stretched margin. In the decoupled models, the domain of crustal thinning covers a region of more than $400 \mathrm{~km}$ in which the zone where the crust is hyperextended, with less than $15 \mathrm{~km}$ thick (Pérez-Gussinyé et al., 2020), represents nearly half of this width. On the other hand, in the coupled models the extension zone is nearly $250 \mathrm{~km}$ with hyperextended crust of less than $100 \mathrm{~km}$. Additional numerical experiments in the present project indicate that the width of the lithospheric extension and the width of hyperextended crust decreases when the degree of coupling between the crust and lithospheric mantle increase. Here in our approach we chose the increase of the scale factor $C$ for the lower crust to simulate the lithospheric coupling, but other options are possible resulting in similar results, like the use of a different creep flow law for the lower crust (e.g. Brune et al., 2014) or changing the initial thermal structure of the lithosphere.

These two sets of numerical experiments presented here are rheologically compatible to the numerical scenarios of Type 2 presented by Pérez-Gussinyé et al. (2020). In both works the initial crustal thickness is $40 \mathrm{~km}$ and the temperature at the base of the crust is close to $600^{\circ} \mathrm{C}$. In these cases, the conjugate margins are asymmetric (although the degree of asymmetry is significantly different between the two works), with the width of the margins as a function of the strength of the lower crust. We believe that the degree of asymmetry of the conjugate margins in our work is smaller than the one obtained by Pérez-Gussinyé et al. (2020) due to the choice of the seed pattern used to nucleate the rifting in the center of the model, in which the introduction of the random perturbation of the initial strain in 


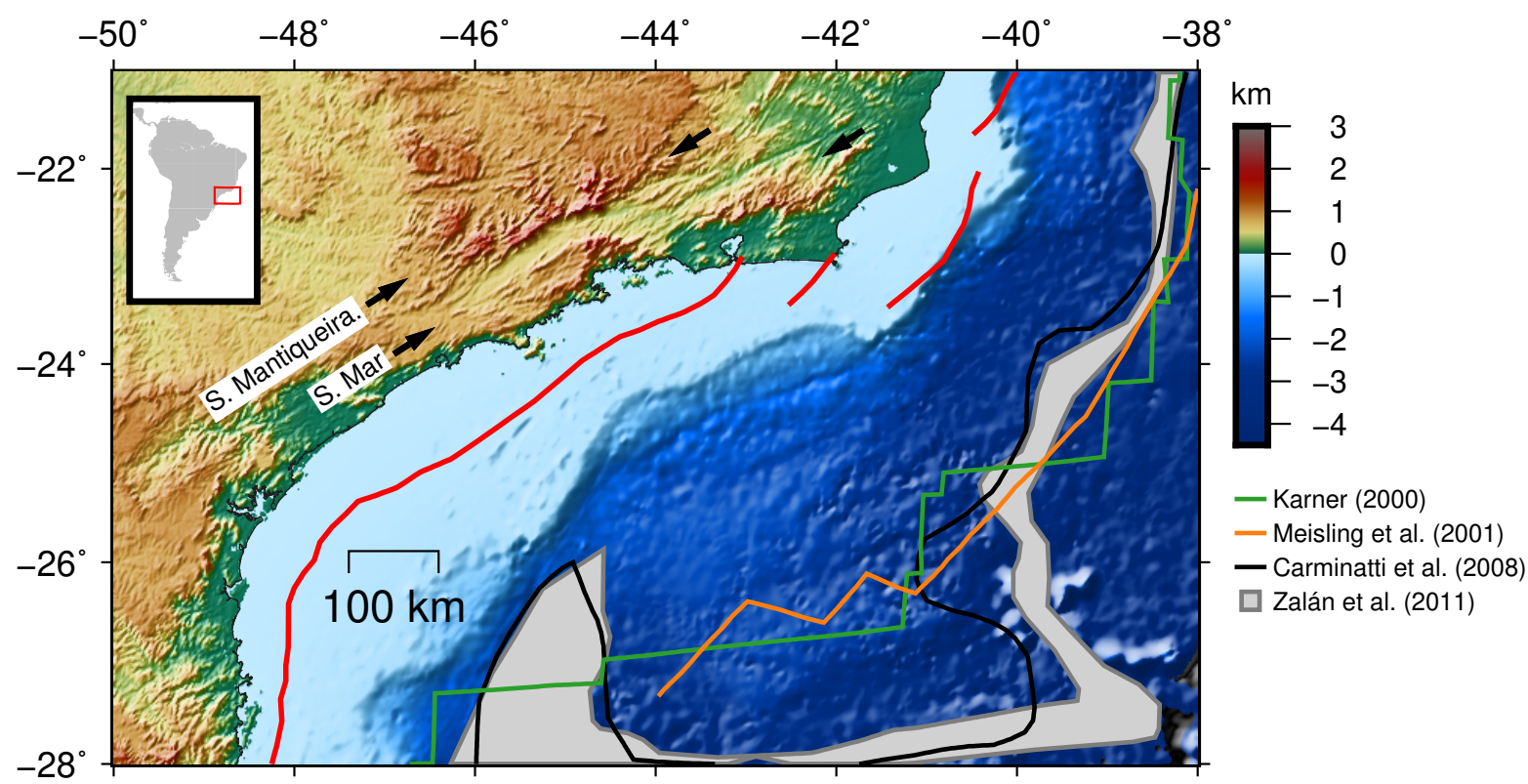

Figure 5.16: Topographic/bathymetric map of southeastern Brazil. The arrows indicate the two parallel escarpments in Southeastern Brazil: the Serra do Mar and Serra da Mantiqueira escarpments. These two escarpments are separated by an elongated depression associated with the Continental Rift of Southeastern Brazil. The thick red line indicates the Cretaceous hinge line extracted from Karner and Gambôa (2007). The other lines indicate the continent-ocean boundary (COB) presented by different authors: (Karner 2000; Meisling et al., 2001, Carminatti et al. 2008; Zalán et al., 2011). COB compilation extracted from Rigoti (2015).

our model created a diffuse pattern of plastic strain, which possibly turned the rifting less asymmetric.

Our scenarios with coupled lithosphere are similar to the models Type $2 \mathrm{a}$ in PérezGussinyé et al. (2020) representing scenarios with strong lower crust, resulting in asymmetric margins with large offset faults but with relatively narrow margins. On the other hand, our scenarios with decoupled lithosphere are compatible with the model Type 2b in PérezGussinyé et al. (2020) representing scenarios with weak lower crust, resulting in asymmetric margins with small offset faults but with wide conjugate margins, with hundreds of kilometers wide. One example of this kind of conjugate margins is the Kwanza-Campos/Espirito Santo margins, where the margins can exceed $200 \mathrm{~km}$ wide (Brune et al., 2014). Southward, in the Santos, the width of the Brazilian margin can reach more than $500 \mathrm{~km}$. One possible explanation for the development of this anomalous stretched margin in Southeastern Brazil is the low degree of coupling between the upper crust and lithospheric mantle during the development of the rifting.

In addition to this singular wide extended margin, the adjacent onshore Southeastern 
Brazilian margin presents a peculiar double pattern of escarpments parallel to the margin, the Serra da Mantiqueira and Serra do Mar escarpments (Figure 5.16). These escarpments are separated by a series of elongated sedimentary basins that preserves Paleogene to Quaternary sedimentation (Riccomini, 1989), showing a clear post-rift tectonism in the development of these basins, named as Continental Rift of Southeasthern Brazil (CRSB) (Riccomini et al., 2004).

We propose here that the development of the CRSB can be explained by local stresses induced by the flexural response of the lithosphere to the unloading of the margin, as previously proposed by Silva and Sacek (2019). Here we expand this analysis taking into account a thermo-mechanical numerical model with a rheology that combines brittle failure and creep flow, simulating the evolution of the margin since the onset of the lithospheric stretching.

In the present numerical experiments, we were able to reproduce the development of normal faults and the formation of a graben in the continental interior similar to the CRSB between the Serra do Mar and Serra da Mantiqueira escarpments. This was possible due to the combination of three different factors:

- The decoupling of the crust and the lithospheric mantle, also favouring the development of a hyperextended margin as observed in the Southeastern Brazilian Margin (Karner, 2000; Zalán et al., 2011) with the continent-ocean boundary hundreds of kilometers far from the coast (Figure 5.16).

- Post-rift exhumation of the margin due to erosion of the margin with magnitude between 3 and $4 \mathrm{~km}$ (Cogné et al. 2011). Additionally, assuming that the initial escarpment was formed along the offshore Cretaceous hinge line (Figure 5.16), the total escarpment retreat can be larger than $100 \mathrm{~km}$ since the continental breakup. Furthermore, thermochronological data (Cogné et al., 2011) indicate that pulses of erosional exhumation during the Late Cretaceous preceded the filling of the interior basins of the CRSB.

- Preexistence of crustal weakness along the continental margin. The formation of a graben in zones of weaknesses is well known (Dunbar and Sawyer, 1988). Also, the crystallographic lattice preferred orientation of olivine crystals in the lithospheric mantle have been related to preexisting weakness zones and rifted margin formation 
(Tommasi and Vauchez, 2001, 2015). In particular, the CRSB evolved on the shear zones of the Precambrian rocks of the Ribeira Belt (Trouw et al., 2000).

It is important to highlight that in our numerical simulations, the graben generated in the continental interior was initially formed during the initial lithospheric stretching in the first $\sim 6$ Myr of simulation and reactivated during the post-rift pulse of erosive exhumation of the margin. There is no clear geological evidence that the CRSB was tectonically active during the formation of the South Atlantic margins, although Cogné et al. (2013) argue that the basement was reactivated during the Late Cretaceous before the initial sedimentary infilling of the basins in the CRSB. In the conjugate margin, onshore tectonism occurred at the time of rifting of South Atlantic due to reactivation of Neoproterozoic shear zones of the Kaoko Belt (Salomon et al., 2015), although the precise time of reactivation is still uncertain. The authors argue that this reactivation did not influenced the main rift and was a side effect of the rifting.

The numerical experiments presented here only can explain the initial stage of tectonism that created the series of grabens in the CRSB. Our two-dimensional thermo-mechanical model is not able to take into account other tectonic forces that modified the geometry of the basins, including the influence of the Andean orogeny and the obliquity of the CRSB relative to the evolving stress state of the lithosphere, and only three-dimensional codes can appropriately simulate these components. 
Chapter 6

\section{Conclusions}

The primary goal of this thesis concerned to the evaluation of the effects of erosion and lithospheric stretching on the post-rift margin evolution using an integrated coupled model of Earth's interior dynamics and surface processes in extensional settings. The results come from numerical experiments based on two independent computational models. The first model, presented on Chapter 2, describes the rheology of the lithosphere using a viscoelastic formulation and considers an already formed divergent margin. Experiments using this model addressed how denudation, passage of a mantle anomaly under the base of the lithosphere and long-range intraplate stresses affects the upper crust stress field on the continental interior. The main outcome from these experiments is that the erosion are capable to generate flexural stresses which would trigger the post-rift tectonism in the continental interior, like the Cenozoic tectonics observed on the Southeastern Brazilian margin. Other factors like the disturbance caused by a mantle thermal anomaly or intraplate stresses are secondary and would not induce post-rift tectonism. Moreover, the scenarios where the lithosphere had a relatively shallow necking depth favoured the occurrence of the post-rift tectonism.

However, the first model poses limitations since it does not simulate the rifting process coupled with surface processes during the thermo-mechanical simulation. Hence, a second numerical approach used a model that describes the lithospheric rheology using a viscoplastic formulation allowing for large deformations and simulation of the margin evolution since the beginning of the lithospheric stretching. The results from numerical experiments of this second model agree with previous conclusions from Chapter 2 and also provided new outcomes. In scenarios where the lower crust had relatively lower viscosity, resulting in a decoupled lithosphere, a hyperextended rifted margin is obtained. This result corresponds 
to the scenarios of the first model comprising a shallow necking depth with low effective elastic thickness. In this case, when denudation of the margin is present, the area where maximum strain occurred is at the limits of the eroded region. This explains why the tectonism occurred on the interior of the continent instead of the denudation region.

On the other hand, in scenarios where the lower crust had relatively high viscosity resulting in a coupled lithosphere, which corresponds to the scenarios with deeper necking depth and thus high effective elastic thickness, the maximum strain occurred precisely beneath the denudation region. In this case, very little strain occurred on the continental interior. These results suggests that the post-rift tectonism in the hinterland is favoured by a decoupled lithosphere.

Other factors that favors the occurrence of post-rift tectonism in the interior of the continent observed in both models is that the higher magnitude of the denudation the higher flexural stresses affecting the hinterland. Therefore, this factor positively contributes to tectonism. Results from both models also indicate that the preexistence of a shear zone in the continent, possibly comprising low cohesion rocks, favors the tectonism.

The Southeastern Brazilian margin is atypical in the world, featuring a hiperextended lithosphere in which the distance from the coastline to the continent ocean boundary exceeds $500 \mathrm{~km}$. From the numerical experiments results, the hiperextension requires a decoupled lithosphere. This factor was of primary importance to generate the tectonism on the interior of the continent.

The two-dimensional models used in this thesis provided important insights into the coupled surface processes and Earth's interior dynamics. However, to address factors which are inherently tree-dimensional in nature, like along strike heterogeneities in lithosphere rheology, complex stress field and plate geometry a three-dimensional model is necessary. 


\section{Bibliography}

Allken V., Huismans R. S., Thieulot C., Factors controlling the mode of rift interaction in brittle-ductile coupled systems: A 3D numerical study, Geochemistry, Geophysics, Geosystems, 2012, vol. 13

Almeida F. F. M., The system of continental rifts bordering the Santos basin, Brazil, Anais da Academia Brasileira de Ciências, 1976, vol. 48, p. 15

Andrés-Martínez M., Pérez-Gussinyé M., Armitage J., Morgan J. P., Thermomechanical implications of sediment transport for the architecture and evolution of continental rifts and margins, Tectonics, 2019, vol. 38, p. 641

Assumpção M., Sacek V., Intra-plate seismicity and flexural stresses in central Brazil, Geophysical Research Letters, 2013, vol. 40, p. 487

Balay S., Abhyankar S., Adams M. F., Brown J., Brune P., Buschelman K., Dalcin L., Eijkhout V., Gropp W. D., Kaushik D., Knepley M. G., May D. A., McInnes L. C., Mills R. T., Munson T., Rupp K., Sanan P., Smith B. F., Zampini S., Zhang H., Zhang H., , 2018a PETSc Web page http://www.mcs.anl.gov/petsc

Balay S., Abhyankar S., Adams M. F., Brown J., Brune P., Buschelman K., Dalcin L., Eijkhout V., Gropp W. D., Kaushik D., Knepley M. G., May D. A., McInnes L. C., Mills R. T., Munson T., Rupp K., Sanan P., Smith B. F., Zampini S., Zhang H., Zhang H., , 2018b Technical Report ANL-95/11 - Revision 3.9 PETSc Users Manual http://www.mcs.anl.gov/petsc. Argonne National Laboratory

Balay S., Gropp W. D., McInnes L. C., Smith B. F., Efficient Management of Parallelism 
in Object Oriented Numerical Software Libraries. In Modern Software Tools in Scientific Computing, Birkhäuser Press, 1997, p. 163

Barr A. H., The Einstein Summation Notation, An Introduction to Physically Based Modeling (Course Notes 19), pages E, 1991, vol. 1

Beaumont C., Keen C. E., Boutilier R., On the evolution of rifted continental margins: comparison of models and observations for the Nova Scotian margin, Geophysical Journal International, 1982, vol. 70, p. 667

Beaumont C., Kooi H., Willet S., Coupled tectonic-surface process models with applications to rifted margins and collisional orogens, in Geomorphology and global tectonics, 2000, pp 29-55

Bercovici D., Treatise on Geophysics, Volume 7: Mantle Dynamics. Elsevier, 2010

Bishop P., Long-term landscape evolution: linking tectonics and surface processes, Earth Surface Processes and Landforms: the Journal of the British Geomorphological Research Group, 2007, vol. 32, p. 329

Bishop P., Goldrick G., Geomorphological evolution of the East Australian continental margin, in Geomorphology and global tectonics, M. A. Summerfield (ed.), 2000, pp 227255

Braun J., Pecube: A new finite-element code to solve the 3D heat transport equation including the effects of a time-varying, finite amplitude surface topography, Computers \& Geosciences, 2003, vol. 29, p. 787

Braun J., Beaumont C., Styles of continental rifting: Results from dynamic models of lithosphere extension, in Sedimentary Basins and Basin-Forming Mechanisms, C. Beaumont and A. J. Tankard (eds.), Memoir-Canadian Society of Petroleum Geologists, 1987, vol. 12, p. 241

Braun J., Deschamps F., Rouby D., Dauteuil O., Flexure of the lithosphere and the geodynamical evolution of non-cylindrical rifted passive margins: Results from a numerical model incorporating variable elastic thickness, surface processes and 3D thermal subsidence, Tectonophysics, 2013, vol. 604, p. 72 
Braun J., Robert X., Simon-Labric T., Eroding dynamic topography, Geophysical Research Letters, 2013, vol. 40, p. 1494

Brune S., Rifts and rifted margins: A review of geodynamic processes and natural hazards, Plate Boundaries and Natural Hazards, 2016, vol. 219, p. 13

Brune S., Heine C., Pérez-Gussinyé M., Sobolev S. V., Rift migration explains continental margin asymmetry and crustal hyper-extension, Nature communications, 2014, vol. 5, p. 1

Brune S., Williams S. E., Butterworth N. P., Müller R. D., Abrupt plate accelerations shape rifted continental margins, Nature, 2016, vol. 536, p. 201

Burov E., Cloetingh S., Erosion and rift dynamics: new thermomechanical aspects of postrift evolution of extensional basins, Earth and Planetary Science Letters, 1997, vol. 150, p. 7

Burov E., Poliakov A., Erosion and rheology controls on synrift and postrift evolution: Verifying old and new ideas using a fully coupled numerical model, Journal of Geophysical Research: Solid Earth, 2001, vol. 106, p. 16461

Burov E., Watts A., et al., The long-term strength of continental lithosphere: "jelly sandwich" or "crème brûlée"?, GSA today, 2006, vol. 16, p. 4

Burov E. B., Diament M., The effective elastic thickness (Te) of continental lithosphere: What does it really mean?, Journal of Geophysical Research: Solid Earth, 1995, vol. 100, p. 3905

Byerlee J. D., Brittle-ductile transition in rocks, Journal of Geophysical Research, 1968, vol. 73 , p. 4741

Carminatti M., Wolff B., Gamboa L., et al., New exploratory frontiers in Brazil. In 19th World Petroleum Congress, 2008

Chang H. K., Kowsmann R. O., Figueiredo A. M. F., Bender A., Tectonics and stratigraphy of the East Brazil Rift system: an overview, Tectonophysics, 1992, vol. 213, p. 97

Cobbold P. R., Meisling K. E., Mount V. S., Reactivation of an obliquely rifted margin, Campos and Santos basins, Southeastern Brazil, AAPG Bulletin, 2001, vol. 85, p. 1925 
Cogné N., Cobbold P. R., Riccomini C., Gallagher K., Tectonic setting of the Taubaté Basin (Southeastern Brazil): Insights from regional seismic profiles and outcrop data, Journal of South American Earth Sciences, 2013, vol. 42, p. 194

Cogné N., Gallagher K., Cobbold P. R., Post-rift reactivation of the onshore margin of southeast Brazil: evidence from apatite (U-Th)/He and fission-track data, Earth and Planetary Science Letters, 2011, vol. 309, p. 118

Crameri F., Schmeling H., Golabek G., Duretz T., Orendt R., Buiter S., May D., Kaus B., Gerya T., Tackley P., A comparison of numerical surface topography calculations in geodynamic modelling: an evaluation of the 'sticky air' method, Geophysical Journal International, 2012, vol. 189, p. 38

Dietrich W. E., Bellugi D. G., Sklar L. S., Stock J. D., Heimsath A. M., Roering J. J., Geomorphic transport laws for predicting landscape form and dynamics, Geophysical Monograph-American Geophysical Union, 2003, vol. 135, p. 103

Dunbar J. A., Sawyer D. S., Continental rifting at pre-existing lithospheric weaknesses, Nature, 1988, vol. 333, p. 450

England P., McKenzie D., A thin viscous sheet model for continental deformation, Geophysical Journal International, 1982, vol. 70, p. 295

Evain M., Afilhado A., Rigoti C., Loureiro A., Alves D., Klingelhoefer F., ... Aslanian D., Deep structure of the Santos Basin-São Paulo Plateau System, SE Brazil, Journal of Geophysical Research: Solid Earth, 2015, vol. 120, p. 5401

Ferrari A. L., Riccomini C., Campo de esforços Plio-Pleistoênico na Ilha da Trindade (oceano Atântico Sul, Brasil) e sua relação com a tectônica regional, Revista Brasileira de Geociências, 1999, vol. 29, p. 195

Gallagher K., Brown R., The Mesozoic denudation history of the Atlantic margins of southern Africa and southeast Brazil and the relationship to offshore sedimentation, Geological Society, London, Special Publications, 1999, vol. 153, p. 41

Gerya T. V., Yuen D. A., Characteristics-based marker-in-cell method with conservative finite-differences schemes for modeling geological flows with strongly variable transport properties, Physics of the Earth and Planetary Interiors, 2003a, vol. 140, p. 293 
Gerya T. V., Yuen D. A., Rayleigh-Taylor instabilities from hydration and melting propel 'cold plumes' at subduction zones, Earth and Planetary Science Letters, 2003b, vol. 212, p. 47

Gleason G. C., Tullis J., A flow law for dislocation creep of quartz aggregates determined with the molten salt cell, Tectonophysics, 1995, vol. 247, p. 1

Hetényi M., Hetbenyi M. I., Beams on elastic foundation: theory with applications in the fields of civil and mechanical engineering. vol. 16, University of Michigan press Ann Arbor, MI, 1946

Hughes T. J., A multidimentional upwind scheme with no crosswind diffusion, Finite Element Methods for Convection Dominated Flows, AMD 34, 1979

Hughes T. J., A theoretical framework for Petrov-Galerkin methods with discontinuous weighting functions: Application to the streamline-upwind procedure, Finite element in fluids, 1982, vol. 4, p. Chapter

Hughes T. J., The Finite Element Method. Dover Publications New York, 2000

Hughes T. J., The finite element method: linear static and dynamic finite element analysis. Courier Corporation, 2012

Huismans R., Beaumont C., Depth-dependent extension, two-stage breakup and cratonic underplating at rifted margins, Nature, 2011, vol. 473, p. 74

Huismans R. S., Beaumont C., Symmetric and asymmetric lithospheric extension: Relative effects of frictional-plastic and viscous strain softening, Journal of Geophysical Research: Solid Earth, 2003, vol. 108

Ito G., van Keken P. E., Hotspots and melting anomalies, in Mantle Dynamics, Treatise on Geophysics, D. Bercovici (ed.), Journal of Geophysical Research: Solid Earth, 2007, vol. 7 , p. 371

Karato S., Wu P., Rheology of the upper mantle: A synthesis, Science, 1993, vol. 260, p. 771 
Karner G., Gambôa L., Timing and origin of the South Atlantic pre-salt sag basins and their capping evaporites, Geological Society, London, Special Publications, 2007, vol. 285 , p. 15

Karner G. D., Rifts of the Campos and Santos Basins, Southeastern Brazil: Distribution and Timing, in Petroleum Systems of South Atlantic Margins, M. Mello, and B. Katz (eds.), 2000, vol. 73, p. 301

Karner G. D., Driscoll N. W., Tectonic and stratigraphic development of the West African and eastern Brazilian Margins: insights from quantitative basin modelling, Geological Society, London, Special Publications, 1999, vol. 153, p. 11

Kaus B. J., Mühlhaus H., May D. A., A stabilization algorithm for geodynamic numerical simulations with a free surface, Physics of the Earth and Planetary Interiors, 2010, vol. 181 , p. 12

Lavier L. L., Manatschal G., A mechanism to thin the continental lithosphere at magmapoor margins, Nature, 2006, vol. 440, p. 324

Lavier L. L., Steckler M. S., The effect of sedimentary cover on the flexural strength of continental lithosphere, Nature, 1997, vol. 389, p. 476

McKenzie D., Some remarks on the development of sedimentary basins, Earth and Planetary science letters, 1978, vol. 40, p. 25

Meisling K. E., Cobbold P. R., Mount V. S., Segmentation of an obliquely rifted margin, Campos and Santos basins, Southeastern Brazil, AAPG bulletin, 2001, vol. 85, p. 1903

Melosh H. J., Raefsky A., The dynamical origin of subduction zone topography, Geophysical Journal International, 1980, vol. 60, p. 333

Moreira J., Madeira C., Gil J., Machado M., Bacia de Santos: Boletim de Geociências da Petrobras, 2007

Moresi L., Dufour F., Mühlhaus H.-B., A Lagrangian integration point finite element method for large deformation modeling of viscoelastic geomaterials, Journal of computational physics, 2003, vol. 184, p. 476 
Moresi L., Solomatov V., Mantle convection with a brittle lithosphere: thoughts on the global tectonic styles of the Earth and Venus, Geophysical Journal International, 1998, vol. 133 , p. 669

Naliboff J., Glerum A., Brune S., Péron-Pinvidic G., Wrona T., Development of 3-D rift heterogeneity through fault network evolution, Geophysical Research Letters, 2020, vol. 47, p. e2019GL086611

O’Sullivan P. B., Foster D. A., Kohn B. P., Gleadow A. J., Multiple postorogenic denudation events: An example from the eastern Lachlan fold belt, Australia, Geology, 1996, vol. 24 , p. 563

Pérez-Gussinyé M., Andrés-Martínez M., Araújo M., Xin Y., Armitage J., Morgan J., Lithospheric strength and rift migration controls on synrift stratigraphy and breakup unconformities at rifted margins: Examples from numerical models, the Atlantic and South China Sea margins, Tectonics, 2020, vol. 39, p. e2020TC006255

Ranalli G., Rheology of the earth, deformation and flow processes in geophysics and geodynamics. Allen and Unwin Boston, 1987, 366 pp

Riccomini C., O Rift Continental do Sudeste do Brasil, São Paulo: Universidade de São Paulo, 1989, Ph.D. Thesis, 319 p.

Riccomini C., Sant'Anna L. G., Ferrari A. L., Evolução geológica do rift continental do sudeste do Brasil, Geologia do continente Sul-Americano: evolução da obra de Fernando Flávio Marques de Almeida, 2004, pp 383-405

Rigoti C. A., Evolução tectônica da Bacia de Santos com ênfase na geometria crustal: Interpretação integrada de dados de sísmica de reflexão e refração, gravimetria e magnetometria, Dissertação de mestrado, Universidade Federal do Rio de Janeiro, 2015, Ph.D. Thesis

Sacek V., Post-rift influence of small-scale convection on the landscape evolution at divergent continental margins, Earth and Planetary Science Letters, 2017, vol. 459, p. 48 
Salazar-Mora C. A., Huismans R. S., Fossen H., Egydio-Silva M., The Wilson cycle and effects of tectonic structural inheritance on rifted passive margin formation, Tectonics, 2018, vol. 37 , p. 3085

Salomon E., Koehn D., Passchier C., Brittle reactivation of ductile shear zones in NW Namibia in relation to South Atlantic rifting, Tectonics, 2015, vol. 34, p. 70

Sant'Anna L., Riccomini C., Rodrigues-Francisco B., Sial A., Carvalho M., Moura C., The Paleocene travertine system of the Itaboraí basin, Southeastern Brazil, Journal of South American Earth Sciences, 2004, vol. 18, p. 11

Sharples W., Moresi L., Jadamec M., Revote J., Styles of rifting and fault spacing in numerical models of crustal extension, Journal of Geophysical Research: Solid Earth, 2015, vol. 120 , p. 4379

Silva R. M., Sacek V., Shallow necking depth and differential denudation linked to post-rift continental reactivation: The origin of the Cenozoic basins in southeastern Brazil, Terra Nova, 2019, vol. 31 , p. 527

Sternai P., Surface processes forcing on extensional rock melting, Scientific reports, 2020, vol. 10 , p. 1

Tackley P. J., Effects of strongly temperature-dependent viscosity on time-dependent, three-dimensional models of mantle convection, Geophysical Research Letters, 1993, vol. 20 , p. 2187

Tackley P. J., King S. D., Testing the tracer ratio method for modeling active compositional fields in mantle convection simulations, Geochemistry, Geophysics, Geosystems, 2003, vol. 4

Theunissen T., Huismans R. S., Long-term coupling and feedback between tectonics and surface processes during non-volcanic rifted margin formation, Journal of Geophysical Research: Solid Earth, 2019, vol. 124, p. 12323

Thieulot C., ELEFANT: a user-friendly multipurpose geodynamics code., Solid Earth Discussions, 2014, vol. 6 
Tommasi A., Vauchez A., Continental rifting parallel to ancient collisional belts: an effect of the mechanical anisotropy of the lithospheric mantle, Earth and Planetary Science Letters, 2001, vol. 185, p. 199

Tommasi A., Vauchez A., Heterogeneity and anisotropy in the lithospheric mantle, Tectonophysics, 2015, vol. 661, p. 11

Trouw R. A. J., Heilbron M., Ribeiro A., Paciullo F., Valeriano C., Almeida J., Tupinambá M., Andreis R., The central segment of the Ribeira Belt, Tectonic Evolution of South America, 2000, vol. 31, p. 287

Turcotte D. L., Schubert G., Geodynamics. Cambridge University press, 2002

Zalán P. V., Severino M. D. C. G., Rigoti C. A., Magnavita L. P., Oliveira J. A. B., Vianna A. R., An entirely new 3D-view of the crustal and mantle structure of a South Atlantic passive margin - Santos, Campos and Espírito Santo Basins, Brazil, B. Geoci. Petrobras, 2011, vol. 13, p. 269

Zhong S., Yuen D. A., Moresi L. N., Schubert G., Numerical methods for mantle convection, Treatise on Geophysics, 2007, vol. 7, p. 227

Zienkiewicz O. C., Taylor R. L., Taylor R. L., Taylor R. L., The finite element method: fluid dynamics. vol. 3, Butterworth-Heinemann, 2000 
Appendix 

Appendix A

\section{Supporting information}

Additional supporting information for the article Shallow necking depth and differential denudation linked to post-rift continental reactivation: The origin of the Cenozoic basins in southeastern Brazil published in Terra Nova (https://doi.org/10.1111/ter.12423).

Data S1. Descriptions of the horizontal compressive stress, necking depth concept and the numerical model. 
Shallow necking depth and differential denudation linked to post-rift continental reactivation: the origin of the Cenozoic basins in southeastern Brazil

Rafael M. Silva and Victor Sacek

Universidade de São Paulo, Instituto de Astronomia, Geofísica e Ciências Atmosféricas,

Departamento de Geofísica, Brazil, rmslobato@gmail.com

\section{Supporting Information}

The content of this file includes text and figures and is divided into the following items:

- 1) Horizontal compressive stress. Description of the force related to the ridge push to simulate a horizontal compressive stress in the model.

- 2) Necking depth definition. Description of the necking depth concept.

- 3) Numerical model. Description of the numerical model.

- 4) Accumulated erosion. Accumulated erosion during the simulation for setup a (Figure S2).

- 5) Deviatoric stress pattern evolution. Deviatoric stress pattern evolution for models $S$ (setup a) with necking depth (a) $z_{n}=8 \mathrm{~km}$ and (b) $z_{n}=12 \mathrm{~km}$ in intervals of $10 \mathrm{Myr}$ (Figures S3-S16).

- 6) Lithospheric uplift and subsidence evolution. Lithospheric uplift and subsidence evolution at time interval of $10 \mathrm{Myr}$ for models $S$ (setup a) with necking depth (a) $z_{n}=4 \mathrm{~km}$, (b) $z_{n}=8 \mathrm{~km}$ and (c) $z_{n}=12 \mathrm{~km}$ (Figure $\mathrm{S} 17$ ).

- 7) Thermal evolution. Thermal evolution of the model in intervals of $20 \mathrm{Myr}$ (Figures S18-S25). 


\section{Horizontal compressive stress}

To simulate a horizontal compressive stress in the model associated with the ridge push, we assumed a force per unit length given by

$$
F(t)=F_{R P}\left(1-\exp ^{-t / \tau_{R P}}\right)
$$

where $t$ is the time and $\tau_{R P}$ is a decaying control factor. $F_{R P}$ is the maximum force, which is based on the plate cooling model for the oceanic lithosphere (Turcotte and Schubert, 2002),

$$
F_{R P}=g \alpha \rho_{m}\left(T_{1}-T_{0}\right) L_{z}^{2}\left[\frac{1}{6}+\frac{\alpha \rho_{m}\left(T_{1}-T_{0}\right)}{8\left(\rho_{m}-\rho_{w}\right)}\right]
$$

where $g$ is the gravitational acceleration, $\rho_{m}$ is the mantle density, $\rho_{w}$ is the water density, $L_{z}$ is the lithosphere thickness, $\alpha$ is the thermal expansion coefficient, $T_{1}$, is the temperature at the base of the lithosphere, and $T_{0}$ is the temperature at the surface. We used the following values for parameters: $\tau_{R P}=60 \mathrm{Myr}, \alpha=3 \times 10^{-5} \mathrm{~K}^{-1}, T_{1}-T_{0}=1300 \mathrm{~K}, \rho_{m}=3300 \mathrm{~kg} / \mathrm{m}^{3}, \rho_{w}=1030 \mathrm{~kg} / \mathrm{m}^{3}, L_{z}=150$ $\mathrm{km}$, and $g=9.8 \mathrm{~m} / \mathrm{s}^{2}$.

\section{References}

Turcotte, D. and Schubert, G., 2002. Geodynamics: New York, Cambridge University Press, 456 p. 


\section{Necking depth definition}

The definition of the necking depth is the depth in the lithosphere that remains horizontal during stretching if no isostatic compensation is applied (Braun and Beaumont, 1987; Braun and Beaumont, 1989). The necking depth is close (physically) to the layer of maximum strength in the lithosphere. Hence, when the lithosphere is stretched, the thinning occurs about this reference level. If the necking depth is shallow (Figure S1), e.g. if the crust is decoupled from the lithospheric mantle, the addition of isostatic forces produces a down warping of the lithosphere, and subsidence occurs. In cases where the necking depth is deep, e.g. if the crust is coupled with the lithospheric mantle, then the addition of isostatic forces, produces an upward movement of the lithosphere, creating flank uplifts.

\section{Kinematic model Regional isostatic response}
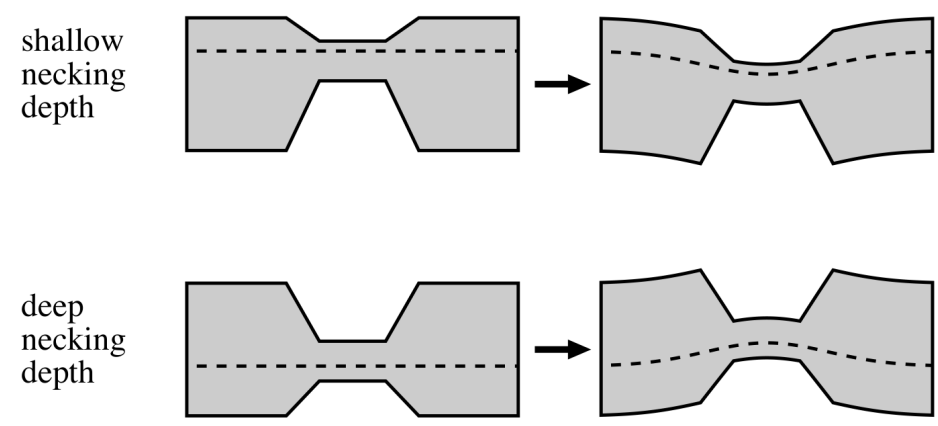

Figure S1: Sketch of the necking depth of the lithosphere and the regional isostatic response to stretching (Braun and Beaumont, 1987; Braun and Beaumont, 1989). The left panels show the kinematic model for a shallow (upper figure) and deep (lower figure) necking depth without isostatic compensation. The gray region is the lithosphere and the dashed lines represent the necking depth. The right panels show the combination of stretching and regional isostatic response of the lithosphere.

\section{References}

Braun, J. and Beaumont, C. , 1987. Styles of continental rifting: Results from dynamic models of lithospheric extension. In: Sedimentary Basins and Basin-Forming Mechanisms (C. Beaumont and A. J. Tankard, eds). Mem. Can. Soc. Pet. Geol. 12, 241-258.

Braun, J. and Beaumont, C., 1989. A physical explanation of the relation between flank uplifts and the breakup unconformity at rifted continental margins. Geology 17. 8, 760-764. 


\section{$3 \quad$ Numerical model}

To evaluate the flexural stresses in the lithosphere we used a $2 \mathrm{D}$ finite element code in which the rheology of the lithosphere is described by a Maxwell viscoelastic material with a nonlinear powerlaw viscosity (Melosh and Raefsky, 1980) in plane-strain deformation. The viscoelastic stresses where calculated following Melosh and Raefsky (1980) and the numerical formulation of Hughes and Taylor (1978).

To evaluate the evolution of the thermal state of the lithosphere we solved the diffusive heat equation

$$
\frac{\partial T}{\partial t}=\kappa \nabla^{2} T
$$

where $T$ is temperature, $t$ is time, $\kappa=6 \times 10^{-7} \mathrm{~m}^{2} / \mathrm{s}$ is the thermal diffusivity, and $\nabla^{2}$ is the Laplacian operator. The numerical solution was obtained using the finite element formulation presented by Braun (2003). The thermal model used the same triangular mesh of the mechanical model. The temperature field changed the element density $\left(\Delta \rho_{T}\right)$ according to

$$
\Delta \rho_{T}=\alpha \rho_{r} \Delta T
$$

where $\alpha=3.25 \times 10^{-5 \circ} \mathrm{C}^{-1}$ is the thermal expansion coefficient, $\rho_{r}$ is the reference density of the layer and $\Delta T$ is the temperature difference between the actual temperature and the one in steady state condition.

\section{References}

Braun, J., 2003. Pecube: A new finite-element code to solve the 3D heat transport equation including the effects of a time-varying, finite amplitude surface topography. Computers \& Geosciences, 29(6), 787-794.

Hughes, T. J. and Taylor, R. L., 1978. Unconditionally stable algorithms for quasi-static elasto/viscoplastic finite element analysis. Computers \& Structures, 8(2), 169-173.

Melosh, H. J. and Raefsky, A., 1980. The dynamical origin of subduction zone topography. Geophysical Journal of the Royal Astronomical Society, 60 (3), 333-354. 


\section{Accumulated erosion}

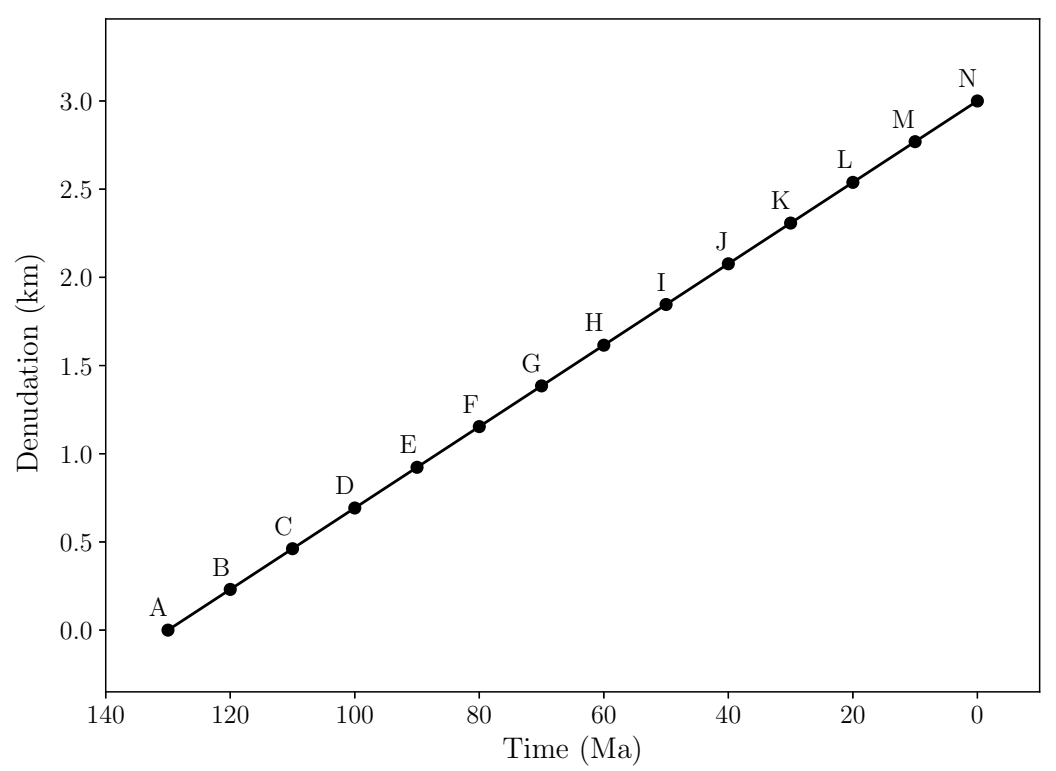

Figure S2: Representative denudation evolution pattern used in the models. Letters indicate time steps shown in Figures S3-S16. 


\section{Deviatoric stress pattern evolution}

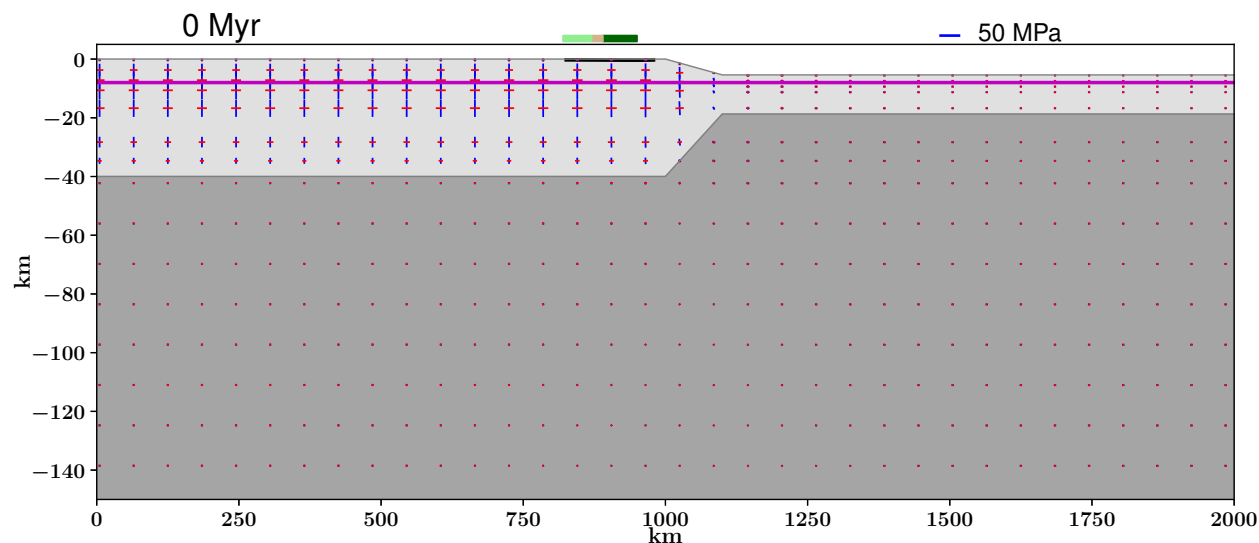

(a) $z_{n}=8 \mathrm{~km}$.

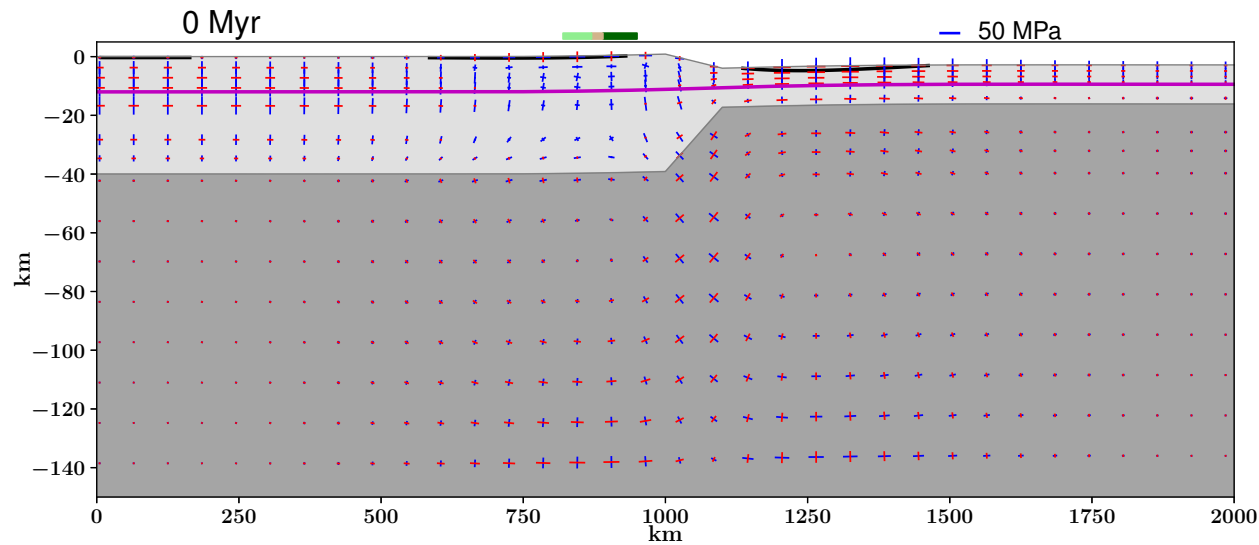

(b) $z_{n}=12 \mathrm{~km}$

Figure S3: Deviatoric stress pattern at time $=0$ Myr. (a) Model $S$ (setup $a$ ), $z_{n}=8 \mathrm{~km}$ and (b) model $S$ $(\operatorname{setup} a), z_{n}=12 \mathrm{~km}$. The complete section of the numerical domain is shown. Blue/red line segments represent principal compression/tension, respectively. Solid, dashed and dotted black lines are the failure limit assuming rock cohesion of 0,50 and $100 \mathrm{MPa}$. Purple line represents the necking depth. Top horizontal bar indicates the Serra da Mantiqueira (light green), the CRSB (light brown) and the Serra do Mar (dark green) areas. Dark gray area in the section corresponds to the mantle. 


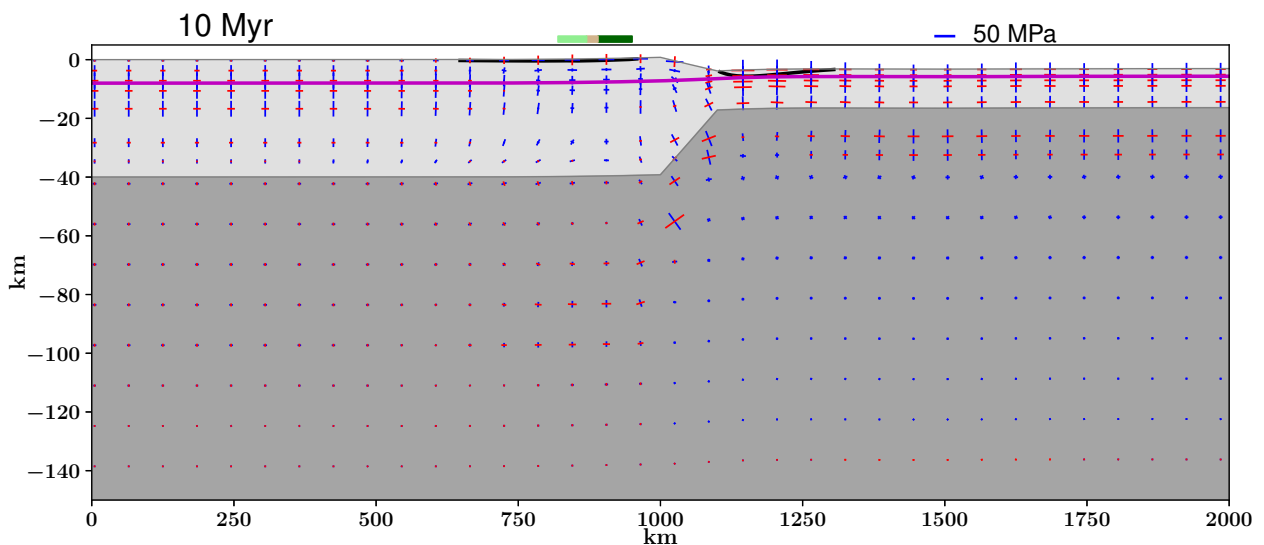

(a) $z_{n}=8 \mathrm{~km}$.

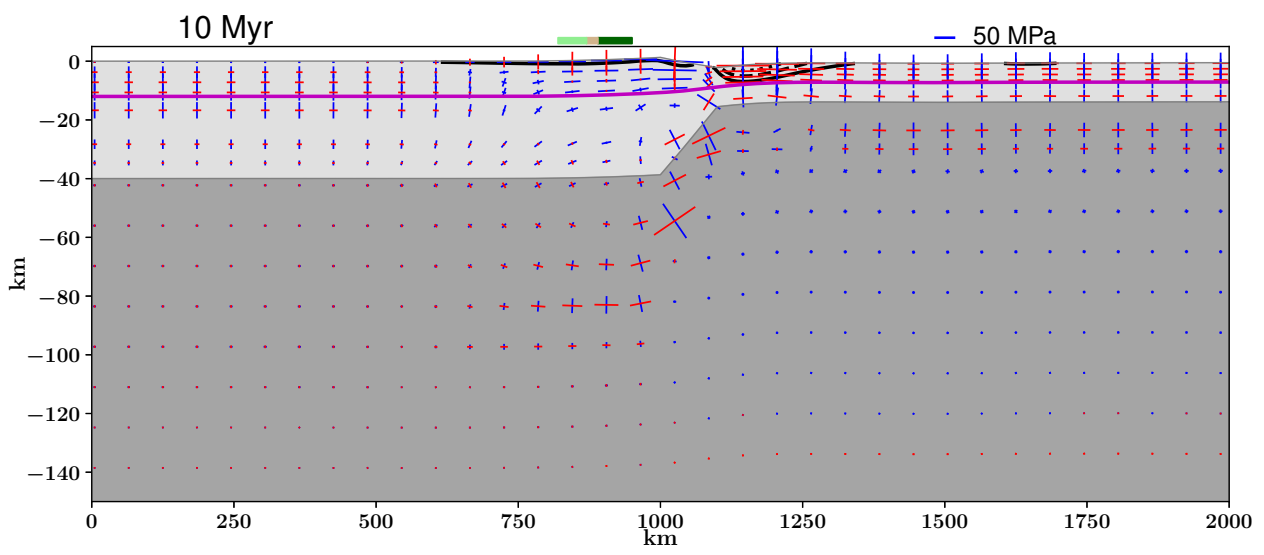

(b) $z_{n}=12 \mathrm{~km}$.

Figure S4: Deviatoric stress pattern at time $=10 \mathrm{Myr}$. (a) Model $S$ ( $\operatorname{setup} a$ ), $z_{n}=8 \mathrm{~km}$ and (b) model $S$ $(\operatorname{setup} a), z_{n}=12 \mathrm{~km}$. The complete section of the numerical domain is shown. Blue/red line segments represent principal compression/tension, respectively. Solid, dashed and dotted black lines are the failure limit assuming rock cohesion of 0,50 and $100 \mathrm{MPa}$. Purple line represents the necking depth. Top horizontal bar indicates the Serra da Mantiqueira (light green), the CRSB (light brown) and the Serra do Mar (dark green) areas. Dark gray area in the section corresponds to the mantle. 


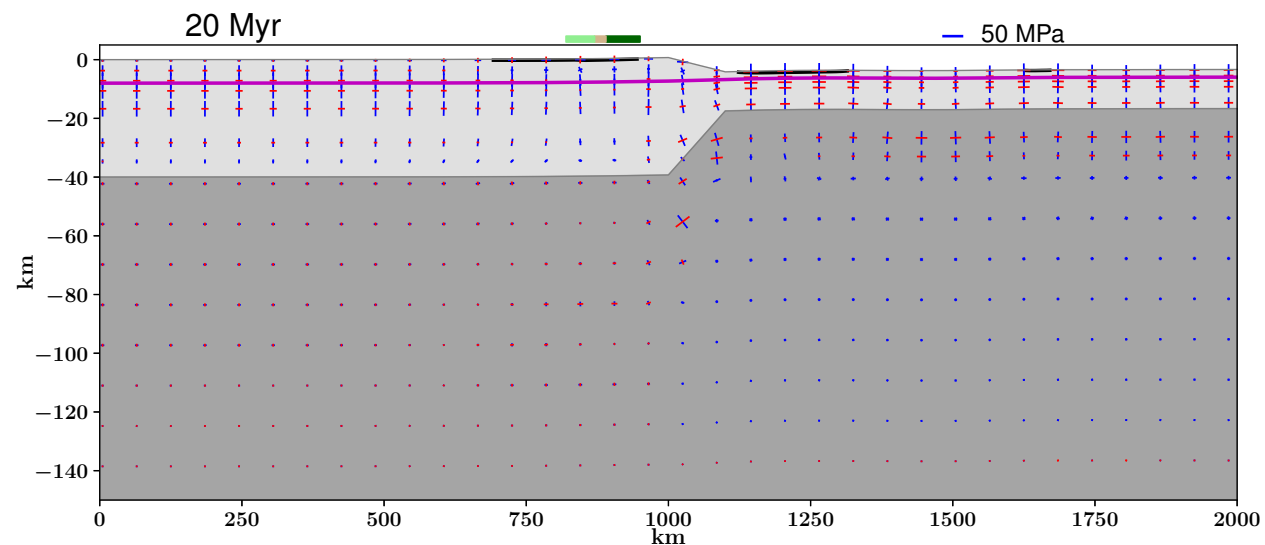

(a) $z_{n}=8 \mathrm{~km}$.

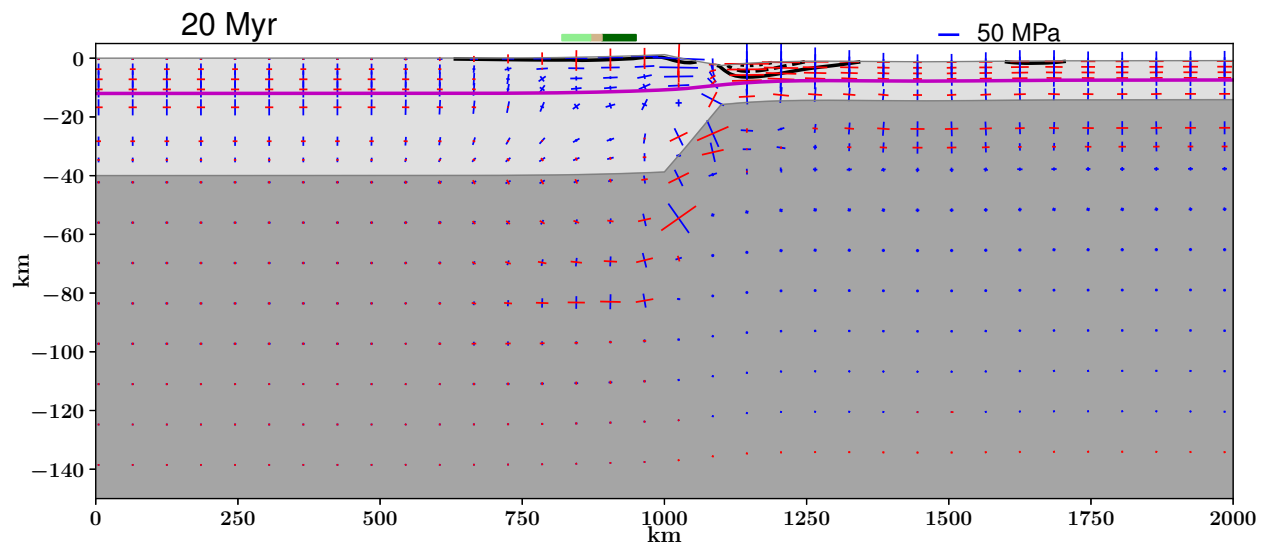

(b) $z_{n}=12 \mathrm{~km}$.

Figure S5: Deviatoric stress pattern at time $=20$ Myr. (a) Model $S$ (setup $a$ ), $z_{n}=8 \mathrm{~km}$ and (b) model $S$ $(\operatorname{setup} a), z_{n}=12 \mathrm{~km}$. The complete section of the numerical domain is shown. Blue/red line segments represent principal compression/tension, respectively. Solid, dashed and dotted black lines are the failure limit assuming rock cohesion of 0,50 and $100 \mathrm{MPa}$. Purple line represents the necking depth. Top horizontal bar indicates the Serra da Mantiqueira (light green), the CRSB (light brown) and the Serra do Mar (dark green) areas. Dark gray area in the section corresponds to the mantle. 


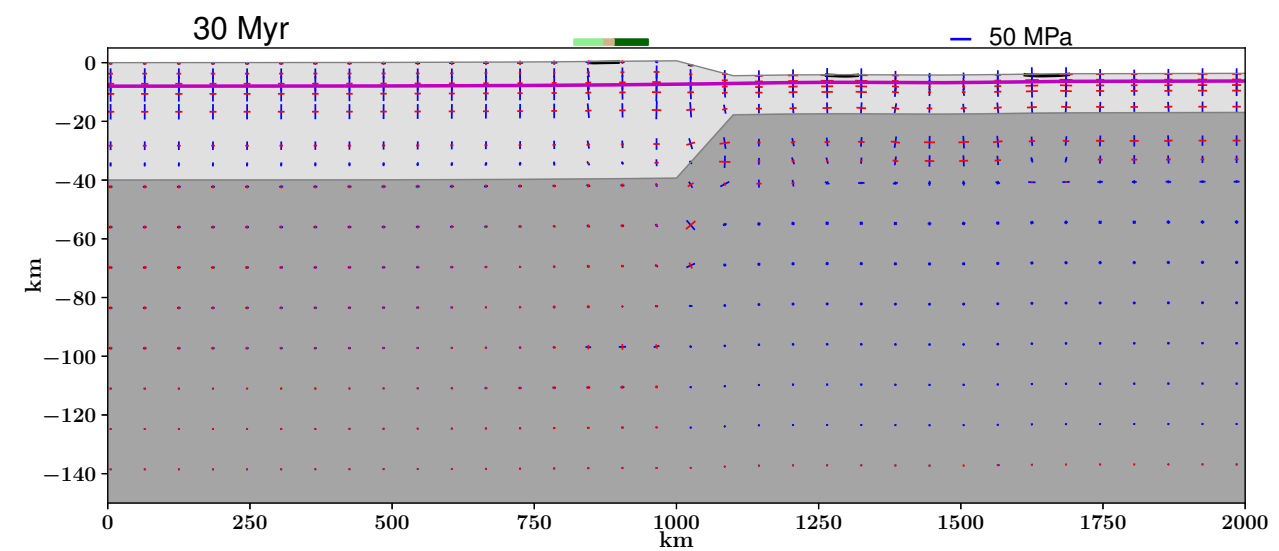

(a) $z_{n}=8 \mathrm{~km}$.

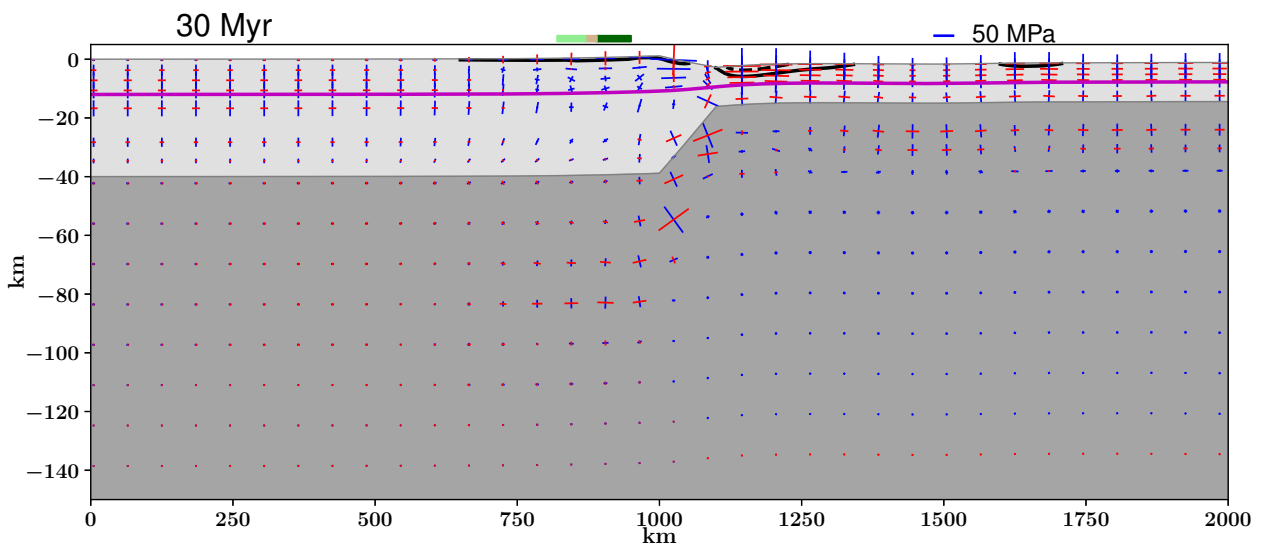

(b) $z_{n}=12 \mathrm{~km}$.

Figure S6: Deviatoric stress pattern at time $=30 \mathrm{Myr}$. (a) Model $S$ (setup $a), z_{n}=8 \mathrm{~km}$ and (b) model $S$ $(\operatorname{setup} a), z_{n}=12 \mathrm{~km}$. The complete section of the numerical domain is shown. Blue/red line segments represent principal compression/tension, respectively. Solid, dashed and dotted black lines are the failure limit assuming rock cohesion of 0,50 and $100 \mathrm{MPa}$. Purple line represents the necking depth. Top horizontal bar indicates the Serra da Mantiqueira (light green), the CRSB (light brown) and the Serra do Mar (dark green) areas. Dark gray area in the section corresponds to the mantle. 


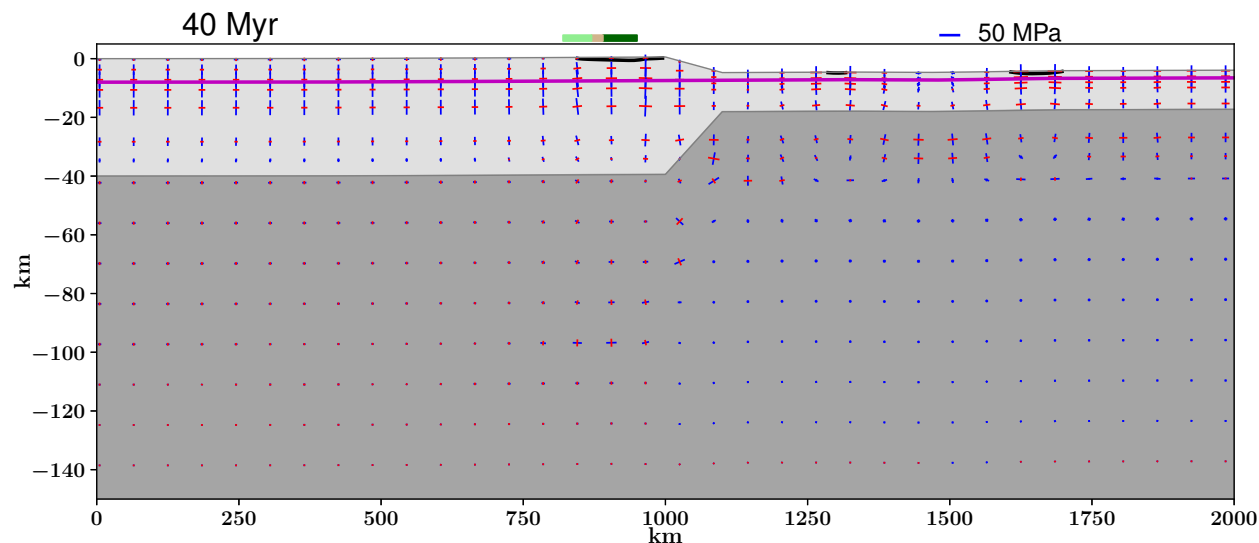

(a) $z_{n}=8 \mathrm{~km}$.

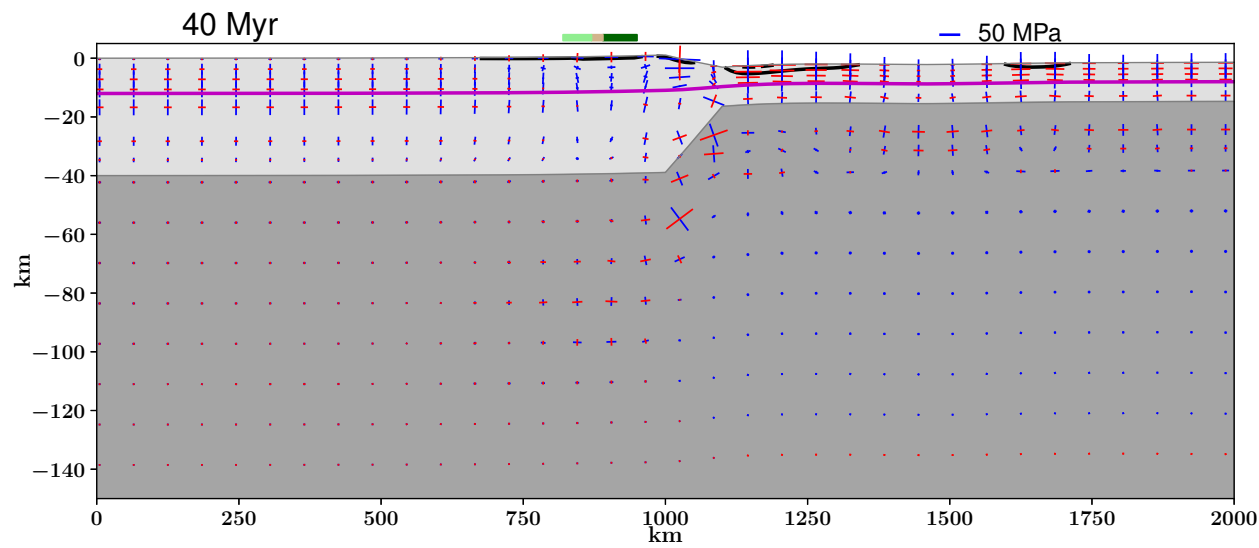

(b) $z_{n}=12 \mathrm{~km}$

Figure S7: Deviatoric stress pattern at time $=40$ Myr. (a) Model $S$ (setup $a$ ), $z_{n}=8 \mathrm{~km}$ and (b) model $S$ $(\operatorname{setup} a), z_{n}=12 \mathrm{~km}$. The complete section of the numerical domain is shown. Blue/red line segments represent principal compression/tension, respectively. Solid, dashed and dotted black lines are the failure limit assuming rock cohesion of 0,50 and $100 \mathrm{MPa}$. Purple line represents the necking depth. Top horizontal bar indicates the Serra da Mantiqueira (light green), the CRSB (light brown) and the Serra do Mar (dark green) areas. Dark gray area in the section corresponds to the mantle. 


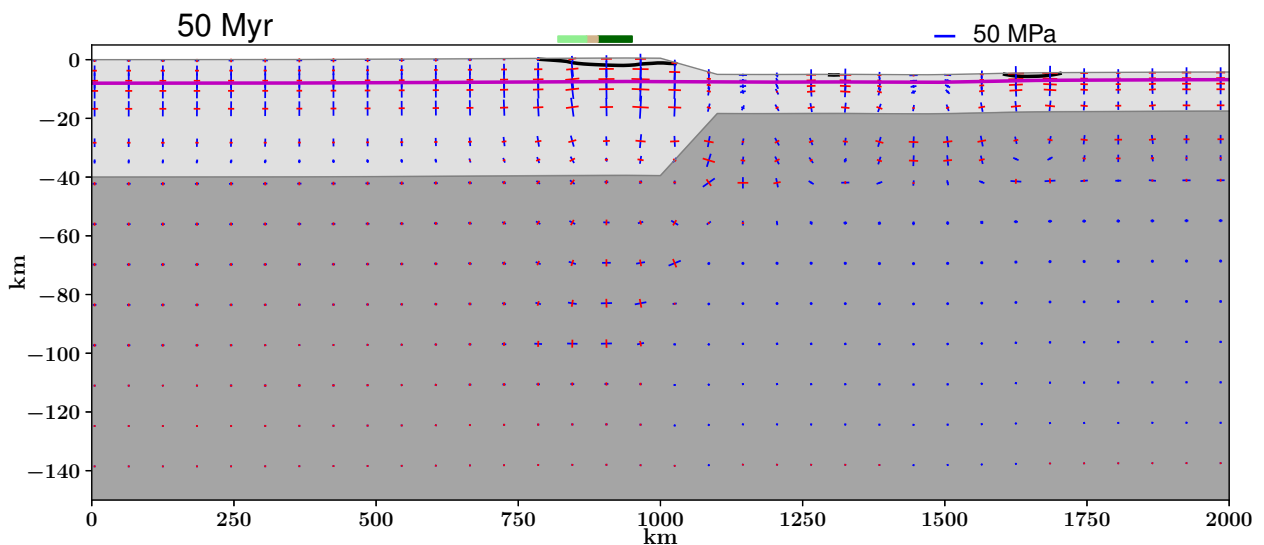

(a) $z_{n}=8 \mathrm{~km}$.

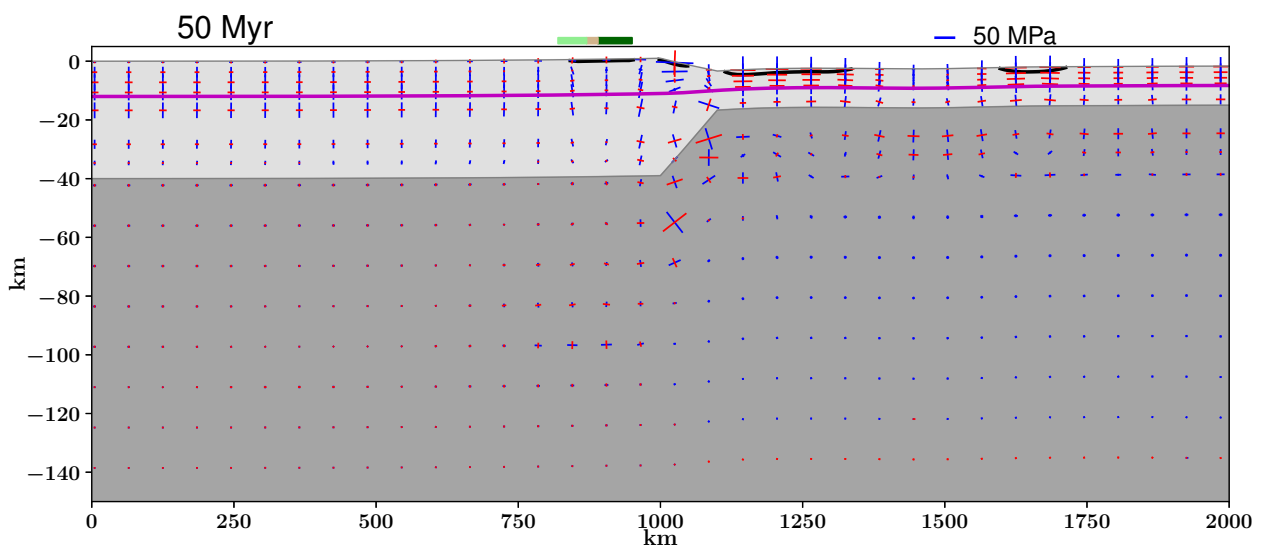

(b) $z_{n}=12 \mathrm{~km}$.

Figure S8: Deviatoric stress pattern at time $=50$ Myr. (a) Model $S$ ( $\operatorname{setup~} a$ ), $z_{n}=8 \mathrm{~km}$ and (b) model $S$ $(\operatorname{setup} a), z_{n}=12 \mathrm{~km}$. The complete section of the numerical domain is shown. Blue/red line segments represent principal compression/tension, respectively. Solid, dashed and dotted black lines are the failure limit assuming rock cohesion of 0,50 and $100 \mathrm{MPa}$. Purple line represents the necking depth. Top horizontal bar indicates the Serra da Mantiqueira (light green), the CRSB (light brown) and the Serra do Mar (dark green) areas. Dark gray area in the section corresponds to the mantle. 


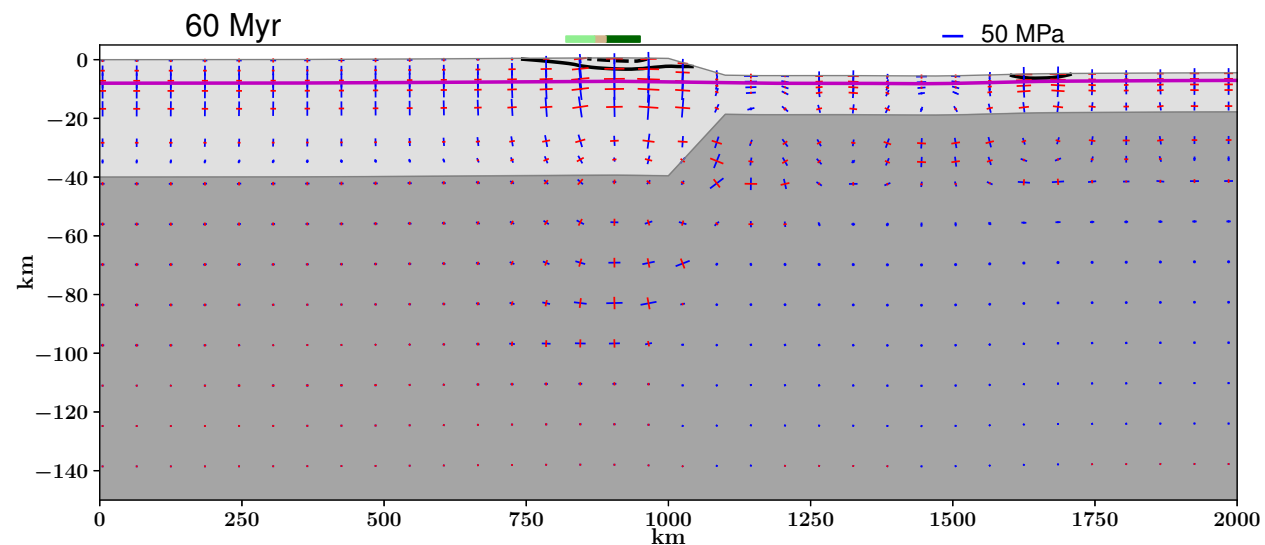

(a) $z_{n}=8 \mathrm{~km}$.

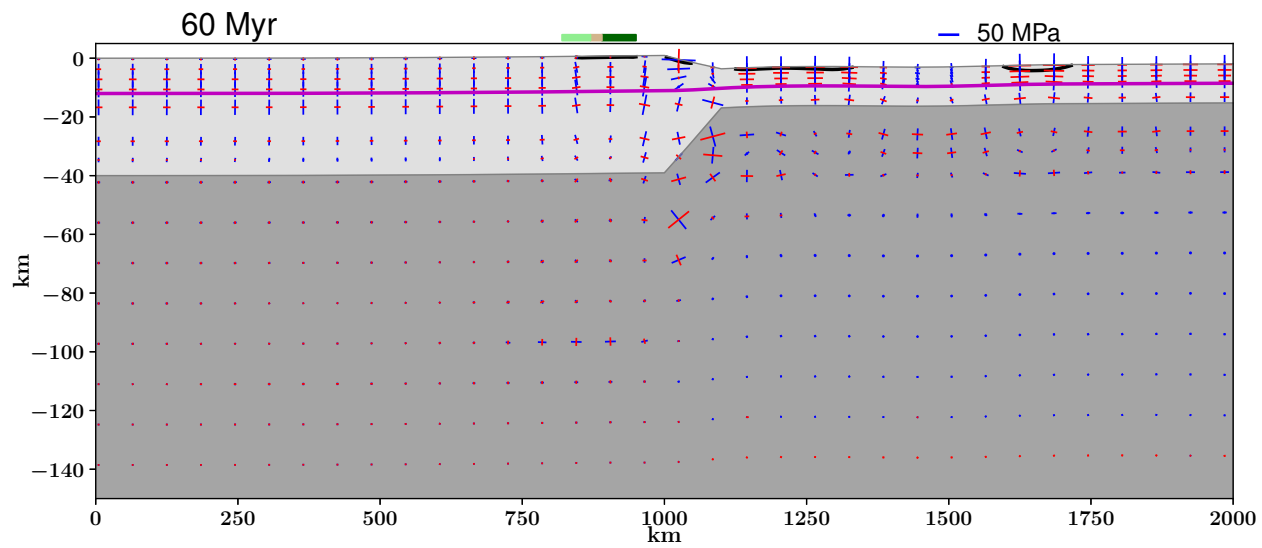

(b) $z_{n}=12 \mathrm{~km}$

Figure S9: Deviatoric stress pattern at time $=60 \mathrm{Myr}$. (a) Model $S$ (setup $a$ ), $z_{n}=8 \mathrm{~km}$ and (b) model $S$ $(\operatorname{setup} a), z_{n}=12 \mathrm{~km}$. The complete section of the numerical domain is shown. Blue/red line segments represent principal compression/tension, respectively. Solid, dashed and dotted black lines are the failure limit assuming rock cohesion of 0,50 and $100 \mathrm{MPa}$. Purple line represents the necking depth. Top horizontal bar indicates the Serra da Mantiqueira (light green), the CRSB (light brown) and the Serra do Mar (dark green) areas. Dark gray area in the section corresponds to the mantle. 


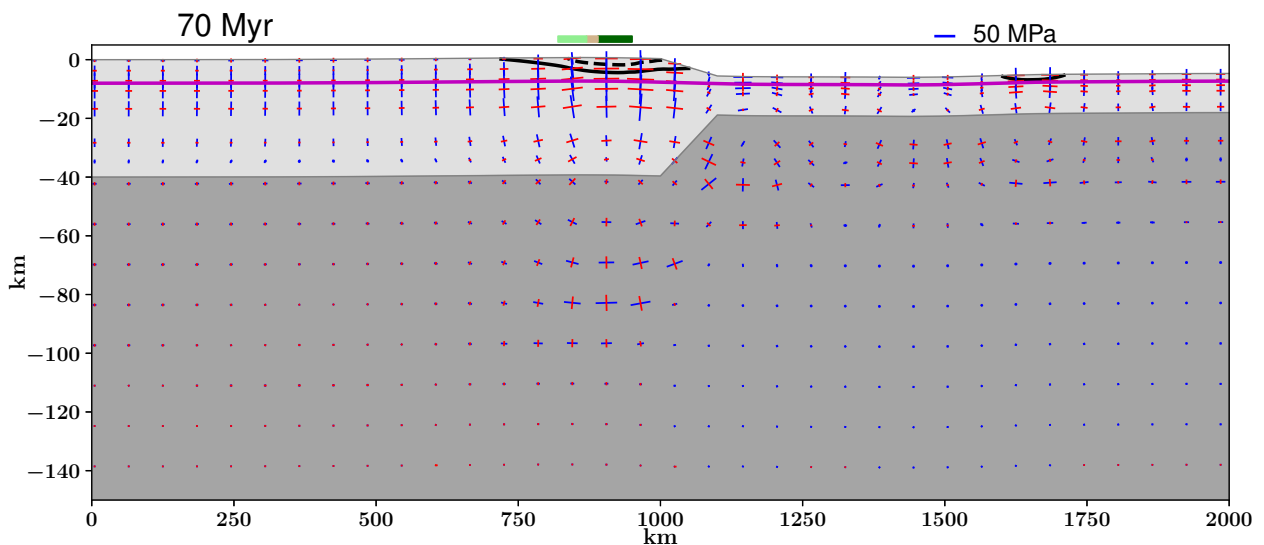

(a) $z_{n}=8 \mathrm{~km}$.

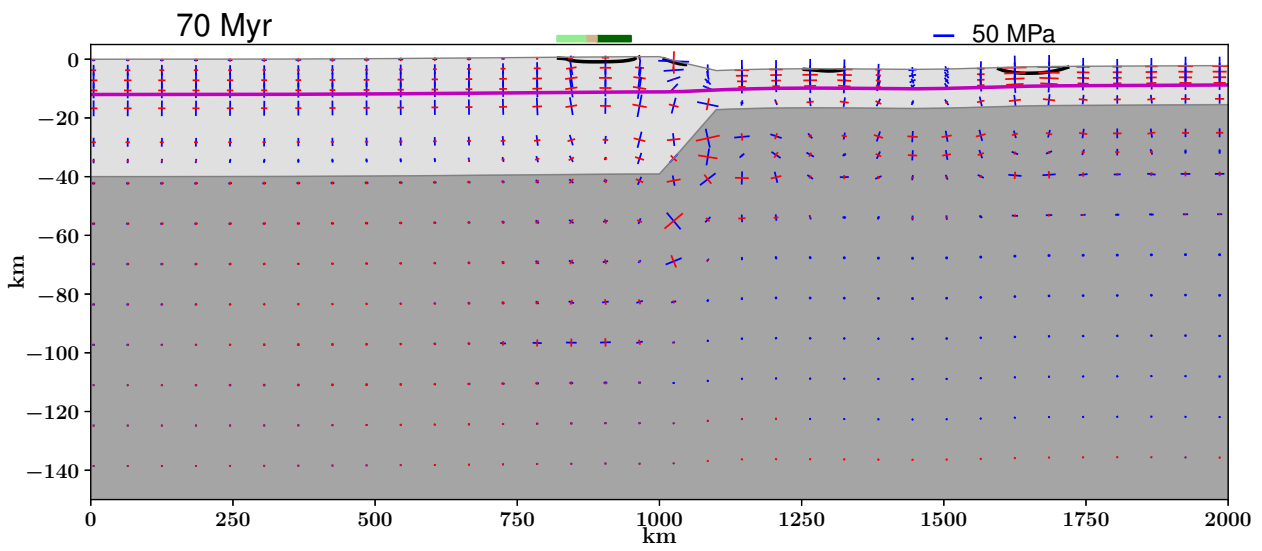

(b) $z_{n}=12 \mathrm{~km}$.

Figure S10: Deviatoric stress pattern at time $=70$ Myr. (a) Model $S$ (setup $a$ ), $z_{n}=8 \mathrm{~km}$ and (b) model $S$ $(\operatorname{setup} a), z_{n}=12 \mathrm{~km}$. The complete section of the numerical domain is shown. Blue/red line segments represent principal compression/tension, respectively. Solid, dashed and dotted black lines are the failure limit assuming rock cohesion of 0,50 and $100 \mathrm{MPa}$. Purple line represents the necking depth. Top horizontal bar indicates the Serra da Mantiqueira (light green), the CRSB (light brown) and the Serra do Mar (dark green) areas. Dark gray area in the section corresponds to the mantle. 


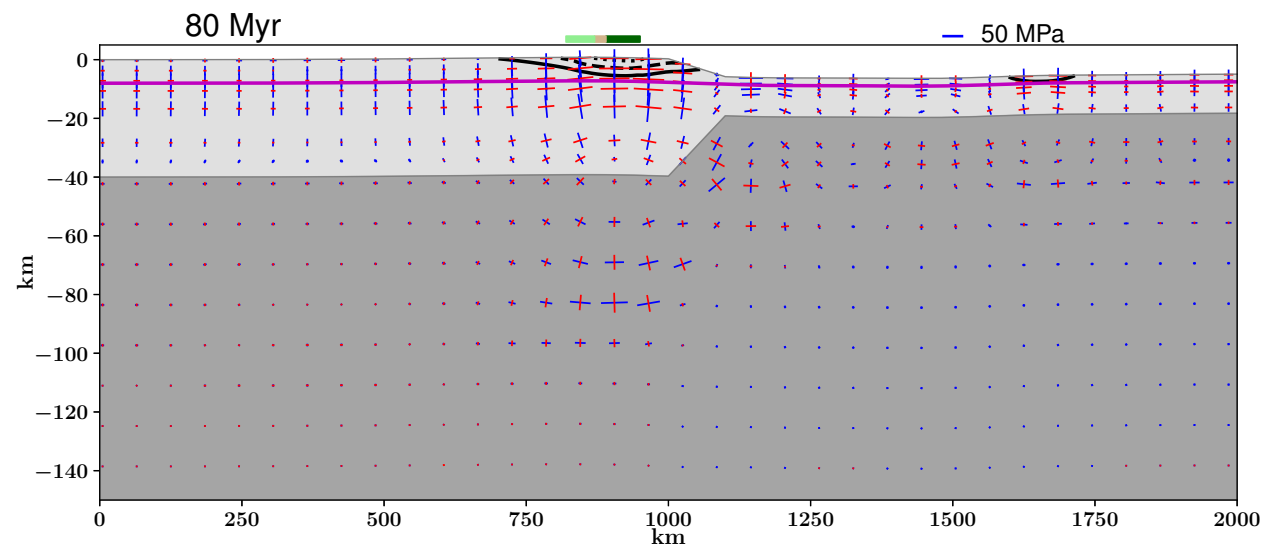

(a) $z_{n}=8 \mathrm{~km}$.

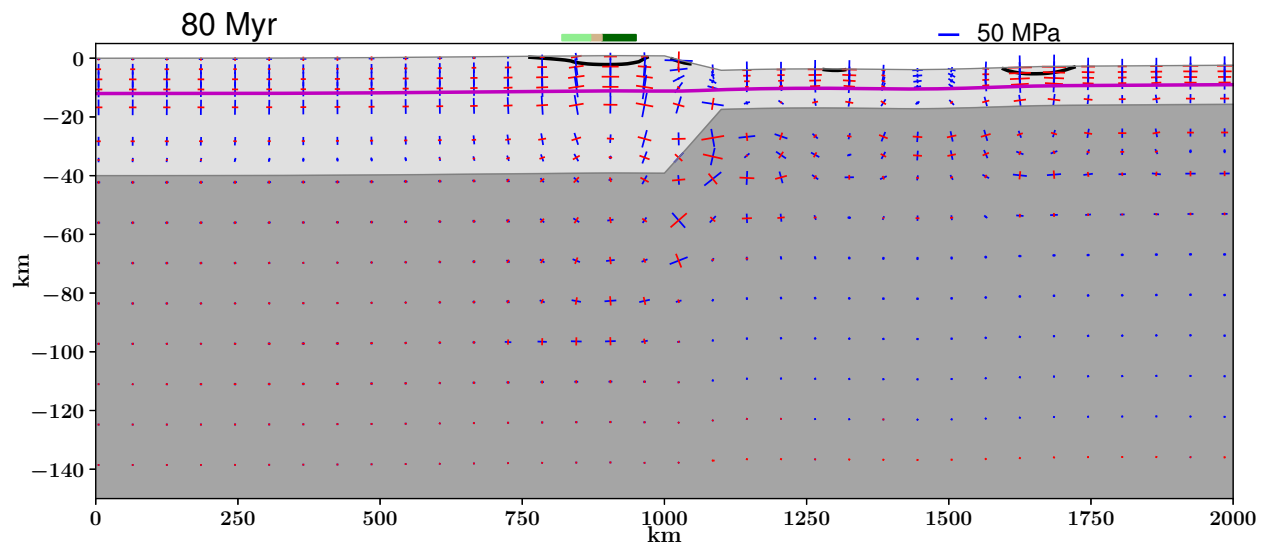

(b) $z_{n}=12 \mathrm{~km}$.

Figure S11: Deviatoric stress pattern at time $=80$ Myr. (a) Model $S(\operatorname{setup} a), z_{n}=8 \mathrm{~km}$ and (b) model $S$ $(\operatorname{setup} a), z_{n}=12 \mathrm{~km}$. The complete section of the numerical domain is shown. Blue/red line segments represent principal compression/tension, respectively. Solid, dashed and dotted black lines are the failure limit assuming rock cohesion of 0,50 and $100 \mathrm{MPa}$. Purple line represents the necking depth. Top horizontal bar indicates the Serra da Mantiqueira (light green), the CRSB (light brown) and the Serra do Mar (dark green) areas. Dark gray area in the section corresponds to the mantle. 


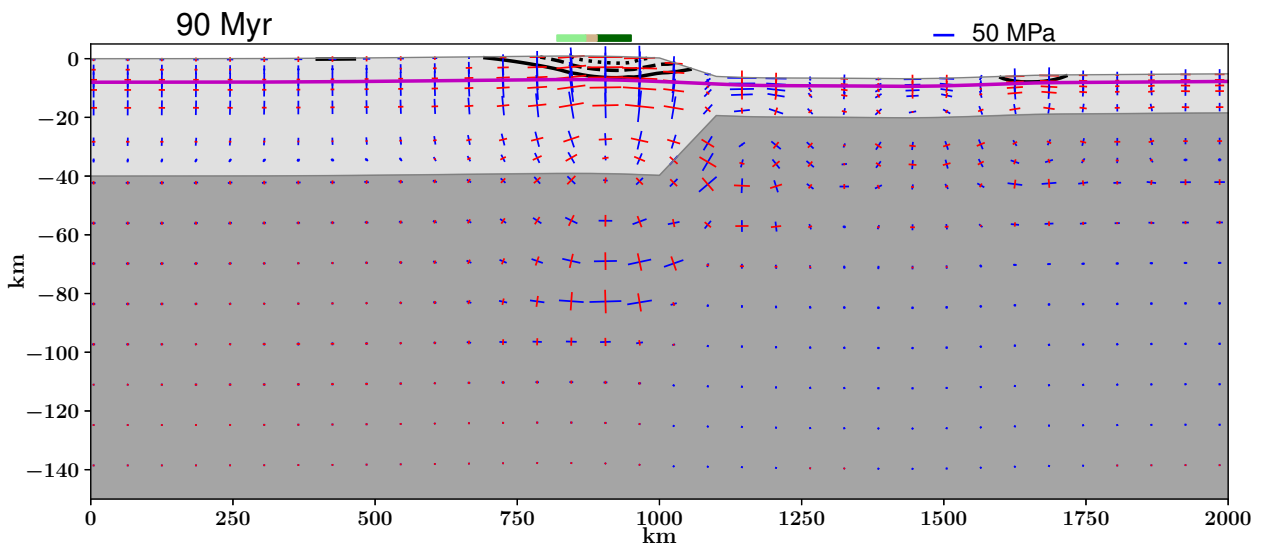

(a) $z_{n}=8 \mathrm{~km}$.

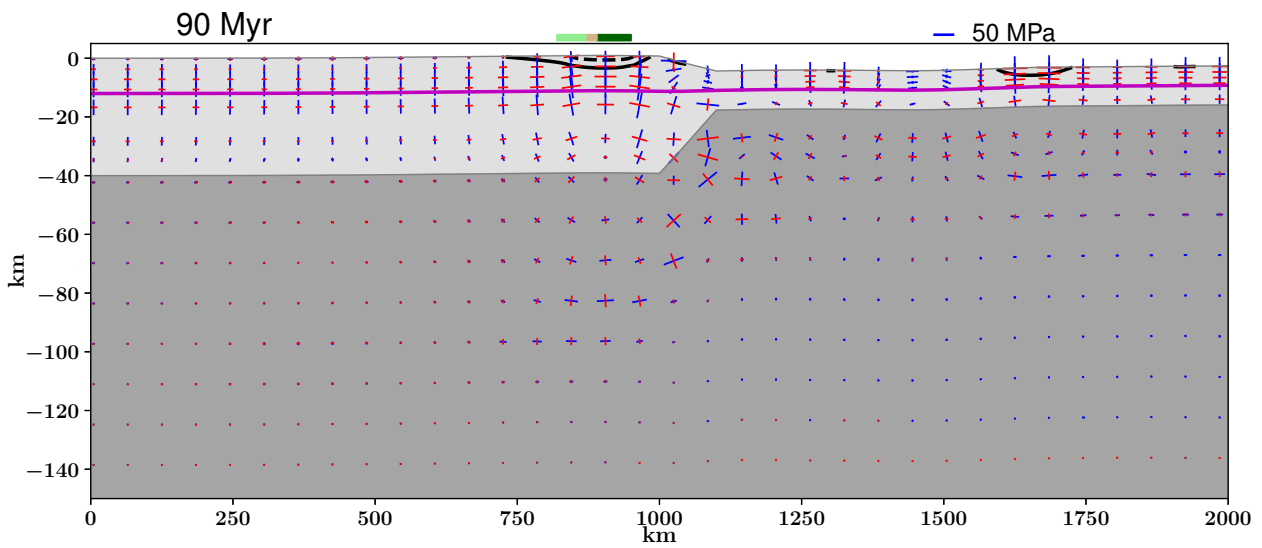

(b) $z_{n}=12 \mathrm{~km}$.

Figure S12: Deviatoric stress pattern at time $=90$ Myr. (a) Model $S$ (setup $a$ ), $z_{n}=8 \mathrm{~km}$ and (b) model $S$ $(\operatorname{setup} a), z_{n}=12 \mathrm{~km}$. The complete section of the numerical domain is shown. Blue/red line segments represent principal compression/tension, respectively. Solid, dashed and dotted black lines are the failure limit assuming rock cohesion of 0,50 and $100 \mathrm{MPa}$. Purple line represents the necking depth. Top horizontal bar indicates the Serra da Mantiqueira (light green), the CRSB (light brown) and the Serra do Mar (dark green) areas. Dark gray area in the section corresponds to the mantle. 


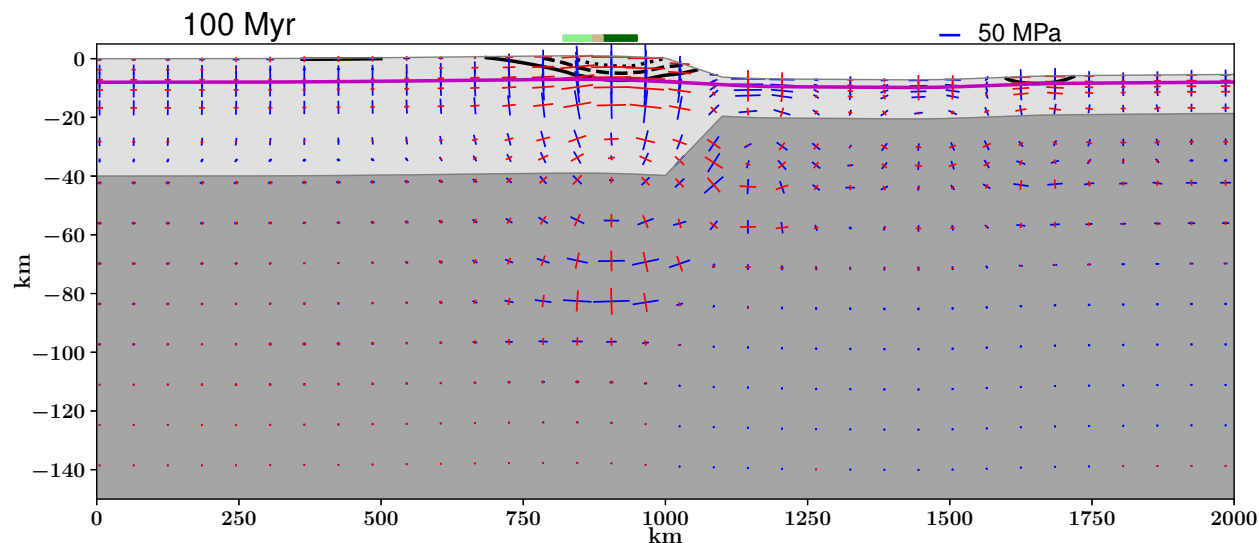

(a) $z_{n}=8 \mathrm{~km}$.

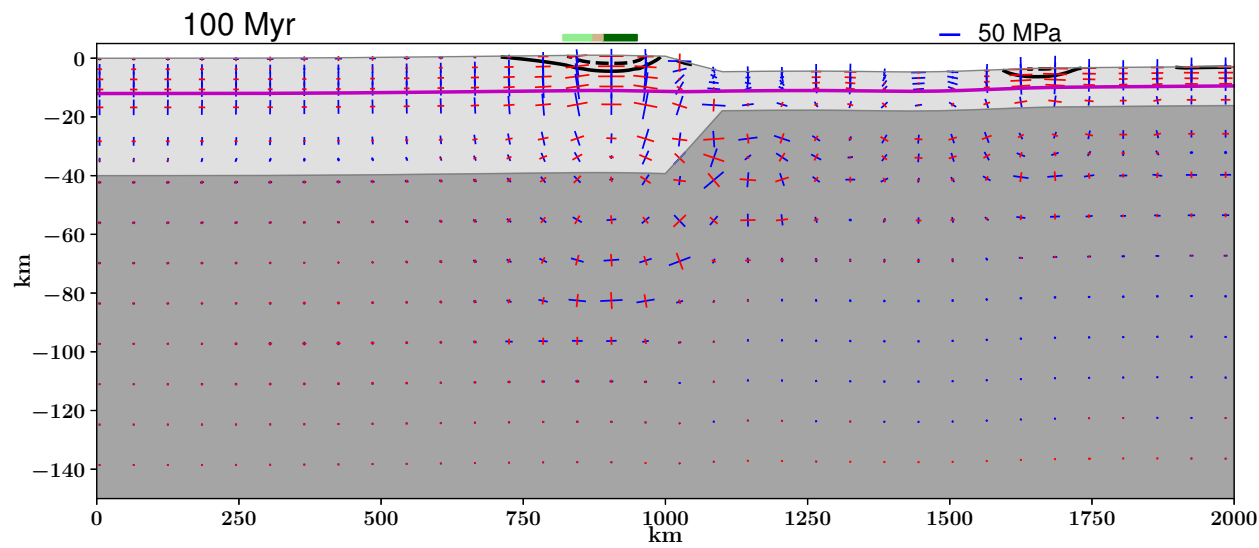

(b) $z_{n}=12 \mathrm{~km}$

Figure S13: Deviatoric stress pattern at time $=100$ Myr. (a) Model $S$ (setup $a$ ), $z_{n}=8 \mathrm{~km}$ and (b) model $S$ $(\operatorname{setup} a), z_{n}=12 \mathrm{~km}$. The complete section of the numerical domain is shown. Blue/red line segments represent principal compression/tension, respectively. Solid, dashed and dotted black lines are the failure limit assuming rock cohesion of 0,50 and $100 \mathrm{MPa}$. Purple line represents the necking depth. Top horizontal bar indicates the Serra da Mantiqueira (light green), the CRSB (light brown) and the Serra do Mar (dark green) areas. Dark gray area in the section corresponds to the mantle. 


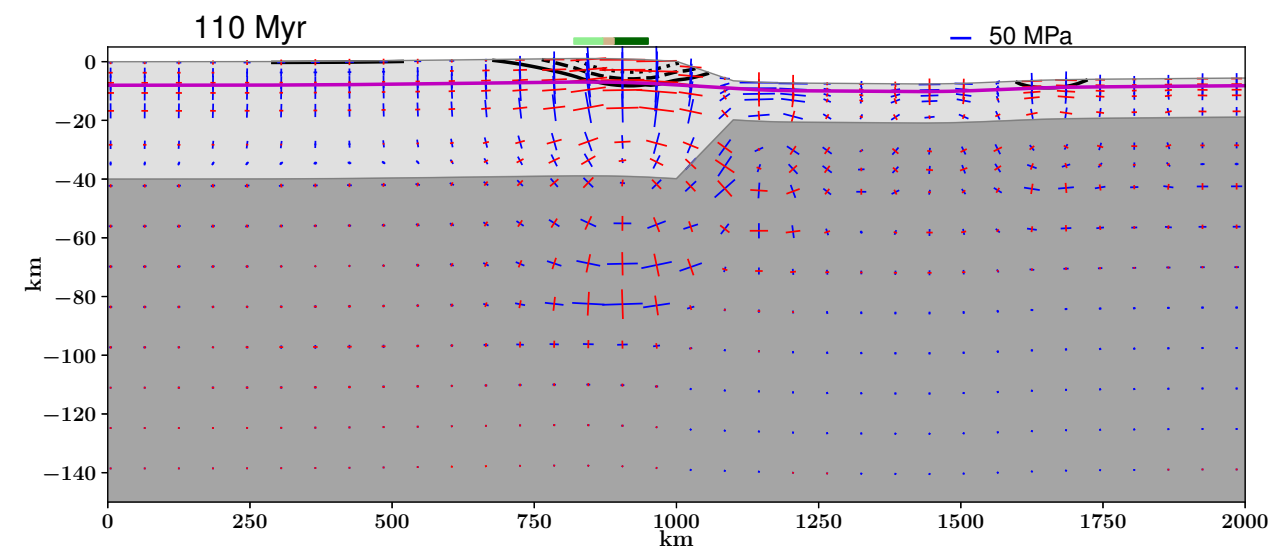

(a) $z_{n}=8 \mathrm{~km}$.

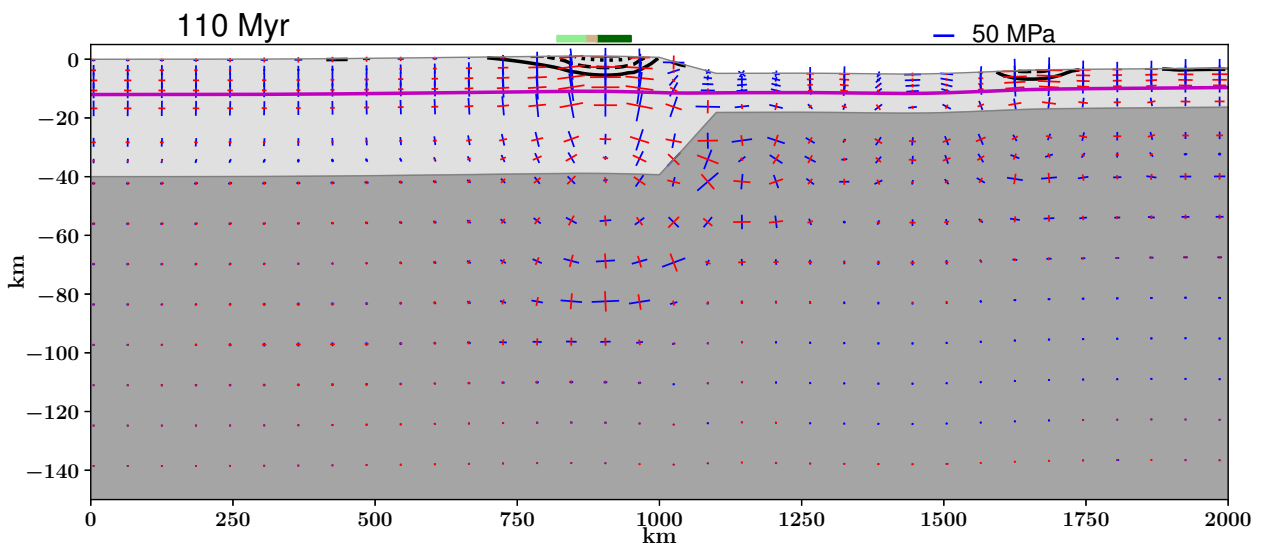

(b) $z_{n}=12 \mathrm{~km}$.

Figure S14: Deviatoric stress pattern at time $=110$ Myr. (a) Model $S$ (setup $a$ ), $z_{n}=8 \mathrm{~km}$ and (b) model $S$ $(\operatorname{setup} a), z_{n}=12 \mathrm{~km}$. The complete section of the numerical domain is shown. Blue/red line segments represent principal compression/tension, respectively. Solid, dashed and dotted black lines are the failure limit assuming rock cohesion of 0,50 and $100 \mathrm{MPa}$. Purple line represents the necking depth. Top horizontal bar indicates the Serra da Mantiqueira (light green), the CRSB (light brown) and the Serra do Mar (dark green) areas. Dark gray area in the section corresponds to the mantle. 


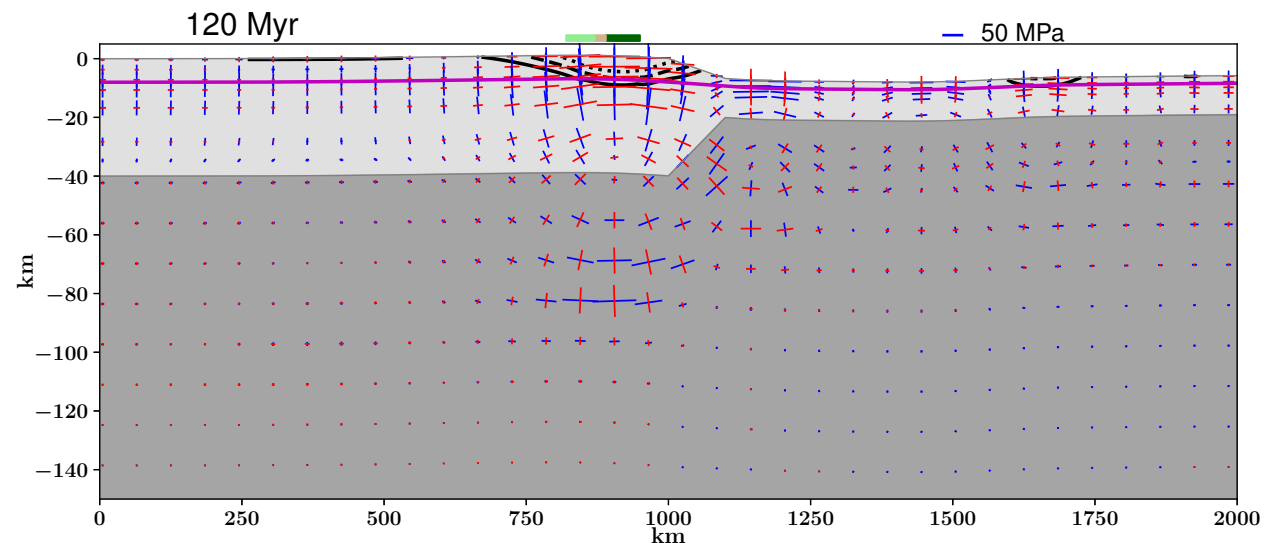

(a) $z_{n}=8 \mathrm{~km}$.

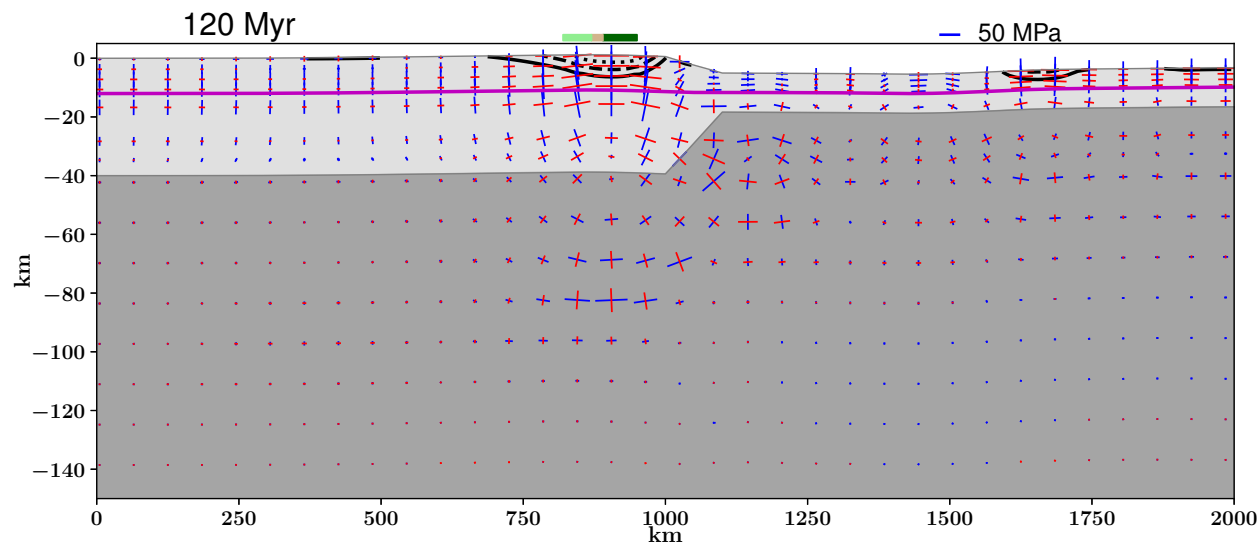

(b) $z_{n}=12 \mathrm{~km}$.

Figure S15: Deviatoric stress pattern at time $=120$ Myr. (a) Model $S$ (setup $a$ ), $z_{n}=8 \mathrm{~km}$ and (b) model $S$ $(\operatorname{setup} a), z_{n}=12 \mathrm{~km}$. The complete section of the numerical domain is shown. Blue/red line segments represent principal compression/tension, respectively. Solid, dashed and dotted black lines are the failure limit assuming rock cohesion of 0,50 and $100 \mathrm{MPa}$. Purple line represents the necking depth. Top horizontal bar indicates the Serra da Mantiqueira (light green), the CRSB (light brown) and the Serra do Mar (dark green) areas. Dark gray area in the section corresponds to the mantle. 


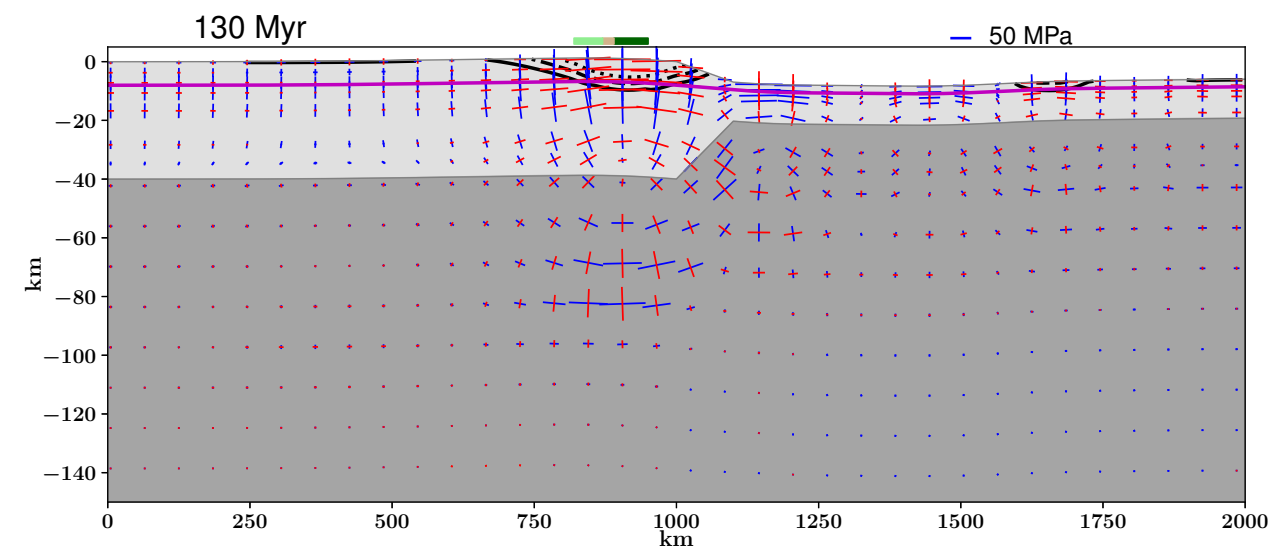

(a) $z_{n}=8 \mathrm{~km}$.

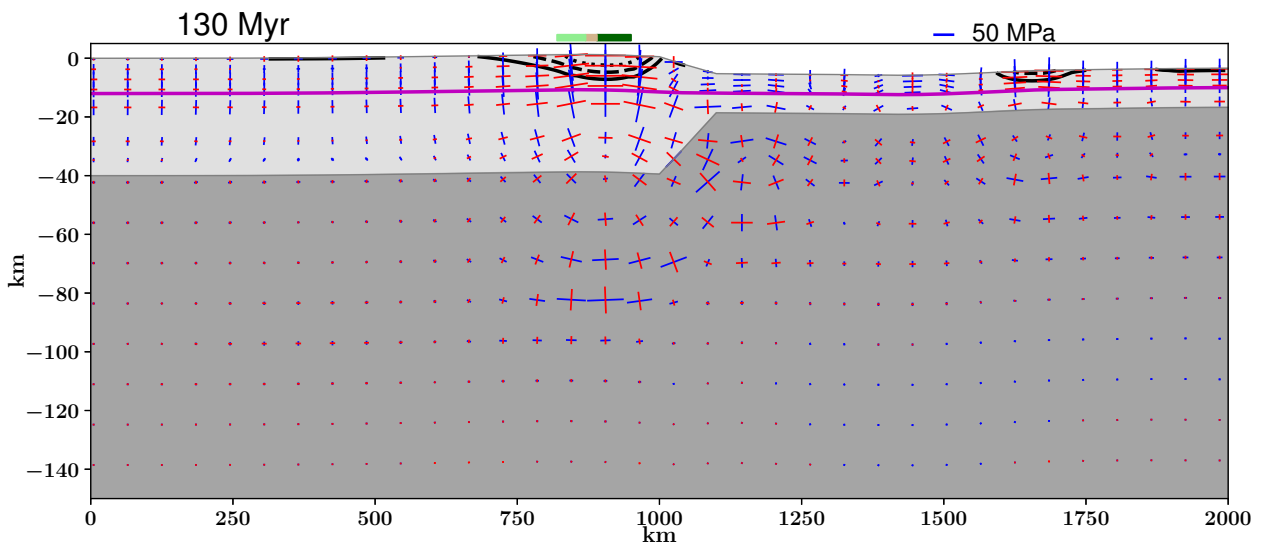

(b) $z_{n}=12 \mathrm{~km}$.

Figure S16: Deviatoric stress pattern at time $=130$ Myr. (a) Model $S$ (setup a), $z_{n}=8 \mathrm{~km}$ and (b) model $S$ $(\operatorname{setup} a), z_{n}=12 \mathrm{~km}$. The complete section of the numerical domain is shown. Blue/red line segments represent principal compression/tension, respectively. Solid, dashed and dotted black lines are the failure limit assuming rock cohesion of 0,50 and $100 \mathrm{MPa}$. Purple line represents the necking depth. Top horizontal bar indicates the Serra da Mantiqueira (light green), the CRSB (light brown) and the Serra do Mar (dark green) areas. Dark gray area in the section corresponds to the mantle. 


\section{Lithospheric uplift and subsidence evolution}

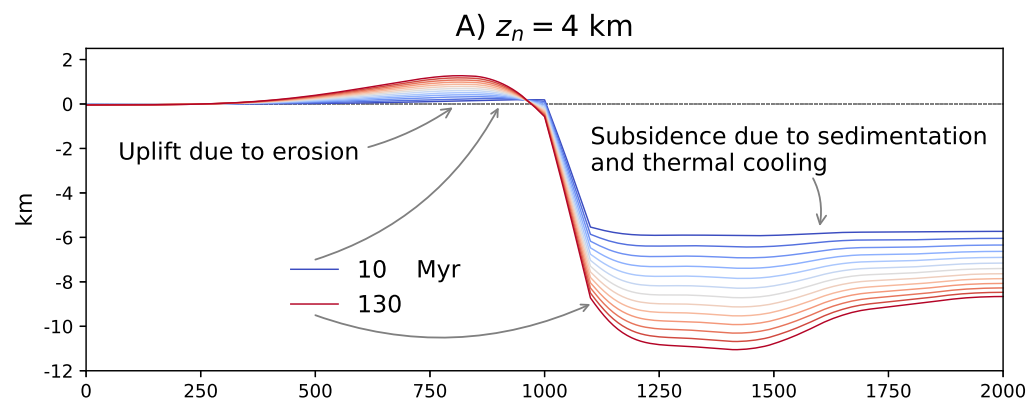

B) $z_{n}=8 \mathrm{~km}$

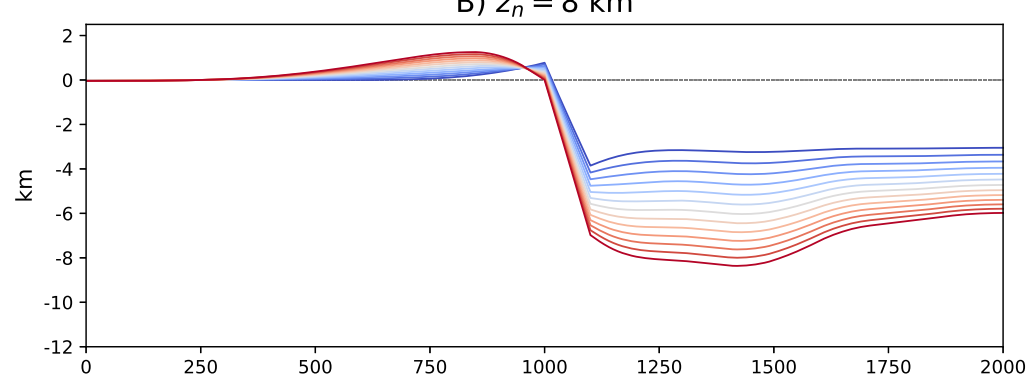

C) $z_{n}=12 \mathrm{~km}$

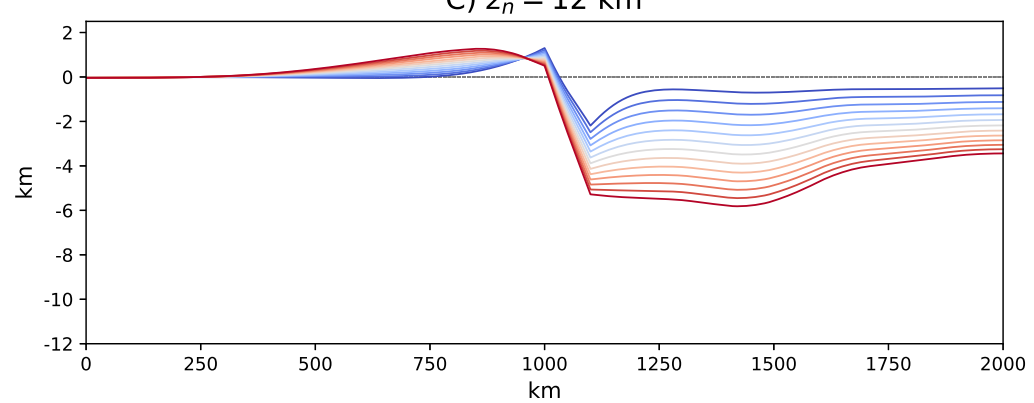

Figure S17: Lithospheric uplift and subsidence evolution at time interval of $10 \mathrm{Myr}$ for models $S$ (setup a) with necking depth (a) $z_{n}=4 \mathrm{~km}$, (b) $z_{n}=8 \mathrm{~km}$ and (c) $z_{n}=12 \mathrm{~km}$. 


\section{Thermal evolution}

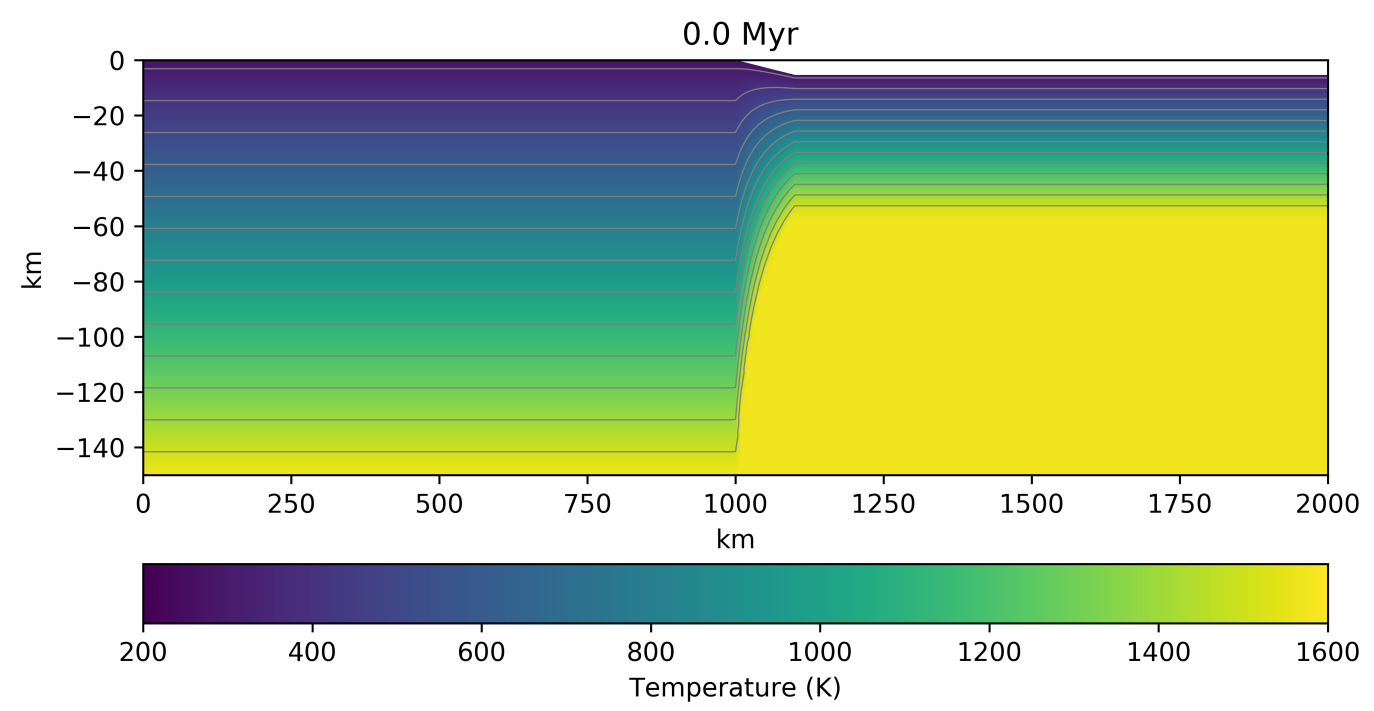

Figure S18: Thermal field at time 0 Myr. 


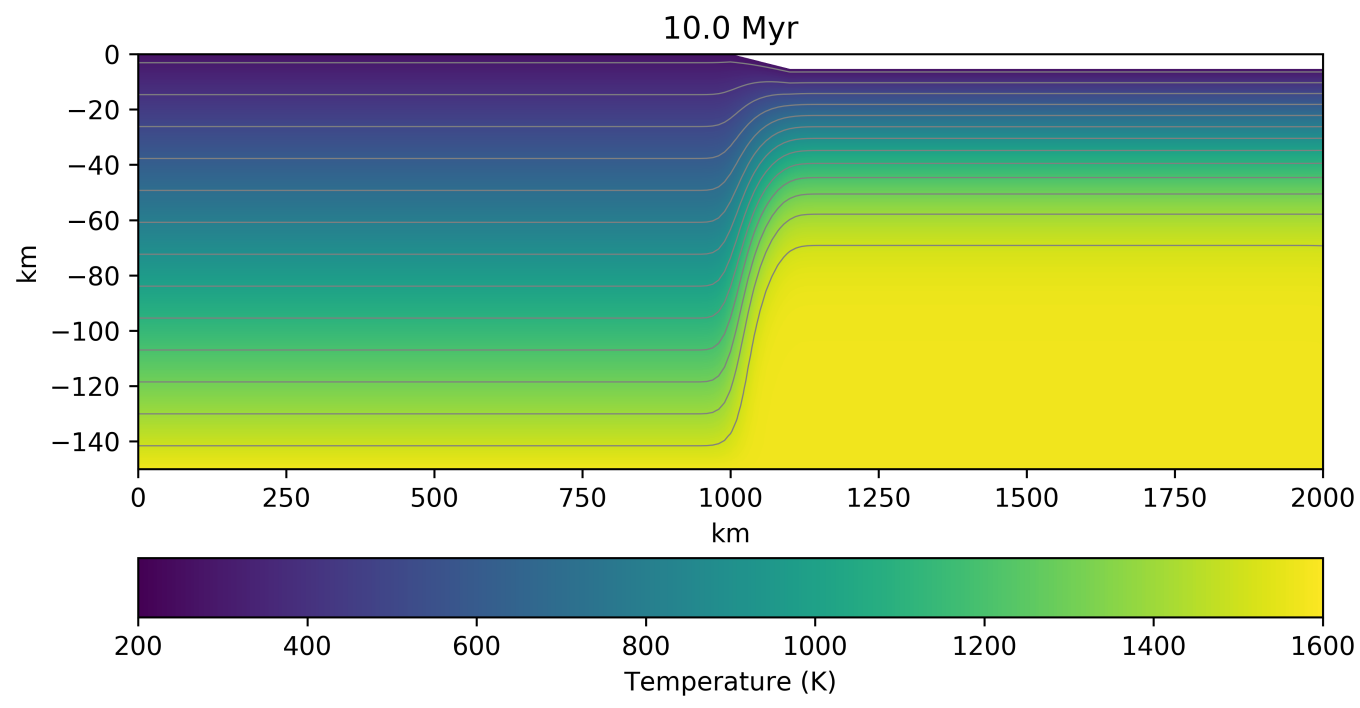

Figure S19: Thermal field at time $10 \mathrm{Myr}$. 


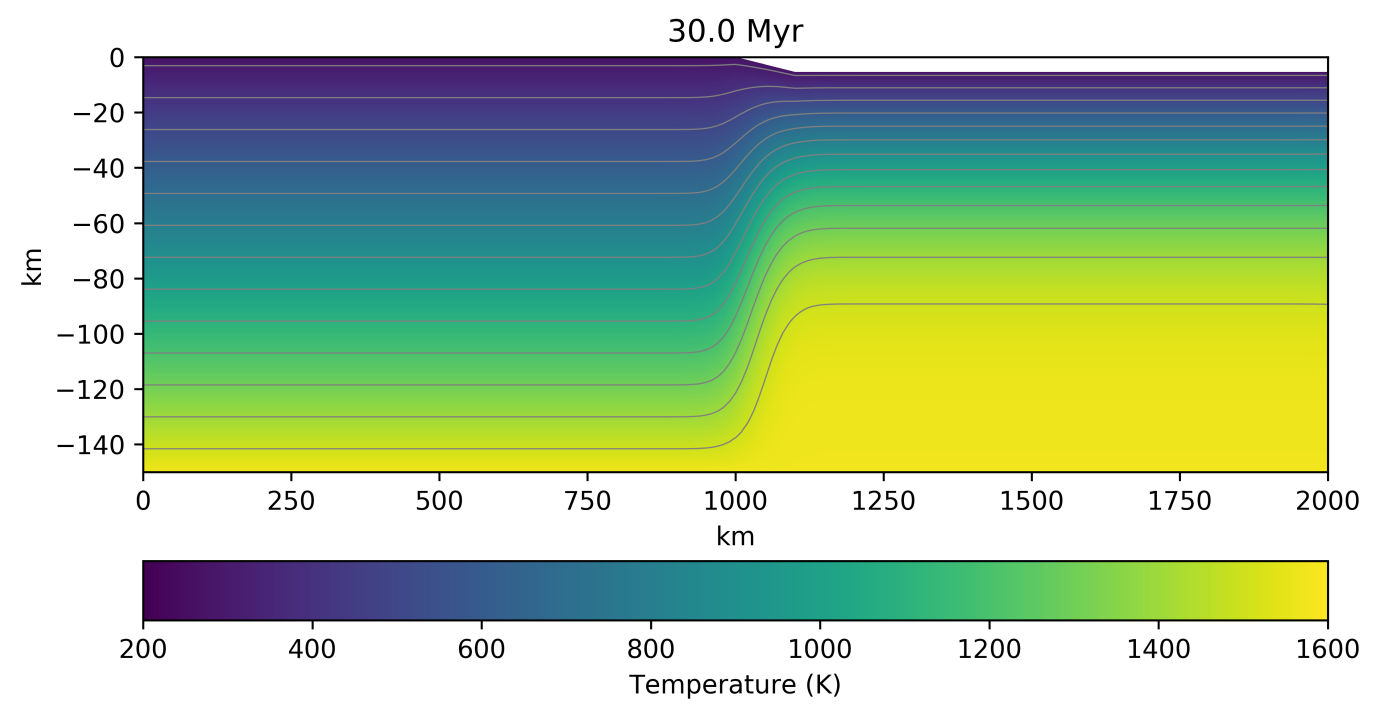

Figure S20: Thermal field at time $30 \mathrm{Myr}$. 


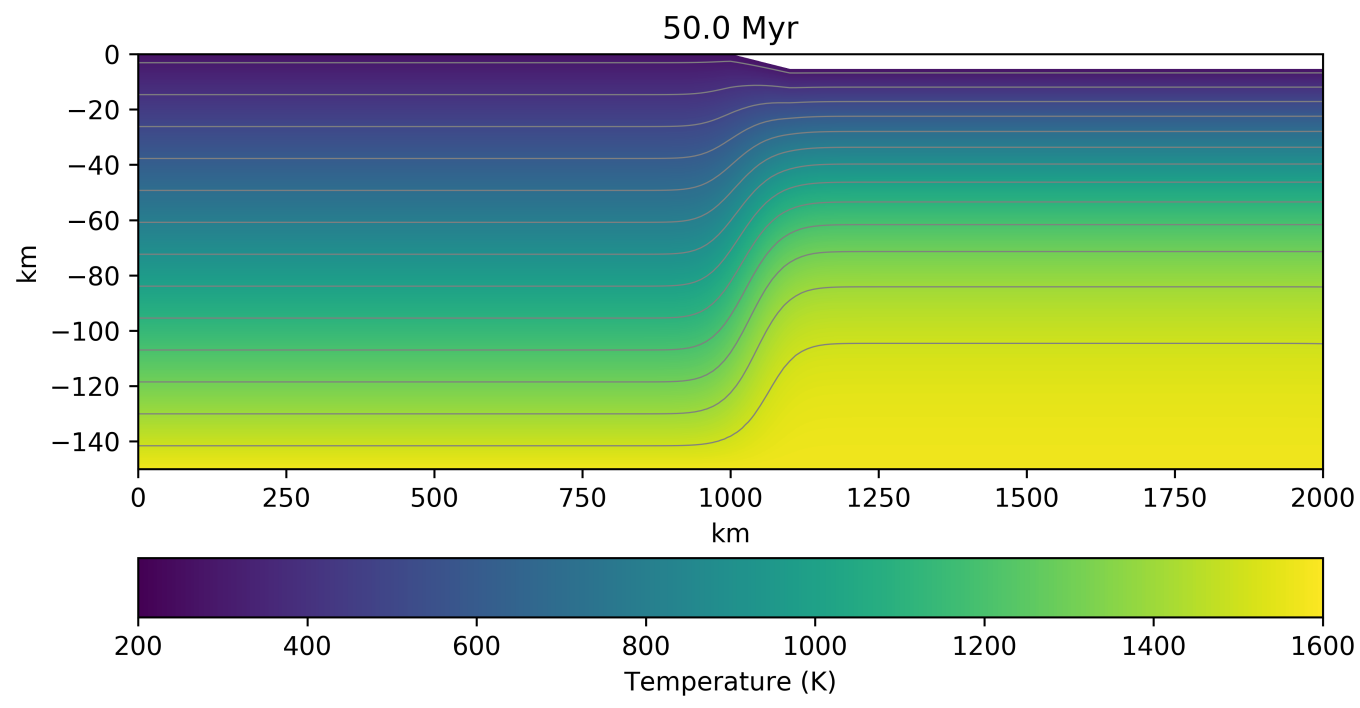

Figure S21: Thermal field at time 50 Myr. 


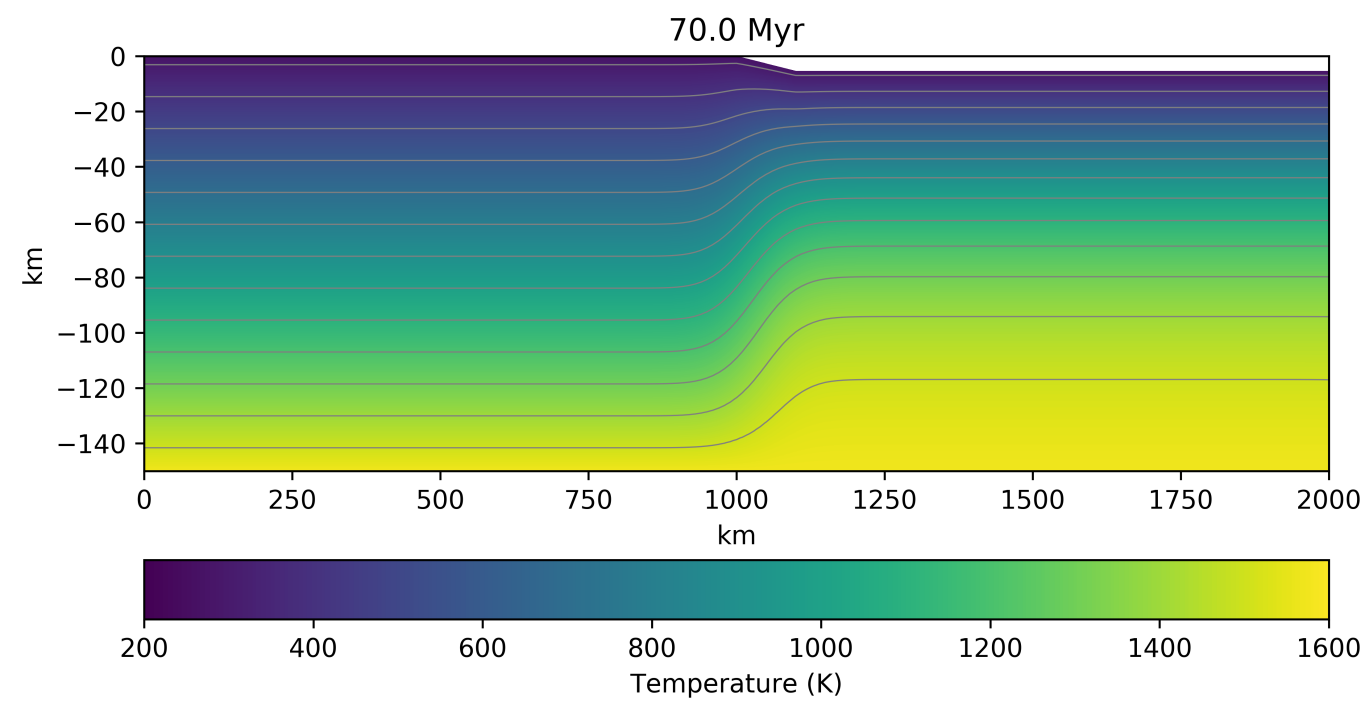

Figure S22: Thermal field at time $70 \mathrm{Myr}$. 


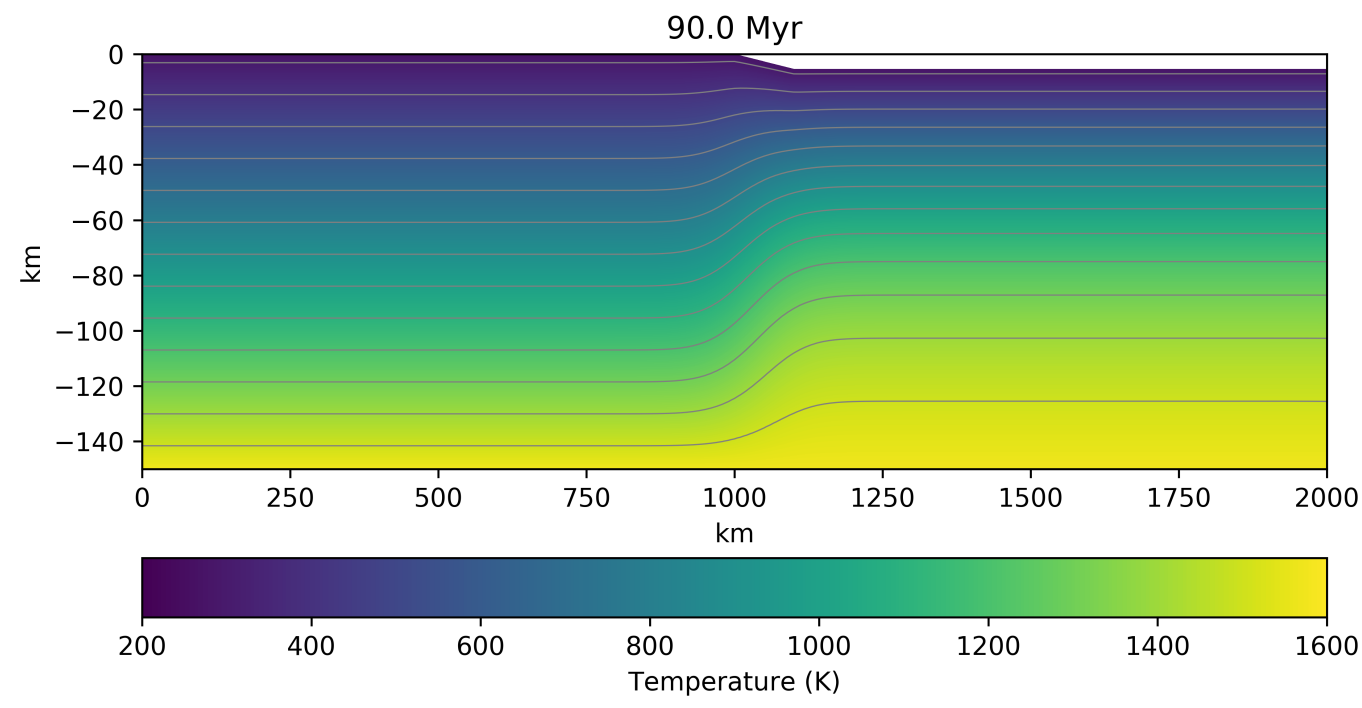

Figure S23: Thermal field at time $90 \mathrm{Myr}$. 


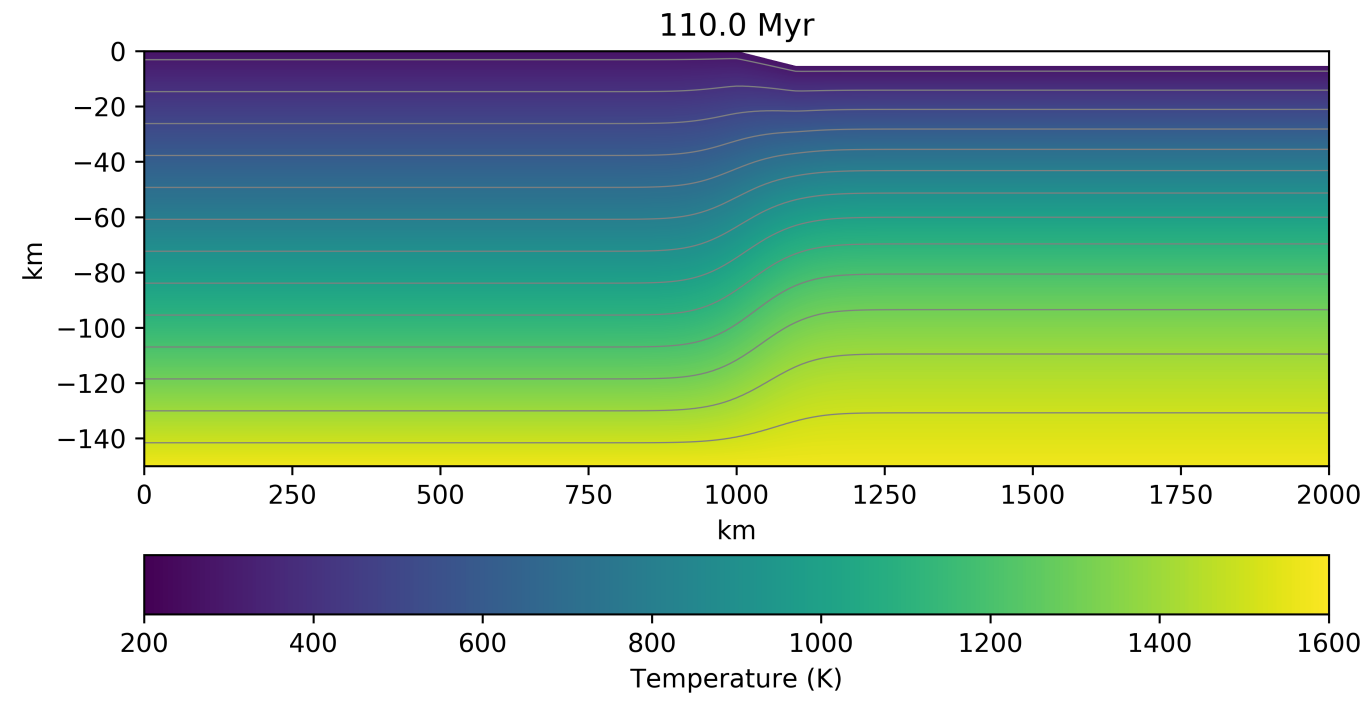

Figure S24: Thermal field at time 110 Myr. 


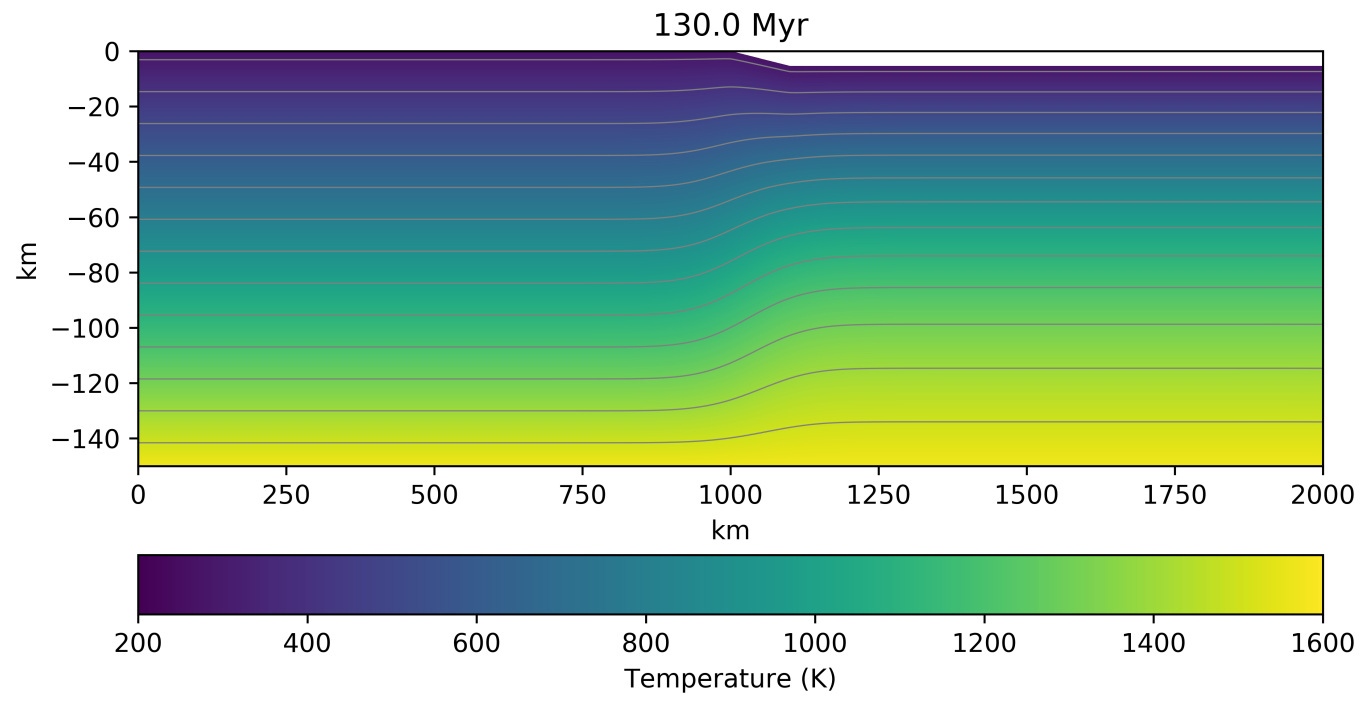

Figure S25: Thermal field at time 130 Myr. 